\title{
Catálogo de Asteraceae (Compositae) de la Región de Arica y Parinacota, Chile
}

\section{Asteraceae (Compositae) of the Arica y Parinacota region, Chile}

\author{
Andrés Moreira-Muñoz ${ }^{1 *}$, Mélica Muñoz-Schick², Alicia Marticorena ${ }^{3} \&$ Vanezza Morales $^{4}$ \\ ${ }^{1}$ Instituto de Geografía, Pontificia Universidad Católica de Valparaíso, Av. Brasil 2241, Valparaíso, Chile. \\ ${ }^{2}$ Museo Nacional de Historia Natural, Casilla 787, Santiago, Chile. \\ ${ }^{3}$ Departamento de Botánica, Universidad de Concepción, Casilla 160-C, Concepción, Chile. \\ ${ }^{4}$ Montecarmelo 53, Providencia, Santiago, Chile. \\ *andres.moreira@pucv.cl
}

\section{RESUMEN}

La familia de las Asteráceas o Compuestas es la más diversa de la flora de Chile, sin embargo, sólo algunas tribus han sido sometidas a un tratamiento sistemático reciente, mientras que el conocimiento de la distribución geográfica de los taxones es aún muy deficiente. A partir de la revisión de ejemplares de herbario y trabajo de campo, se realizó una prospección de la flora de Asteráceas de la Región de Arica y Parinacota. Ello da como resultado la presencia de 144 taxones en la región, de los cuales un $82,6 \%$ es nativo (119) y un $9 \%$ es endémico (13) de Chile, mientras que el 8,3\% restante corresponde a especies alóctonas o naturalizadas (12). El género Senecio es el más diverso en la región con 27 especies nativas, incluyendo seis especies endémicas de Chile. Se constató la presencia de cinco especies nuevas para la flora de Chile: Achyrocline ramosissima Britton, Gamochaeta humilis Wedd., Mniodes kunthiana (DC.) S.E. Freire et al. (=Lucilia violacea Wedd.), Pseudogynoxys cordifolia (Cass.) Cabrera y Senecio evacoides Sch. Bip. Sobre la base de los materiales recolectados, se ha publicado recientemente la nueva especie Pseudognaphalium munoziae N. Bayón, C. Monti \& S.E. Freire. Adicionalmente, se ha revisado la correcta denominación de la especie endémica Stevia philippiana. La mayor diversidad de especies se encuentra en la provincia de Parinacota, sobre los $3.000 \mathrm{~m}$ s.n.m. Las Asteráceas no sólo destacan en la región por su diversidad, sino también por constituir un elemento esencial de la vegetación, especialmente de las unidades vegetacionales de precordillera y altiplano, denominadas genéricamente como "tolar". La mayor parte de los pisos de vegetación de la provincia de Parinacota poseen especies de Asteráceas como especies dominantes, especialmente de los géneros Parastrephia, Lophopappus, Baccharis y Senecio. Si bien la región posee un porcentaje importante de superficie bajo protección, varias de las especies estudiadas, especialmente de precordillera, quedan fuera del sistema de áreas protegidas.

Palabras clave: Flora de Chile, Catálogo florístico, Reserva de la Biosfera Lauca, conservación de la biodiversidad, especies endémicas.

\begin{abstract}
The family of the Asteraceae is the most diverse in the Chilean flora; nevertheless, only some tribes have undergone a recent systematic treatment, while the knowledge about the geographical distribution of the taxa is still very incomplete. From the review of herbarium specimens and fieldwork, a survey of the Compositae flora of the Arica y Parinacota Region was performed. The study shows the presence of 144 taxa of the Asteraceae family in the region of which $82.6 \%$ is native (119) and $9 \%$ is endemic to Chile (13), while $8.3 \%$ are considered as exotic species (12). The genus Senecio is the one showing the highest diversity in the region, with the presence of 27 species, including six endemic ones. The revision of the botanical material reveals the presence of five new species for the Chilean flora: Achyrocline ramosissima Britton, Gamochaeta humilis Wedd., Mniodes kunthiana (DC.) S.E. Freire et al. (=Lucilia violacea Wedd.), Pseudogynoxys cordifolia (Cass.) Cabrera, and Senecio evacoides Sch. Bip. A new species has been recently described based on our recent field surveys: Pseudognaphalium munoziae N. Bayón, C. Monti \& S.E. Freire. Additionally, the correct denomination of the endemic species Stevia philippiana has been recently undertaken. The greatest diversity of species is found in the province of Parinacota, above 3,000 m asl. Compositae stand out in the region not only for its diversity but also as a crucial element of the vegetation, being a fundamental component of the precordillera and altiplano vegetation belts, known as "tolar", in which species pertaining to genera like Parastrephia, Lophopappus, Baccharis, or Senecio tend to dominate. Indeed, most
\end{abstract}


La familia Asteraceae en Arica y Parinacota: Moreira-Muñoz, A. ET AL.

of the vegetation belts described in the Parinacota province show members of the Asteraceae as dominant species. In spite of a big amount of the regional surface under formal protection, several species occur outside the protection units.

KEYwords: Chilean flora, floristic catalogue, Lauca Biosphere Reserve, biodiversity conservation, endemic species.

\section{INTRODUCCIÓN}

El mundo vegetal de los Andes centrales, compartidos por Perú, Bolivia, Chile y Argentina, atrajo a botánicos y naturalistas a partir de mediados del siglo XIX. Trabajos clásicos e impresionantes son los de Franz J.F. Meyen (1834/1835) "Reise um die Erde..."; Hugh A. Weddell (1855/1861) "Chloris Andina"; August Weberbauer (1911) "Die Pflanzenwelt der peruanischen Anden", traducido muy posteriormente al español (Weberbauer 1945). Dichos trabajos ciertamente involucran muchas especies del Chile más septentrional. Gran parte de las primeras colecciones de la flora de Asteráceas de la región de Arica y Parinacota se realizaron en la región limítrofe de Chile-Perú, en la "cordillera de Tacora". Es el caso por ejemplo de los tipos de Plazia daphnoides y Diplostephium meyenii recolectados por Wedell entre 1855 y 1857, el de Senecio tacorensis, recolectado por Pearce en 1865, o el tipo de Xenophyllum lycopodioides recolectado por Werdermann en 1926.

Federico Philippi, en su "Viaje a la provincia de Tarapacá”, llegó a esta última provincia, sin alcanzar Parinacota (Philippi 1885; Muñoz-Shick \& Prina 1987). Durante la travesía, F. Philippi enfermó, y hubo de quedarse en el poblado de Pica. Mientras tanto, Carlos Rahmer avanzó hacia Camarones. La mayoría de las especies recolectadas durante este viaje provienen, en todo caso, de la cordillera de Antofagasta. Muchas de ellas resultaron ser desconocidas para la ciencia, por lo que el afamado naturalista y padre de Federico, Rodulfo A. Philippi, se dio a la tarea de describirlas (Philippi 1891). El viaje arrojó un total de 95 especies de Asteráceas, incluyendo la descripción de varias de las que conocemos hoy para Arica y Parinacota, como es el caso de Conyza deserticola, Grindelia tarapacana, Trichocline caulescens, Ophryosporus pinifolius, Villanova robusta, entre otras.

Ya cerrando el siglo (1897), R. Pöhlmann, participante de una expedición de geomensura, aprovechó la oportunidad para realizar observaciones geológicas y botánicas en el nacimiento de las quebradas de Camarones y Vítor. Algunos de los lugares visitados permanecen hasta hoy muy aislados, como Aico, Esquiña y Taruguire. La colección de especímenes botánicos fue enviada al Herbario Nacional de Chile (SGO). Quien la recibió fue Carlos Reiche, que luego participaría en la publicación de sus hallazgos (Pöhlmann \& Reiche 1900). Reiche, apoyado desde Berlín por G. Hieronymus, logró identificar alrededor de 145 especies, de las cuales 43 corresponden a Asteráceas. En su pionero trabajo, Pöhlmann menciona que el paso del desierto a la estepa de altura está condicionado por la presencia, en los fondos de quebradas, de "bosques de matorrales" (Buschwälder) o tolares en los que dominan especies de Solanáceas y Asteráceas.

Si bien Reiche hizo un esfuerzo por sistematizar el conocimiento de la familia hasta esa fecha (Reiche 1904, 1905), sólo muy posteriormente, en los años '60, vendría un auge de expediciones a la región por parte de los botánicos de la Universidad de Concepción, lo que mejoró ostensiblemente el conocimiento botánico, incluyendo la descripción de varias especies nuevas para la ciencia (Ricardi 1962, Ricardi \& Marticorena 1964, 1966): $S$. behnii Ricardi \& Martic., S. coscayanus Ricardi \& Martic., S. laucanus Ricardi \& Martic., S. pfisteri Ricardi \& Martic.

Posteriormente han sido publicadas una serie de guías que han ayudado a la divulgación de la flora regional y sus elementos más conspicuos, incluidas las Asteráceas. Podemos citar "Alcances sobre Flora y Vegetación de la Cordillera de los Andes: Región de Arica y Parinacota y Región de Tarapacá" (Trivelli \& Valdivia 2009); "Flora presente en la región de Arica y Parinacota" (González \& Molina 2015); "Plantas medicinales de la comuna de Putre" (Huanca Mamani \& Castro Mollo 2014). También ha habido importantes avances en el conocimiento de la flora no vascular de la región (Ardiles \& Fariña 2014).

Últimamente, dos catastros aportan un panorama acerca de la flora vascular de la región de Arica y Parinacota (Faúndez et al. 2014, Gatica-Castro et al. 2015). Según esto, la flora vascular de la región de Arica y Parinacota comprende alrededor de 600 especies, pertenecientes a 304 géneros y 81 familias (Faúndez et al. 2014). La riqueza de especies se concentra en la provincia de Parinacota (Luebert \& Gajardo 2005), puesto que las condiciones de sequía que dominan en la provincia de Arica constituyen una gran limitante para la vida vegetal, la que se encuentra prácticamente restringida a los valles de Lluta, Azapa, Vítor y Camarones, principalmente en forma de tierras de cultivo. Las familias mejor representadas en la flora vascular regional son las Asteráceas, Poáceas, Fabáceas, Malváceas y Solanáceas (Faúndez et al. 2014). Alrededor de un 22\% de la flora pertenece a la familia de las Asteráceas.

LA familia Asteríceas en Chile

La familia de las Asteráceas es la más diversa de la flora de Chile, con 20 tribus, 123 géneros y 838 especies (MoreiraMuñoz et al. 2012). A nivel nacional, representa casi un $20 \%$ 
de la flora vascular; esta proporción es levemente superior en la región de Arica y Parinacota. La familia presenta también los más altos niveles de endemismo en Chile Central (Vanderplank et al. 2014, Tabla 7.1). Varios géneros, con presencia de especies en la región han sido revisados recientemente en un tratamiento sistemático, mejorando el conocimiento taxonómico de la familia. Es el caso de las revisiones de Perezia (Katinas 2012), Pseudognaphalium (Freire et al. 2014a) y Plazia (Dillon \& Luebert 2014), por citar los más recientes. Otros géneros aún carecen de una revisión moderna, aunque se cuenta con trabajos clásicos muy exhaustivos como los de Angel L. Cabrera. Varias de estas publicaciones tratan específicamente géneros de Chile, como Senecio (Cabrera 1949) o Mutisia (Cabrera 1965). También resultan de mucha utilidad los tratamientos regionales de la flora argentina, especialmente Flora de Jujuy (Cabrera 1978), Flora de San Juan (Kiesling 2013) o la serie de volúmenes de la Flora Argentina (Cabrera et al. 1999, Zuloaga et al. 2014, Gutiérrez \& MoreiraMuñoz 2015). La taxonomía y distribución geográfica de la subfamilia Mutisioideae ha sido revisada recientemente por Moreira-Muñoz et al. (2012). Adicionalmente, el género Stevia (Eupatorieae) ha sido recientemente revisado para Chile (Gutiérrez et al. 2016). Sin embargo, no existe a la fecha un trabajo que actualice el conocimiento sistemático, taxonómico, de la diversidad y distribución geográfica de Asteráceas para la región de Arica y Parinacota. Este vacío es el que viene a llenar esta contribución, sobre la base de una exhaustiva revisión nomenclatural y de materiales de herbarios nacionales y extranjeros, más el trabajo de campo y recolección de ejemplares.

\section{MATERIALES Y MÉTODOS}

ÁreA DE ESTUDiO

La Región de Arica y Parinacota, de creación relativamente reciente (año 2007), se ubica en el extremo norte del país, a partir del hito tripartito limítrofe con Perú y Bolivia (17³0' $\left.\mathrm{S}, 6^{\circ} 28^{\prime} \mathrm{W}\right)$, por la cordillera andina, hasta el límite con la región de Tarapacá $\left(18^{\circ} 56^{\prime} \mathrm{S}, 68^{\circ} 57^{\prime} \mathrm{W}\right)$ hacia el sur. Por la costa limita con la Línea de la Concordia al Norte, y el límite sur es la desembocadura de la Quebrada de Camarones (Fig. 1). Morfoestructuralmente, la región constituye el escarpe occidental de la gran planicie altiplánica compartida con Bolivia, Perú, y el NW de Argentina (Fig. 1). En el transecto altitudinal de mar a cordillera, la región se puede dividir en: a) una estrecha Cordillera de la Costa; b) una Depresión Central o Pediplano; c) la Precordillera; d) la Planicie altiplánica o Altiplano; e) la cadena volcánica en el límite con Bolivia (Fig. 1).

En el paso de la provincia de Arica a la de Parinacota se aprecia la transición desde la Depresión central eminentemente árida, hacia la Precordillera más húmeda y vegetada. En la provincia de Parinacota se destacan dos cadenas montañosas paralelas de orientación norte-sur separadas por la cuenca del Río Lauca, pero unidas por el sistema de los Nevados de Putre (Fig. 1). El paisaje geomorfológico está marcado por una gran diversidad de distintas formas volcánicas, ya sean estratovolcanes o restos de gigantescas calderas tanto de explosión como de colapso (González-Ferrán 1995). Destacan en el margen occidental el Volcán Tacora (5.980 m s.n.m.), el volcán activo más septentrional de Chile; y el complejo Nevados de Putre, compuesto de unos ocho centros eruptivos asociados, entre ellos el más activo el Taapaca (5.824 m s.n.m.). En el margen oriental limítrofe con Bolivia se ubican los estratovolcanes más recientemente activos, como el complejo Nevados de Payachatas (volcanes Parinacota, 6.350 m s.n.m. y Pomerape, 6.250 m s.n.m.); y el Volcán Guallatiri (6.060 m s.n.m.), junto con antiguos centros, calderas y domos, como el centro eruptivo Guane-Guane, la caldera Lauca, y los domos Chucuyo y Caquena (González-Ferrán 1995).

Este complejo paisaje volcánico se encuentra incidido por dos ríos principales, el Lluta al norte de los Nevados de Putre, y el río Lauca al Sureste. El poblado de Putre, localizado a $3.560 \mathrm{~m}$ s.n.m., se ubica en la base de los Nevados de Putre, un poco antes de ascender a la planicie altiplánica. El gran salar de Surire, de $144 \mathrm{~km}^{2}$, se ubica en el extremo austral de la provincia de Parinacota a $4.260 \mathrm{~m}$ s.n.m. (Fig. 1).

Biogeografía del Desierto y Altiplano

La Región de Arica y Parinacota se ubica en dos grandes unidades biogeográficas: el Desierto Pacífico y la Puna (Cabrera \& Willink 1973, Udvardy 1975). El elemento florístico del Desierto Pacífico incluye géneros como Acantholippia (Verbenaceae), Ambrosia (Asteraceae), Atriplex (Amaranthaceae), Browningia (Cactaceae), que se encuentran en la provincia de Arica, bajo los 3.300 m s.n.m., en condiciones de extrema aridez (Luebert \& Gajardo 2005). Estos géneros tienen un origen neotropical posiblemente miocénico-pliocénico, en relación con la consolidación de la condición de hiperaridez asociada a la corriente de Humboldt y el alzamiento andino (Rundel et al. 1991, Hartley 2003, Luebert \& Gajardo 2005). La intensificación de la corriente de Humboldt, relacionada con el cierre del corredor oceánico de América Central, coincide con el comienzo del período de hiperaridez del Desierto Pacífico (Hartley 2003).

El elemento puneño, desarrollado bajo condiciones de mayor humedad proveniente del Amazonas, incluye géneros típicos como Antochloa (Poaceae), Andeimalva, Nototriche (Malvaceae), Oreocereus (Cactaceae), Pycnophyllum (Caryophyllaceae), Weberbauera (Brassicaceae) y ciertamente varios géneros de Asteraceae (Chersodoma, Lophopappus, Parastrephia, Plazia). Si bien posee una 
distribución más amplia, hasta los Andes tropicales, también resulta característica la presencia del género Polylepis (Rosaceae), con ejemplares arbóreos que marcan el límite altitudinal más alto a escala global (Kessler 2006).

La transición entre el elemento desértico y puneño se encuentra en precordillera, en las nacientes de las quebradas principales. Ahí se encuentra una comunidad boscosa caracterizada por la presencia de por Morella pavonis (C. DC.) Parra-O (Myricaceae), el huacán, que debe haber estado mucho más extendida antes de la expansión agrícola en los valles profundos (Luebert 2004). Es muy probable que estos bosques sean un relicto de vegetación de ambientes tropicales más húmedos y cálidos. Sus relaciones biogeográficas aparentes son los bosques riparios de Alnus acuminata Kunth. y Morella pubescens (Humb. \& Bonpl. ex Willd.) Wilbur de los Yungas de Perú y Bolivia (Luebert 2004). El escaso registro paleobotánico de la Formación Chucal muestra hojas relativamente pequeñas, afines a estas regiones subtropicales de clima estacional y lluvias de verano (Charrier et al. 1994).

\section{GEOECOLOGÍA Y PISOS DE VEGETACIÓN}

Ya los estudios de geoecología y vegetación clásicos de los Andes Centrales reconocen la estrecha relación entre el relieve, el clima y la vegetación en la región (Troll 1968). El Altiplano se encuentra sometido al régimen de precipitaciones estivales del verano austral: la precipitación muestra un marcado gradiente altitudinal, de $0 \mathrm{~mm}$ al nivel del mar (Arica), a $162 \mathrm{~mm}$ anuales en Putre. Mientras que en Parinacota llueve $384 \mathrm{~mm}$ al año, y en Chungará y Caquena $379 \mathrm{~mm}$ y 427, respectivamente (Luebert \& Gajardo 2005, Luebert \& Pliscoff 2006). Las precipitaciones tienen un origen en las tormentas convectivas amazónicas, y se concentran en los meses de diciembre a marzo (invierno boliviano). Ello crea regímenes bioclimáticos muy distintos en un trayecto altitudinal muy corto, que va desde la sequía máxima del bioclima Tropical Hiperdesértico desde la costa a los 2.800 m s.n.m., a la humedad del bioclima Tropical Pluviestacional, a mayor altura (Luebert \& Pliscoff 2006), específicamente denominado piso criorotropical pluviestacional (Luebert \& Gajardo 2005).

El régimen bioclimático crea un contraste muy marcado entre la árida provincia de Arica y la húmeda provincia de Parinacota. La vegetación de la provincia de Arica está casi exclusivamente restringida a los principales valles de Lluta, Azapa, Vítor y Camarones, tratándose principalmente de áreas de cultivo con baja presencia de especies nativas, que se distribuyen principalmente en las desembocaduras o en las cabeceras de las quebradas alrededor de los $3.000 \mathrm{~m}$ s.n.m.

La vegetación de la provincia de Parinacota, en cambio, destaca por su riqueza de especies nativas y la diversidad fisionómica, asociada a una mayor disponibilidad hídrica producto de las lluvias de verano (invierno boliviano) (Villagrán et al. 1982, Luebert \& Gajardo 2005). Villagrán

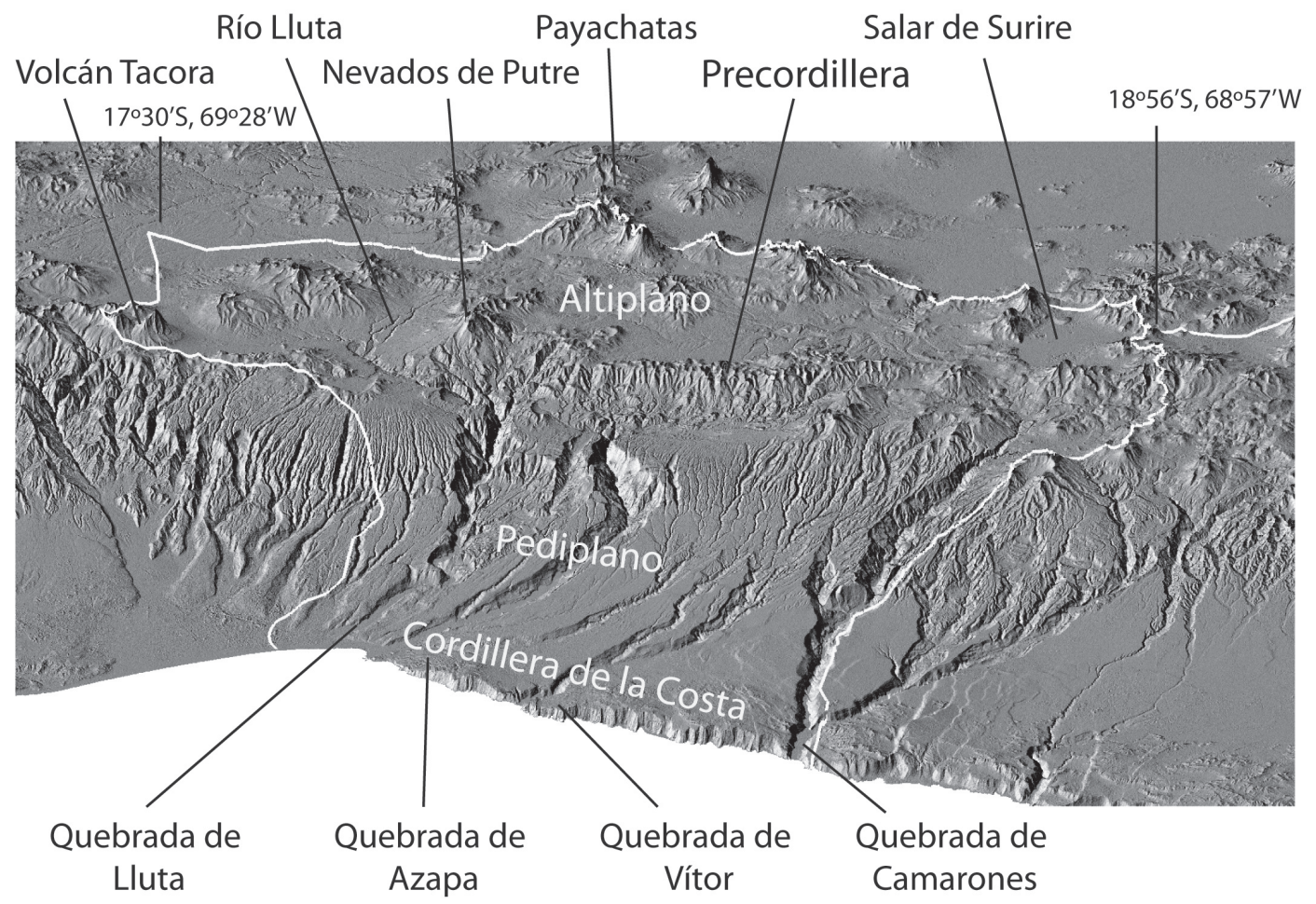

FIgURA 1. Principales elementos morfoestructurales de la Región de Arica y Parinacota.

Figure 1. Main morphostructural elements of the Arica y Parinacota Region. 
et al. (1982) reconocen cinco pisos de vegetación a la latitud de $18^{\circ}-19^{\circ} \mathrm{S}$, desde el mar al Altiplano: desierto, piso prepuneño, piso puneño, piso altoandino, piso subnival. Quintanilla (1988) por su parte reconoce 10 unidades de vegetación, mientras que Gajardo (1994) las agrupa en cinco formaciones vegetacionales (Tabla I). Luebert \& Gajardo (2005) reconocen cuatro pisos vegetacionales en la provincia de Parinacota y luego se amplía la clasificación a 11 pisos de vegetación para la Región de Arica y Parinacota (Luebert \& Pliscoff 2006) (Tabla I). La mayor parte de los pisos de vegetación de la provincia de Parinacota poseen especies de
Asteráceas como dominantes, e.g. "Matorral bajo tropical andino de Fabiana ramulosa y Diplostephium meyenii" entre 3.300-3.900 m s.n.m.; o el "Matorral bajo tropical andino de Parastrephia lepidophylla y P. quadrangularis" (Tabla I). Hay que considerar que las clasificaciones se basan en la descripción de la zonación altitudinal de la vegetación; en el piso de altiplano se encuentran además en situaciones de azonalidad e intrazonalidad los bofedales altiplánicos, los yaretales, los pajonales y queñoales, formando un complejo mosaico vegetacional a una escala de mayor detalle (Hernández 1980).

TABLA I. Unidades de vegetación descritas por distintos autores para la Región de Arica y Parinacota.

TABLE I. Vegetation units as proposed by different authors for Arica y Parinacota Region.

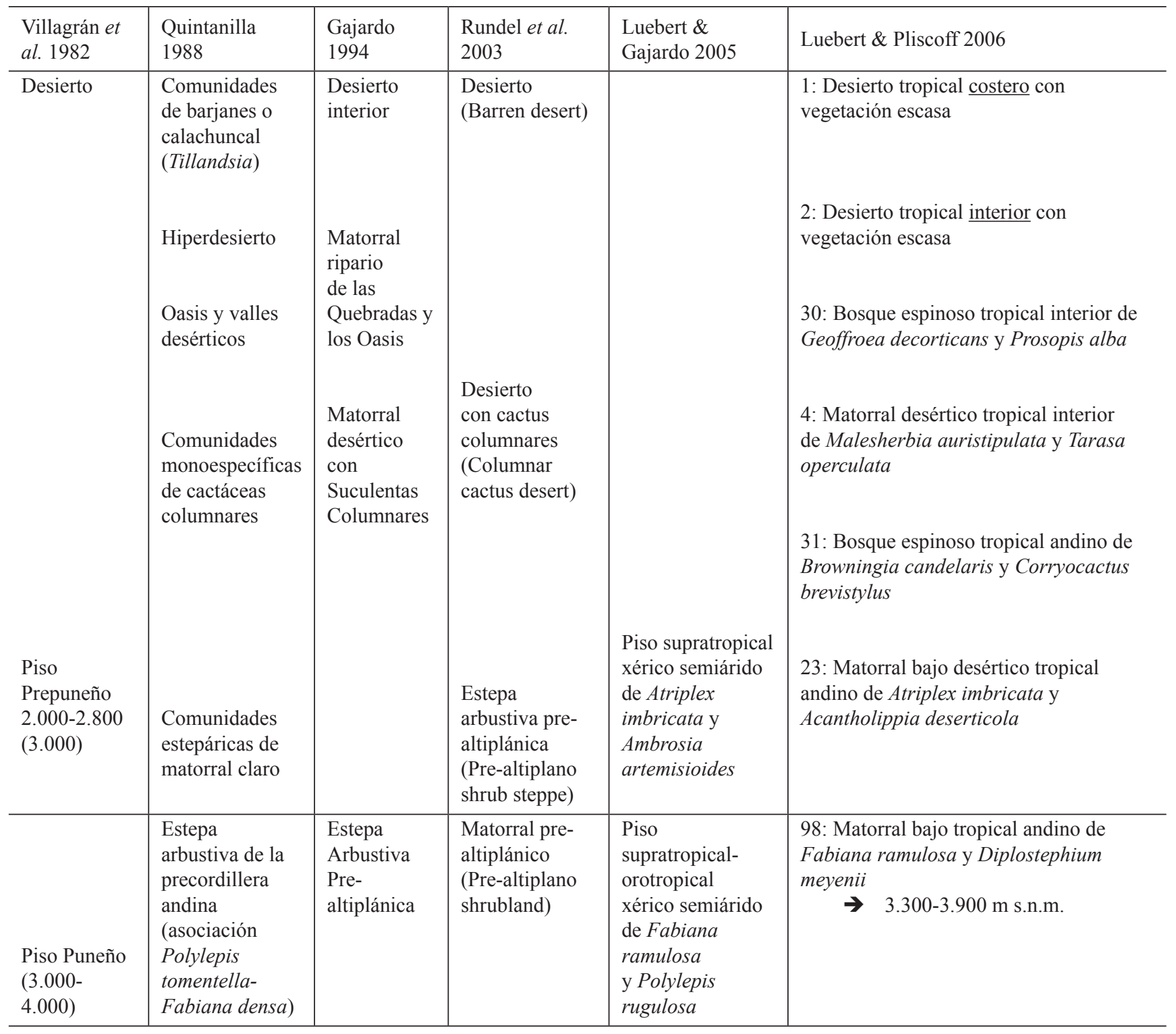




\begin{tabular}{|c|c|c|c|c|c|}
\hline \multirow[t]{2}{*}{$\begin{array}{l}\text { Piso } \\
\text { Altoandino } \\
4.000-4.900 \\
\text { "pajonales y } \\
\text { llaretales" }\end{array}$} & $\begin{array}{l}\text { Estepa arbustiva } \\
\text { altiplánica } \\
\text { Estepa } \\
\text { altoandina de } \\
\text { la hoya del río } \\
\text { Lauca } \\
\text { Comunidades } \\
\text { de bofedales } \\
\text { de la tundra } \\
\text { altiplánica }\end{array}$ & $\begin{array}{l}\text { Estepa } \\
\text { Alto-Andina } \\
\text { Altiplánica }\end{array}$ & $\begin{array}{l}\text { Estepa } \\
\text { arbustiva } \\
\text { altiplánica } \\
\text { (altiplano shrup } \\
\text { steppe) }\end{array}$ & $\begin{array}{l}\text { Piso orotropical- } \\
\text { criorotropical } \\
\text { pluviestacional } \\
\text { seco de } \\
\text { Parastrephia } \\
\text { lucida y Polylepis } \\
\text { tarapacana }\end{array}$ & $\begin{array}{l}\text { 101: Matorral bajo tropical andino } \\
\text { de Parastrephia lepidophylla y } P \text {. } \\
\text { quadrangularis } \\
\quad \rightarrow \quad 3.800-4.300 \text { m s.n.m. } \\
\text { 100: Matorral bajo tropical andino } \\
\text { de Parastrephia lucida y Festuca } \\
\text { orthophylla } \\
\quad \rightarrow \quad \text { Laderas, lomajes y planicies } \\
\quad \text { entre } 4.000-4.400 \text { m s.n.m. }\end{array}$ \\
\hline & & & $\begin{array}{l}\text { Matorral bajo } \\
\text { (scrub) de } \\
\text { Azorella y } \\
\text { Polylepis }\end{array}$ & $\begin{array}{l}\text { Piso } \\
\text { criorotropical } \\
\text { pluviestacional } \\
\text { seco de Senecio } \\
\text { zoellneri } \\
\text { y Azorella } \\
\text { compacta }\end{array}$ & $\begin{array}{l}\text { 102: Matorral bajo tropical andino de } \\
\text { Azorella compacta y Pycnophyllum molle } \\
\quad \rightarrow \quad \text { Sobre } 4.600 \text { m s.n.m. }\end{array}$ \\
\hline $\begin{array}{l}\text { Piso } \\
\text { Subnival } \\
4.900-5.200\end{array}$ & $\begin{array}{l}\text { Estepa } \\
\text { altoandina } \\
\text { subdesértica }\end{array}$ & & & & \\
\hline
\end{tabular}

Rundel et al. (2003) discuten la aplicación del concepto de 'piso puneño' pues el concepto 'Puna' ha sido usado tanto para nombrar a la gran provincia biogeográfica del Altiplano (Cabrera \& Willink 1973, Udvardy 1975) como para referirse a la parte sur del Altiplano, específicamente el NW de Argentina (e.g. Ruthsatz 1977). Rundel et al. (2003) remarcan la diferencia entre una "Estepa arbustiva pre-altiplánica" localizada bajo 3.500 m s.n.m., el "Matorral pre-altiplánico" de 3.500 a 4.000 m s.n.m., y una "Estepa arbustiva altiplánica" sobre los $4.000 \mathrm{~m}$ s.n.m. La mayoría de los autores coincide en que el piso de mayor cobertura y diversidad de especies es el piso del "Matorral prealtiplánico" (Arroyo et al. 1982, Fig. 4; Rundel et al. 2003). Este piso ha sido denominado "Piso supratropicalorotropical xérico semiárido de Fabiana ramulosa y Polylepis rugulosa" por Luebert \& Gajardo (2005) o "Matorral bajo tropical andino de Fabiana ramulosa y Diplostephium meyenii" según Luebert \& Pliscoff (2006) (Tabla I). Estos últimos autores lo ubican entre 3.300 y 3.900 $\mathrm{m}$ s.n.m. Se estima en este piso una precipitación anual en promedio de $160 \mathrm{~mm}$, con un alto coeficiente de variación interanual (Muñoz \& Bonacic 2006). La precipitación se concentra en los meses de diciembre a marzo, y el invierno es extremadamente seco (Rundel et al. 2003).

\section{Conservación de AsteraceAe}

El trabajo de Luebert \& Pliscoff(2006) incluye una evaluación del grado de representatividad de los pisos vegetacionales en el Sistema Nacional de Áreas Silvestres Protegidas del Estado (SNASPE). Los pisos desérticos y de precordillera tienen una baja representatividad, mientras que los pisos altiplánicos y altoandinos se encuentran bien representados en las unidades del SNASPE de la región (Luebert \& Pliscoff 2006). Las tres unidades de SNASPE de la provincia de Parinacota conforman la Reserva de la Biosfera Lauca (Román 2014) (Tabla II). En su conjunto estas tres unidades abarcan casi el 50\% de superficie de los pisos: a) Matorral bajo tropical andino de Parastrephia lucida y Azorella compacta; b) Matorral bajo tropical andino de Parastrephia lucida y Festuca orthophylla y; c) Matorral bajo tropical andino de Azorella compacta y Pycnophyllum molle (Moreira-Muñoz \& Troncoso 2014). El piso de precordillera (Matorral bajo tropical andino de Fabiana ramulosa y Diplostephium meyenii) alcanza un $6,7 \%$ de presencia en el SNASPE (Luebert \& Pliscoff 2006). Recientemente se ha incorporado al SNASPE de la región, el Monumento Natural Quebrada de Cardones (año 2010), que protege en parte los pisos: a) Bosque espinoso tropical andino de Browningia candelaris y Corryocactus brevistylus; b) Matorral bajo desértico tropical 
TABLA II. Unidades de consevación en la Región de Arica y Parinacota.

TABle II. Conservation units in the Arica y Parinacota Region.

\begin{tabular}{|c|c|c|c|c|}
\hline Provincia & Categoría & ORGANISMO A CARGO & $\begin{array}{l}\text { SUPERFICIE } \\
\text { (hectáreas) }\end{array}$ & $\begin{array}{l}\mathrm{N}^{\circ} \text { PISOS BAJO } \\
\text { PROTECCIÓN }\end{array}$ \\
\hline \multirow{2}{*}{ Arica } & $\begin{array}{l}\text { Santuario de la Naturaleza Humedal de la } \\
\text { Desembocadura del Río Lluta }\end{array}$ & $\begin{array}{l}\text { Consejo de Monumentos } \\
\text { Nacionales }\end{array}$ & 31 & 1 \\
\hline & Monumento Natural Quebrada de Cardones & CONAF (SNASPE) & 11.326 & 5 \\
\hline \multirow{3}{*}{ Parinacota } & Parque Nacional Lauca & CONAF (SNASPE) & 139.296 & 7 \\
\hline & Reserva Nacional Las Vicuñas & CONAF (SNASPE) & 205.631 & 3 \\
\hline & Monumento Natural Salar de Surire & CONAF (SNASPE) & 17.433 & 3 \\
\hline
\end{tabular}
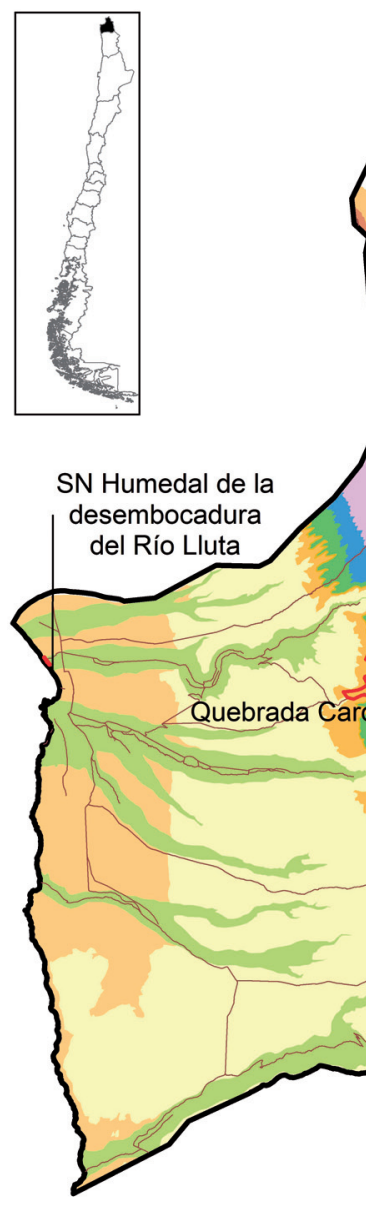

$19^{\circ} 20^{\prime} \mathrm{S}-$ $70^{\circ} 20^{\prime} 0$

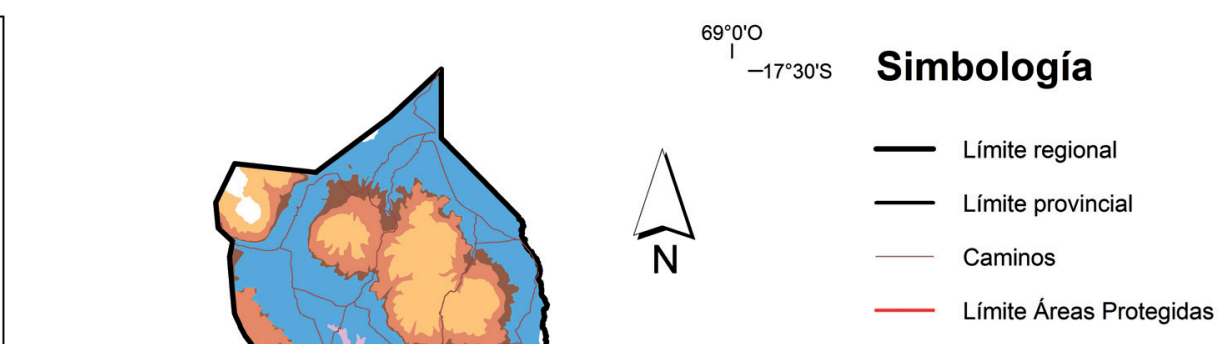

\section{Pisos vegetacionales}

Desierto tropical costero con vegetación escasa

Desierto tropical interior con vegetación escasa

Bosque espinoso tropical interior de Geoffroea decorticans y Prosopis alba

Matorral desértico tropical interior Malesherbia auristipulata y Tarasa rahmeri

Bosque espinoso tropical andino de Browningia candelaris y Corryocactus brevistylus

Matorral bajo desértico tropical andino de Atriplex imbricata y Acantholippia deserticola

Matorral bajo tropical andino de Fabiana ramulosa y Diplostephium meyenii

Matorral bajo tropical andino de Parastrephia lepidophylla y $P$. quadrangularis

Matorral bajo tropical andino de Azorella compacta y Pycnophyllum molle

Matorral bajo tropical andino de Parastrephia lucida y Azorella compacta

Matorral bajo tropical andino de Parastrephia lucida y Festuca orthophylla

Áreas sin vegetación

Figura 2. Áreas protegidas y pisos de vegetación de la Región de Arica y Parinacota. Fuente: CONAF, Luebert \& Pliscoff (2006). FIgURE 2. Protected areas and vegetation belts of Arica y Parinacota Region. Source: CONAF, Luebert \& Pliscoff (2006). 
andino de Atriplex imbricata y Acantholippia deserticola; y c) Matorral bajo tropical andino de Fabiana ramulosa y Diplostephium meyenii.

Como se aprecia en la Tabla II (Fig. 2), el área protegida que muestra la presencia de un mayor número de pisos vegetacionales es el Parque Nacional Lauca, aunque para su relativamente menor área, el Monumento Natural Quebrada de Cardones resulta igualmente muy importante.

La RN Las Vicuñas posee, según el Plan de Manejo, 104 especies de flora, de las cuales 33, es decir, casi un tercio, corresponden a Asteráceas (CONAF 1998). El Monumento Natural Salar de Surire no posee una lista de especies, mientras que la lista del Parque Nacional Lauca se encuentra desactualizada (Hernández 1980).

Adicionalmente a las áreas protegidas de la región, se han propuesto una serie de Sitios Prioritarios de Conservación (Muñoz-Schick et al. 1996, CONAMA 2002). Entre ellos destaca la ampliación del Parque Nacional Lauca o la Reserva Nacional Las Vicuñas hacia sectores precordilleranos, abarcando el matorral pre-altiplánico (CEE 2000, Rundel et al. 2003).

Recientemente se ha evaluado el estado de conservación regional de la flora vascular (Gatica-Castro et al. 2015), con el resultado que más de un tercio de la flora estaría amenazada (En Peligro o Vulnerable). Ello incluye especies tradicionalmente explotadas como las queñoas (Polylepis spp.) (Saavedra 2012) y la yareta (Azorella compacta Phil.) (Kleier et al. 2015), así como varias especies endémicas de Asteráceas (e.g. Oriastrum tarapacensis, Senecio laucanus, Villanova robusta). Aún así, muchas especies se encuentran en categoría de "Datos Insuficientes" (DD). Es necesario mejorar sustancialmente el conocimiento de la distribución de las especies de Asteráceas en la región para tener una mejor idea de su estado de amenaza; aquellas de condición endémica de Chile o de la Región de Arica y Parinacota, así como las de distribución muy restringida, constituyen ciertamente un claro objeto de conservación a futuro.

REVISIÓN DE LA FLORA Y CAMPAÑAS DE TERRENO

Se ha revisado los ejemplares de los Herbarios SGO, CONC e IEF pertenecientes a la región de Arica-Parinacota. Se georreferenció los ejemplares sobre la base de las localidades publicadas en: Instituto Geográfico Militar (IGM 1984), Risopatrón (1924), San Román (1892) y la Base de Datos GeoNames (www.geonames.org). El análisis de localidades históricas de recolectores antiguos, varias de las cuales dan origen a ejemplares tipo, fue realizado y publicado por Muñoz-Schick et al. (2012). Algunos registros no han logrado ser georreferenciados debido a que: a) no se ha encontrado la localidad específica en ninguno de los textos de referencia; b) se refiere a una zona muy amplia (e.g. Cordillera de Parinacota). Con estos antecedentes se realizaron seis campañas de terreno: mayo 2011, junio y octubre 2012, marzo y junio 2015 y mayo 2016. Las muestras han sido depositadas en SGO con duplicados en CONC y se han enviado ejemplares a LP y BA para confirmar su determinación.

La nomenclatura de los taxones sigue el Catálogo del Cono Sur (Zuloaga et al. 2008) en su versión electrónica (www2.darwin.edu.ar), así como monografías y revisiones más recientes (e.g. Katinas 2012, Freire et al. 2014a, b). En algunos casos se menciona la nomenclatura nueva y la antigua, por estar esta última más difundida. La distribución de los taxones ha sido comparada con los Catálogos disponibles para Perú (Brako \& Zarucchi 1993, Dillon \& Sagástegui-Alva 2001, Dillon 2006), Argentina (Zuloaga et al. 2014) y Bolivia (Jørgensen et al. 2014).

\section{RESULTADOS}

El Apéndice 1 presenta el catálogo de especies de Asteraceae de la Región de Arica y Parinacota, ordenados por tribus, de acuerdo a Funk et al. (2009). El catálogo incluye información taxonómica del Tipo del nombre de la especie, condición o estatus (nativa, endémica o adventicia), distribución general, distribución en Chile y en la región en estudio, así como altitud, hábitat y piso altitudinal característico. Se agrega un ejemplar de referencia (exsiccata), y una nota para aquellos taxones que están confusos en la literatura taxonómica. Un taxón fue identificado sólo al nivel de género: Viguiera sp., puesto que los tratamientos actuales no abordan en detalle las especies chilenas.

El catálogo incluye cinco especies nuevas para la Flora de Chile: Achyrocline ramosissima Britton, Gamochaeta humilis Wedd., Mniodes kunthiana (DC.) S.E. Freire et al. (=Lucilia violacea Wedd.), Pseudogynoxys cordifolia (Cass.) Cabrera, y Senecio evacoides Sch. Bip.

Adicionalmente, el trabajo de campo ha aportado materiales para la descripción de la nueva especie Pseudognaphalium munoziae N. Bayón, C. Monti \& S.E. Freire (Freire et al. 2013). Por último, se ha podido determinar la correcta denominación de la especie Stevia philippiana, endémica de Chile (Gutiérrez et al. 2016).

\section{DIVERSIDAD FLORÍSTICA}

La flora vascular de Compuestas registrada para la Región de Arica y Parinacota está constituida por 55 géneros y 144 taxones específicos e infraespecíficos, incluyendo 119 taxones nativos, 13 especies endémicas y 12 introducidas.

La Tabla III muestra una síntesis de la diversidad de taxones por tribus y géneros presentes en la región incluyendo la tribu, el número de géneros presentes en la región, el elemento florístico, número de especies en Chile, número de especies en la región, especies endémicas de Chile presentes en la región, y número de subespecies o variedades presentes en Arica y Parinacota. 
Tabla III. Síntesis de diversidad de Asteraceae de Arica y Parinacota según tribus y géneros, incluyendo el elemento florístico y el número de especies en Chile y en Arica y Parinacota, y número de taxones endémicos de Chile presentes en Arica y Parinacota, así como número de subespecies o variedades. Elemento florístico: $1=$ Pantropical; $3=$ Neotropical; $4=$ Antitropical; $7=$ Cosmopolita .

TABLE III. Overview of the diversity of Asteraceae from Arica y Parinacota region, including the tribe, genus, floristic element, species numbers in Chile and Arica y Parinacota. Also numbers of endemics taxa and subspecies or varieties. Floristic element: $1=$ Pantropical; 3 = Neotropical; 4 = Antitropical; 7 = Cosmopolitan.

\begin{tabular}{|c|c|c|c|c|c|c|c|}
\hline TRIBU & $\begin{array}{c}\mathrm{N}^{\circ} \\
\text { GÉNEROS }\end{array}$ & GÉNERos & $\begin{array}{l}\text { ELEMENTO } \\
\text { FLORÍSTICO }\end{array}$ & $\begin{array}{c}\mathrm{N}^{\circ} \\
\text { ESPECIES } \\
\text { EN CHILE }\end{array}$ & $\begin{array}{l}\mathrm{N}^{\circ} \text { ESPECIES } \\
\text { ARICA- } \\
\text { PARINACOTA }\end{array}$ & $\begin{array}{c}\mathrm{N}^{\circ} \text { TAXONES } \\
\text { ENDÉMICOS DE } \\
\text { CHILE PRESENTES } \\
\text { EN A-P }\end{array}$ & $\begin{array}{c}\mathrm{N}^{\circ} \text { SUBESPECIES } \\
\text { O VARIEDADES }\end{array}$ \\
\hline Barnadesieae & 1 & Chuquiraga & 3 & 5 & 2 & 1 & 1 \\
\hline \multirow[t]{2}{*}{ Onoseridae } & 2 & Aphyllocladus & 3 & 1 & 1 & 1 & 1 \\
\hline & & Plazia & 3 & 2 & 1 & & \\
\hline \multirow[t]{5}{*}{ Nassauvieae } & 5 & Leucheria & 3 & 42 & 1 & & \\
\hline & & Lophopappus & 3 & 2 & 2 & & \\
\hline & & Perezia & 3 & 20 & 4 & & \\
\hline & & Polyachyrus & 3 & 7 & 1 & & \\
\hline & & Trixis & 3 & 1 & 1 & & \\
\hline \multirow[t]{4}{*}{ Mutisieae } & 4 & Chaetanthera & 3 & 28 & 1 & & \\
\hline & & Mutisia & 3 & 23 & 3 & & 1 \\
\hline & & Oriastrum & 3 & 14 & 2 & 1 & 1 \\
\hline & & Trichocline & $3 * *$ & 5 & 1 & & \\
\hline Cardueae & 1 & Centaurea* & - & 6 & 1 & & \\
\hline \multirow[t]{5}{*}{ Cichorieae } & 5 & Helminthotheca* & - & 1 & 1 & & \\
\hline & & Hypochaeris & 4 & 31 & 5 & & \\
\hline & & Picrosia & 3 & 1 & 1 & & \\
\hline & & Sonchus* & - & 4 & 3 & & \\
\hline & & Taraxacum* & - & 3 & 1 & & \\
\hline \multirow[t]{5}{*}{ Senecioneae } & 5 & Chersodoma & 3 & 3 & 3 & & \\
\hline & & Pseudogynoxys* & - & 1 & 1 & & \\
\hline & & Senecio & 7 & 224 & 27 & 6 & 1 \\
\hline & & Werneria & 3 & 8 & 7 & & \\
\hline & & Xenophyllum & 3 & 5 & 5 & & \\
\hline \multirow[t]{6}{*}{ Gnaphalieae } & 6 & Achyrocline & 1 & 2 & 2 & & \\
\hline & & Cuatrecasasiella & 3 & 1 & 1 & & \\
\hline & & Facelis & 3 & 2 & 1 & & \\
\hline & & Gamochaeta & 3 & 24 & 4 & & \\
\hline & & Mniodes & 3 & 5 & 5 & & \\
\hline & & Pseudognaphalium & 7 & 12 & 7 & 2 & \\
\hline \multirow[t]{8}{*}{ Astereae } & 8 & Baccharis & 3 & 40 & 9 & & 2 \\
\hline & & Conyza & 1 & 20 & 2 & & \\
\hline & & Diplostephium & 3 & 2 & 2 & & \\
\hline & & Erigeron & 4 & 17 & 1 & & \\
\hline & & Grindelia & 3 & 3 & 2 & & \\
\hline & & Laennecia & 3 & 1 & 1 & & \\
\hline & & Parastrephia & 3 & 4 & 4 & & \\
\hline & & Symphyotrichum & 4 & 4 & 1 & & \\
\hline
\end{tabular}


La familia Asteraceae en Arica y Parinacota: MoreIrA-Muñoz, A. ET AL.

\begin{tabular}{|c|c|c|c|c|c|c|c|}
\hline TRIBU & $\begin{array}{c}\mathrm{N}^{\circ} \\
\text { GÉNEROS }\end{array}$ & GÉNEROS & $\begin{array}{l}\text { ELEMENTO } \\
\text { FLORÍSTICO }\end{array}$ & $\begin{array}{c}\mathrm{N}^{\circ} \\
\text { ESPECIES } \\
\text { EN CHILE }\end{array}$ & $\begin{array}{l}\mathrm{N}^{\circ} \text { ESPECIES } \\
\text { ARICA- } \\
\text { PARINACOTA }\end{array}$ & $\begin{array}{c}\mathrm{N}^{\circ} \text { TAXONES } \\
\text { ENDÉMICOS DE } \\
\text { CHILE PRESENTES } \\
\text { EN A-P }\end{array}$ & $\begin{array}{c}\mathrm{N}^{\circ} \text { SUBESPECIES } \\
\text { O VARIEDADES }\end{array}$ \\
\hline Anthemideae & 1 & Cotula & 1 & 1 & 1 & & \\
\hline \multirow[t]{2}{*}{ Inuleae } & 2 & Pluchea & 1 & 1 & 1 & & \\
\hline & & Tessaria & 3 & 1 & 1 & & \\
\hline \multirow[t]{3}{*}{ Coreopsideae } & 3 & Bidens & 7 & 2 & 2 & & 2 \\
\hline & & Coreopsis & 3 & 1 & 1 & & \\
\hline & & Heterosperma & 3 & 2 & 2 & & \\
\hline Tageteae & 1 & Tagetes & 3 & 3 & 2 & & \\
\hline Bahieae & 1 & Schkuhria & 3 & 2 & 2 & & \\
\hline \multirow[t]{4}{*}{ Heliantheae } & 4 & Ambrosia & 3 & 4 & 3 & & \\
\hline & & Galinsoga* & - & 1 & 1 & & \\
\hline & & Spilanthes & 1 & 1 & 1 & & \\
\hline & & Viguiera & 3 & 4 & 2 & & \\
\hline Helenieae & 1 & Flaveria & 4 & 2 & 1 & & \\
\hline \multirow[t]{2}{*}{ Perityleae } & 2 & Perityle & 4 & 1 & 1 & & \\
\hline & & Villanova & 3 & 2 & 1 & 1 & \\
\hline \multirow[t]{3}{*}{ Eupatorieae } & 3 & Helogyne & 3 & 2 & 1 & & \\
\hline & & Ophryosporus & 3 & 8 & 2 & & \\
\hline & & Stevia & 3 & 1 & 1 & 1 & \\
\hline Total & 55 & & & & $143 * * *$ & 13 & 9 \\
\hline
\end{tabular}

*Géneros que presentan sólo especies adventicias en la región. / Genera showing only introduced species in the region.

**Hasta hace poco reconocido como género austral-asiático, sin embargo, Australia ha sido transferida a otro género (Pasini com. pers.) / Usually recognized as an austral-asiatic genus; the Australian populations have been recently transferred to another genus (Pasini com. pers.) ***Son 144 taxones considerando las dos subespecies de Baccharis santelicis. / In total there are 144 taxa, including the two subspecies of Baccharis santelicis.

TABLA IV. Proporción de elementos florísticos en los géneros nativos de Asteráceas de Arica y Parinacota $(n=49)$.

TABLE IV. Proportion of floristic elements shown by the native genera of Asteraceae of the Arica y Parinacota flora region ( $\mathrm{n}=49$ ).

\begin{tabular}{lccc}
\hline Elemento florístico & $\begin{array}{c}N^{0} \text { GÉneros de Arica Y } \\
\text { Parinacota }\end{array}$ & $\begin{array}{c}\text { \% GÉneros de Arica Y } \\
\text { Parinacota }\end{array}$ & $\begin{array}{c}\text { \% GÉneros de Asteráceas } \\
\text { De Chile* }\end{array}$ \\
\hline Pantropical & 5 & 10,2 & 7,3 \\
Australasiático & 0 & 0 & 3,3 \\
Neotropical & 36 & 73,5 & 43,1 \\
Antitropical & 5 & 10,2 & 21,1 \\
Sud-templado & 0 & 0 & 8,9 \\
Endémico & 0 & 0 & 13 \\
Cosmopolita & 3 & 6,1 & 3,3 \\
\hline
\end{tabular}

*extraídos de Tabla 8.3 en Moreira-Muñoz (2011)./ From Table 8.3 in Moreira-Muñoz (2011). 


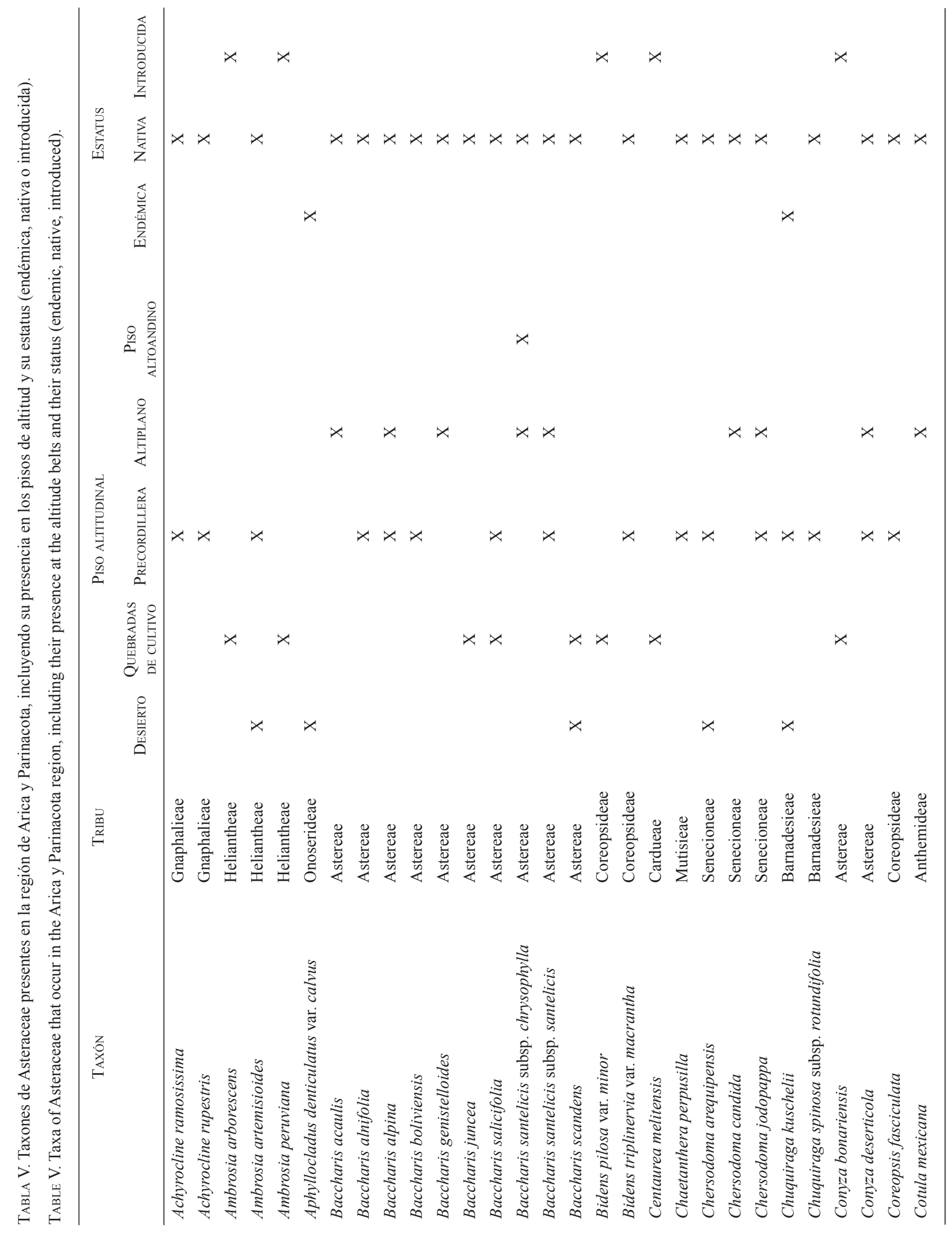




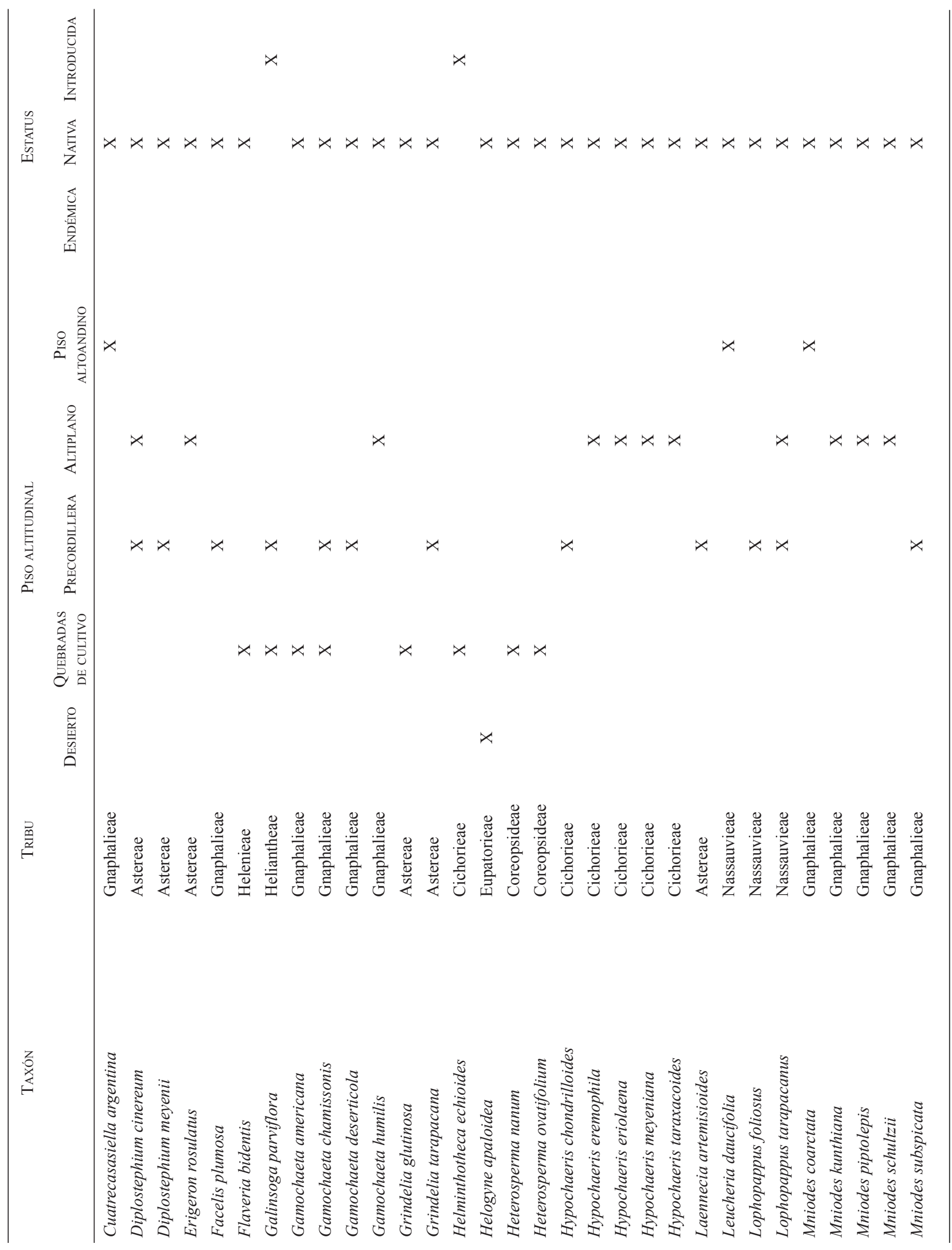


Gayana Bot. 73(2), 2016

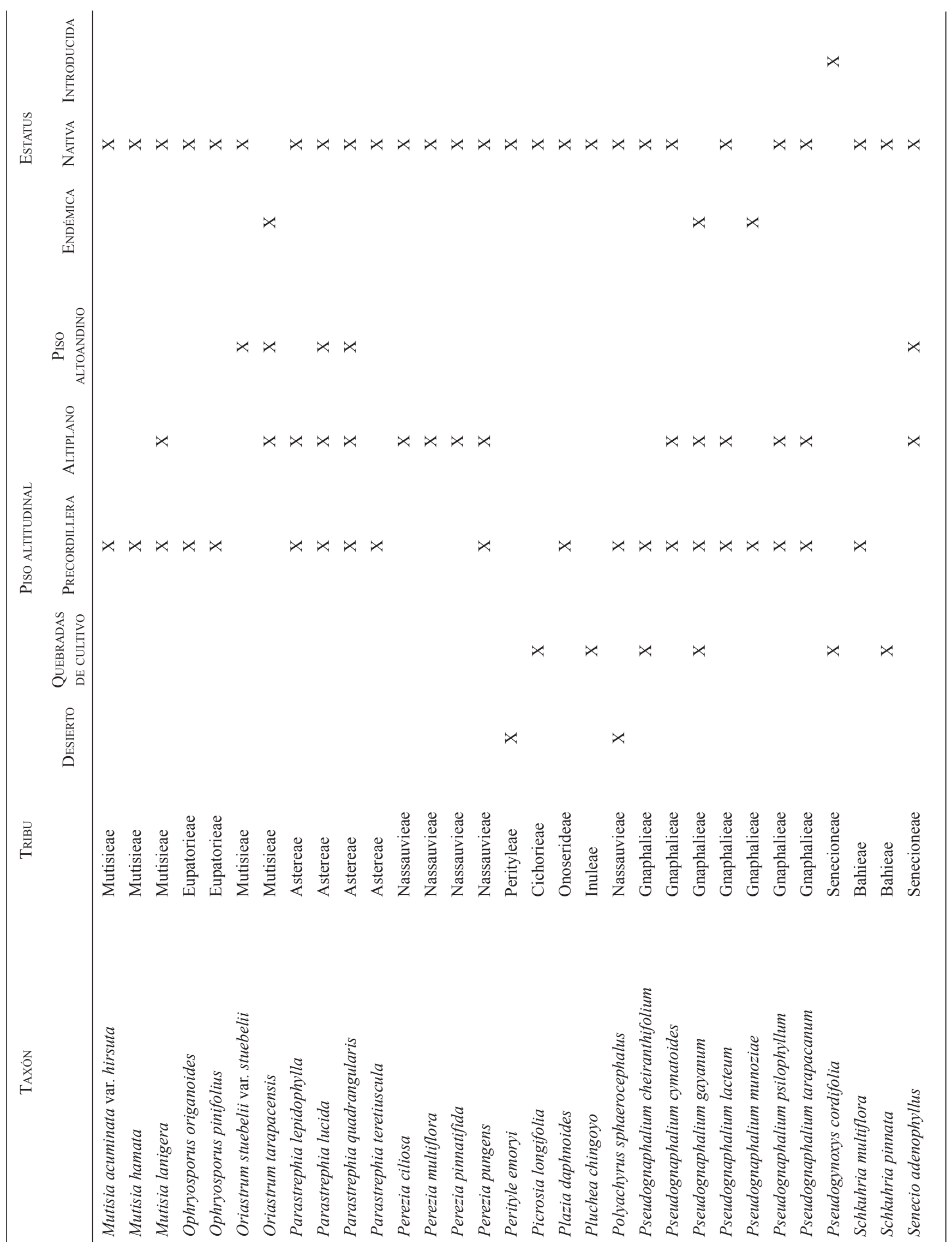


La familia Asteraceae en Arica y Parinacota: Moreira-Muñoz, A. ET AL.

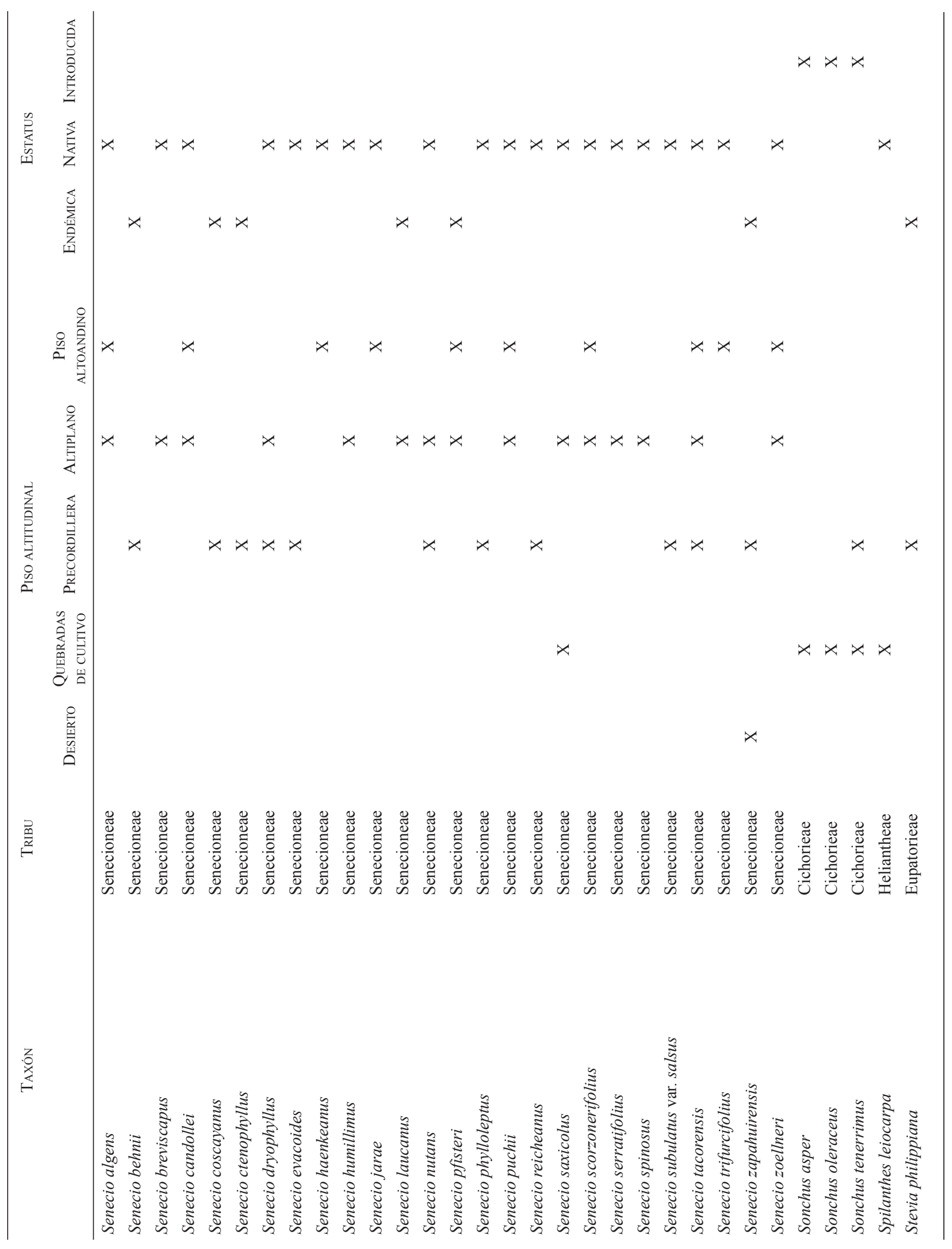


Gayana Bot. 73(2), 2016

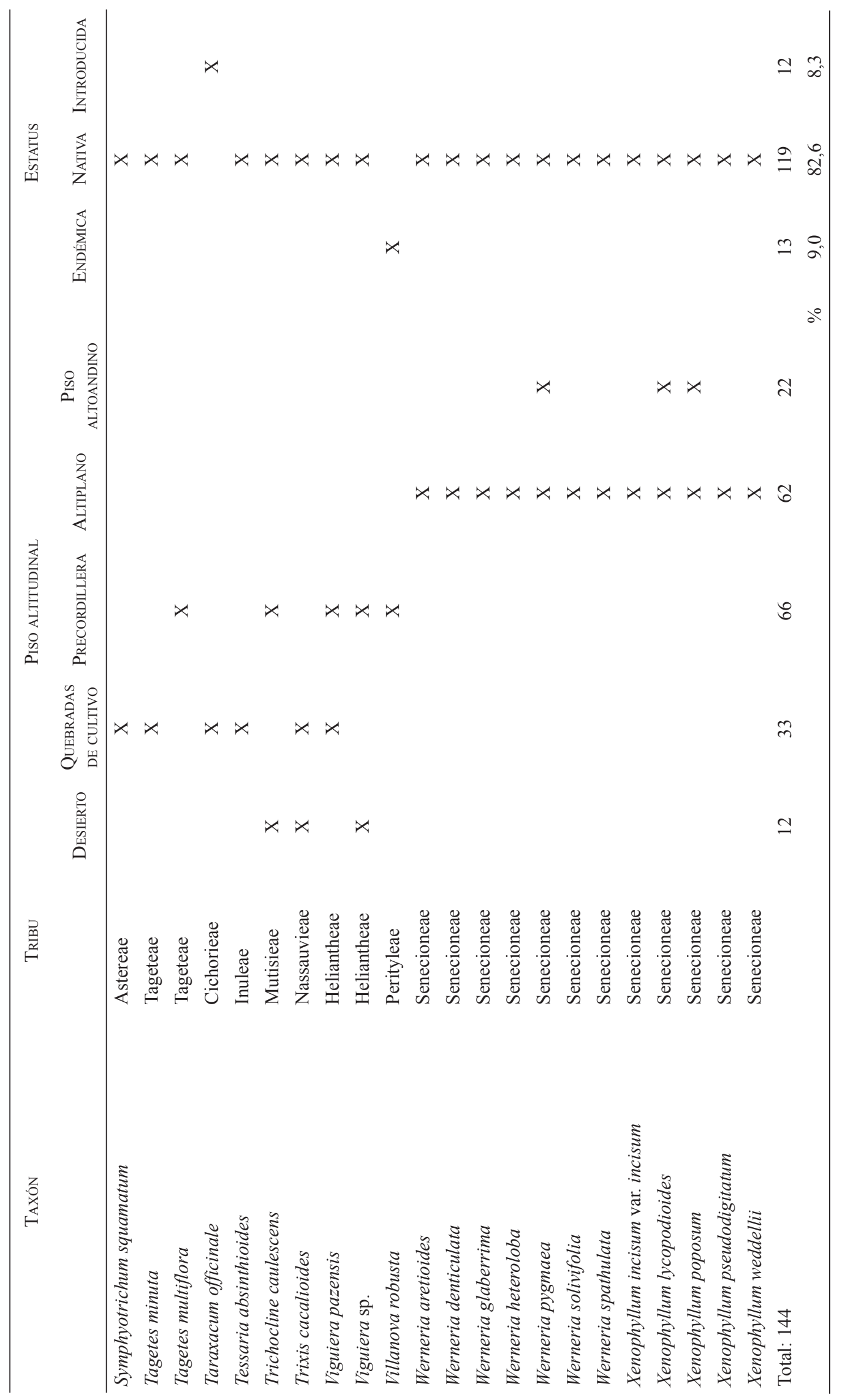


La familia Asteraceae en Arica y Parinacota: MoreIrA-Muñoz, A. ET AL.

TABla VI. Especies de Asteraceae endémicas de Chile y su distribución por regiones, pisos y localidades en la región. Regiones: A-P = Arica y Parinacota; Tarap. = Tarapacá; Antof. = Antofagasta; Mag. = Magallanes.

TABLE VI. Chilean endemic species present in the Arica y Parinacota region, including their presence in Chile and in the altitude profile. Regions: A-P = Arica y Parinacota; Tarap. = Tarapacá; Antof. = Antofagasta; Mag. = Magallanes.

\begin{tabular}{|c|c|c|c|c|}
\hline ESPECIE ENDÉMICA & Distribución en Chile & Piso altitudinal & $\begin{array}{l}\text { LOCALIDADES EN LA } \\
\text { REGIÓN }\end{array}$ & $\begin{array}{c}\text { CATEGORÍA de CONSERVACIÓN } \\
\text { (SEGÚN GATICA-CASTRO ET AL. } \\
2015 \text { ) }\end{array}$ \\
\hline Chuquiraga kuschelii & A-P & Precordillera & Quebrada Allane & En Peligro \\
\hline Senecio laucanus & A-P & Altiplano & Las Cuevas, PN Lauca & En Peligro \\
\hline $\begin{array}{l}\text { Aphyllocladus } \\
\text { denticulatus var. calvus }\end{array}$ & $\begin{array}{l}\text { A-P, Tarap.; especie } \\
\text { y variedad endémicas } \\
\text { de Chile }\end{array}$ & Precordillera & Timar & Vulnerable \\
\hline Oriastrum tarapacensis & A-P, Tarap. & Altiplano & $\begin{array}{c}\text { Colpitas, Co. Guane- } \\
\text { Guane }\end{array}$ & En Peligro \\
\hline $\begin{array}{l}\text { Pseudognaphalium } \\
\text { munoziae }\end{array}$ & A-P, Tarap. & Precordillera & $\begin{array}{c}\text { Quebrada Allane, subida } \\
\text { a Chapiquiña }\end{array}$ & - \\
\hline Senecio behnii & A-P, Tarap. & Precordillera & Alrededores de Putre & Vulnerable \\
\hline Senecio coscayanus & A-P, Tarap. & Precordillera & Alrededores de Putre & - \\
\hline Senecio zapahuirensis & A-P, Tarap. & Precordillera & $\begin{array}{c}\text { Alrededores de Putre y } \\
\text { Zapahuira }\end{array}$ & En Peligro \\
\hline Villanova robusta & A-P, Tarap. & Precordillera & Sector Tojotojone & En Peligro \\
\hline Stevia philippiana & A-P, Antof. & Precordillera & $\begin{array}{c}\text { Alrededores de Putre y } \\
\text { Socoroma }\end{array}$ & Vulnerable \\
\hline Senecio ctenophyllus & A-P, Tarap., Antof. & Precordillera & Alrededores de Putre & Casi amenazado \\
\hline Senecio pfisteri & A-P, Tarap., Antof. & Altiplano & $\begin{array}{c}\text { Cerro Milagro, sobre } \\
\text { Termas de Jurasi }\end{array}$ & Vulnerable \\
\hline $\begin{array}{l}\text { Pseudognaphalium } \\
\text { gayanum }\end{array}$ & A-P a Mag. & Precordillera & $\begin{array}{c}\text { Alrededores de Putre y } \\
\text { Zapahuira }\end{array}$ & - \\
\hline
\end{tabular}

Son 18 las tribus de Asteráceas presentes en la región; la tribu Cardueae se encuentra representada sólo por una especie alóctona, Centaurea melitensis. La tribu Cichorieae presenta una mayor proporción de géneros introducidos. Al nivel de géneros nativos, la tribu mejor representada es Astereae (8), seguida por Gnaphalieae (6). Al nivel de especies la tribu más diversa es Senecioneae, con 42 especies, seguida por Astereae y Gnaphalieae, con 22 y 20 especies respectivamente. Evidentemente el género más diverso en la región es Senecio, con 27 especies nativas, incluyendo seis especies endémicas de Chile y una especie endémica de la provincia de Parinacota (S. laucanus) (Tablas III y V). Le siguen desde lejos en riqueza, el género Baccharis (nueve especies y dos variedades) y Pseudognaphalium (siete especies).

\section{RELACIONES FITOGEOGRÁFICAS}

Los géneros nativos de Asteraceae de la Región de Arica y Parinacota (49) pertenecen en su gran mayoría $(73,5 \%)$ al elemento Neotropical, seguido por el elemento Antitropical, también característico de la flora de Asteráceas de Chile (Tabla IV). Por el contrario, tanto el elemento Endémico como el elemento Sud-templado están ausentes en la flora de Asteráceas del extremo norte de Chile. El elemento Neotropical es el que domina en la flora de Chile (43,1\%), y 
en el extremo Norte su proporción se vuelve absolutamente dominante (Tabla IV), dando cuenta de la estrecha relación con las floras de Perú, Bolivia y el NW de Argentina. Si bien el elemento Endémico, muy característico de Chile Central, desaparece en el Norte, dentro del elemento Neotropical existen géneros de Asteraceae endémicos del Altiplano, como Chersodoma, Helogyne, Lophopappus, Parastrephia y Plazia.

DIVERSIDAD EN EL GRADIENTE ALTITUDINAL Y ENDEMISMO La Tabla V muestra una síntesis de las especies, variedades y subespecies de Asteraceae presentes en la Región de Arica y Parinacota, ordenadas alfabéticamente, incluyendo su presencia en el gradiente de altitud y su estatus de endémica, nativa o introducida.

La gran mayoría de las especies de Asteráceas de Arica y Parinacota son especies nativas $(81,9 \%)$, compartidas principalmente con Perú, Bolivia y/o el NW de Argentina, es decir, corresponden a especies nativas del Altiplano. Pocas especies alcanzan Chile central, sobre todo aquellas de amplia distribución en el Neotrópico, como Gamochaeta americana. Algunas especies son típicas de toda la cordillera andina, como por ejemplo Werneria pygmaea. Por otro lado, un porcentaje reducido de especies $(8,3 \%)$ corresponde a especies introducidas, la mayoría de éstas ubicadas en sectores cultivados de las quebradas principales. El Catálogo incluye una especie introducida adventicia nueva para Chile: Pseudogynoxys cordifolia. Debido a que las prospecciones se han concentrado en la provincia de Parinacota, es probable que en el futuro se incremente el número de especies introducidas registradas en sitios anexos a cultivos en las grandes quebradas de la región, lo cual escapa de la intención de este trabajo.

Un 9\% (13) corresponde a taxones endémicos de Chile. De ellos, una especie es de amplia distribución en Chile (Pseudognaphalium gayanum), mientras que dos especies son endémicas de las tres regiones más septentrionales, incluyendo Antofagasta (Senecio ctenophyllus, S. pfisteri). Siete especies son endémicas de Arica y Parinacota y Tarapacá. Una especie (Stevia philippiana) muestra una distribución disyunta costa-cordillera, entre Parinacota y la costa de Antofagasta. Dos especies, Chuquiraga kuschelii y Senecio laucanus son endémicas de la Región de Arica y Parinacota (Tabla VI, Fig. 3).

Varias de las especies endémicas, debido a su rango de distribución restringido a escala nacional y también por su presencia muy localizada en la región, han sido incluidas en alguna categoría de conservación a escala regional (GaticaCastro et al. 2015). De las especies endémicas (Tabla VI), la mayoría pertenece al piso de precordillera o pre-altiplánico, mientras que sólo cuatro de ellas son de la Puna o Altiplano. Estas últimas muy probablemente se encuentren protegidas en alguna de las áreas protegidas de la provincia de Parinacota (Tabla II), pero el estado de conservación real de sus poblaciones es desconocido. Es posible que la especie que no pudo ser reconocida al nivel específico, Viguiera sp., pertenezca a la categoría de especie endémica. Se requiere con urgencia revisar la taxonomía del género.

La Tabla V da cuenta de la presencia de las especies de Asteraceae en el gradiente altitudinal. La precordillera concentra el mayor número de especies (66), seguido por el piso de altiplano (62). Existen especies de amplia presencia en el gradiente; algunas de las especies más comunes desde precordillera hasta el piso altoandino son las "tolas" (Parastrephia lucida y P. quadrangularis). Otras especies se restringen a un solo nivel altitudinal, como el caso de las especies de Werneria y Xenophyllym, que se distribuyen en el altiplano. Aún así, es tarea pendiente la de afinar el conocimiento de la distribución geográfica de las especies en el gradiente de altitud y en los distintos sectores de la región. Es necesario consignar que si se corrige por superficie, la precordillera alcanza una notable mayor riqueza, puesto que ésta se restringe a una delgada franja altitudinal entre 3.300 y 3.900 m s.n.m. (Fig. 1) y ha sido ampliamente reconocida por su riqueza de especies (Rundel et al. 2003, Luebert \& Gajardo 2005). Corresponde al piso vegetacional 'Matorral bajo tropical andino de Fabiana ramulosa y Diplostephium meyenii', de Luebert \& Pliscoff (2006). Por su parte, en el Altiplano de la región, son varios los pisos vegetacionales que poseen especies de Asteráceas como dominantes, como es el caso de los pisos 'Tropical andino de Parastrephia lepidophylla y P. quadrangularis' (3.800-4.300 m s.n.m.); 'Matorral bajo tropical andino de Parastrephia lucida y Festuca orthophylla'(4.000-4.400 m s.n.m.); y el 'Matorral bajo tropical andino de Parastrephia lucida y Azorella compacta'(4.300-4.600 m s.n.m.) (Luebert \& Pliscoff 2006) (Tabla I).

La riqueza disminuye drásticamente tanto en los pisos bajos (desértico) como en el piso superior (altoandino). Estos pisos también poseen especies de Asteráceas de carácter dominante; es el caso por ejemplo del 'Piso supratropical xérico semiárido de Atriplex imbricata y Ambrosia artemisioides' (Luebert \& Gajardo 2005), o el 'Piso criorotropical pluviestacional seco de Senecio zoellneri y Azorella compacta' (Luebert \& Gajardo 2005).

\section{ASTERÁCEAS COMO OBJETO DE CONSERVACIÓN}

Es preciso considerar que todas las formaciones vegetacionales se encuentran sometidas a intervención humana que data de siglos, incluyendo la extracción de leña durante la época de explotación del salitre. Ello debe haber disminuido drásticamente la cobertura vegetacional, especialmente de las especies arborescentes o leñosas. Algunas especies se han ido recuperando, pero esta recuperación es extremadamente lenta debido a las condiciones ambientales que limitan el crecimiento, como es el caso de Azorella compacta (yareta) (Kleier et al. 2015), que por lo demás se sigue explotando hasta el día de hoy. 

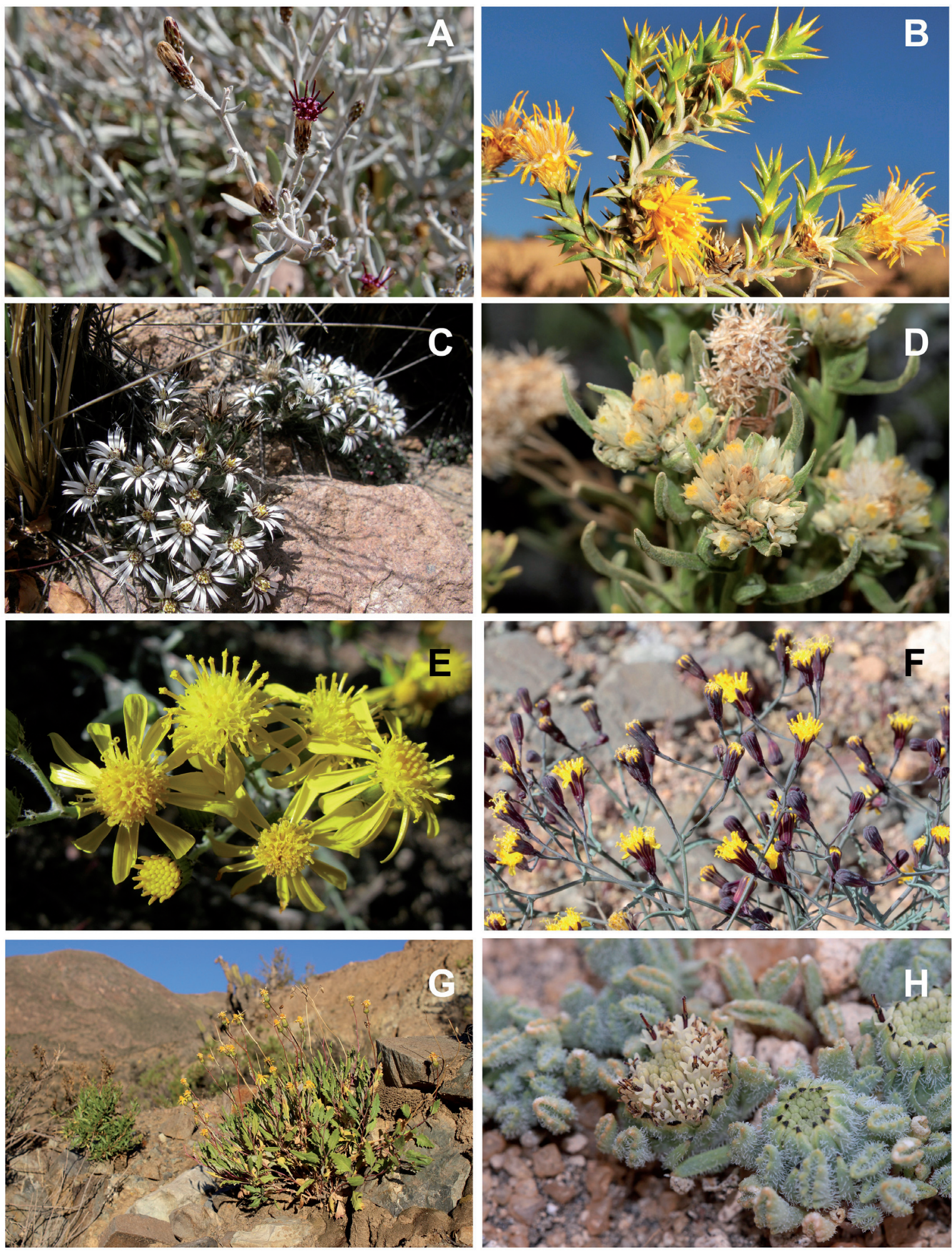

Figura 3. Especies endémicas de Asteraceae presentes en la Región de Arica y Parinacota. A) Aphyllocladus denticulatus var. calvus, B) Chuquiraga kuschelii, C) Oriastrum tarapacensis, D) Pseudognaphalium munoziae, E) Senecio behnii, F) Senecio ctenophyllus, G) Senecio coscayanus, H) Senecio laucanus. Créditos A-F, H: Andrés Moreira-Muñoz; G: Andrés Huanca Mamani.

Figure 3. Some endemic Asteraceae species occurring in the Arica y Parinacota Region.A) Aphyllocladus denticulatus var. calvus, B) Chuquiraga kuschelii, C) Oriastrum tarapacensis, D) Pseudognaphalium munoziae, E) Senecio behnii, F) Senecio ctenophyllus, G) Senecio coscayanus, H) Senecio laucanus. Credits A-F, H: Andrés Moreira-Muñoz; G: Andrés Huanca Mamani. 
Las especies de Asteráceas reconocidas como amenazadas son principalmente aquellas endémicas que poseen un rango de distribución restringido, como es el caso de Senecio laucanus, Chuquiraga kuschelii, Oriastrum tarapacensis, Senecio behnii, Senecio zapahuirensis, Villanova robusta y Stevia philippiana (Gatica-Castro et al. 2015) (Tabla VI). Otras especies, sin ser endémicas, se conocen de muy pocas localidades en la región, como es el caso de Lophopappus foliosus, cuya presencia conocida en Chile se circunscribe a la Quebrada Allane (Faúndez \& Macaya 1998). Otras especies han sido reconocidas para Chile en este trabajo, como Mniodes kunthiana (=Lucilia violacea), Senecio evacoides, Achyrocline ramosissima y Gamochaeta humilis, o han sido descritas recientemente, como es el caso de Pseudognaphalium munoziae. Por otro lado, es preciso mejorar el conocimiento de especies que no han logrado ser encontradas en las últimas campañas de terreno, como Cuatrecasasiella argentina o Erigeron rosulatus.

Varias de estas especies se encuentran en el área del Parque Nacional Lauca (e.g. Senecio laucanus) y la Reserva Nacional Las Vicuñas, pero el estado real de conservación de sus poblaciones es desconocido, así como los impactos de faenas y prospecciones mineras, el tráfico de vehículos y la posible extracción para distintos usos.

\section{CONCLUSIONES Y COMENTARIOS}

La revisión de los principales herbarios chilenos junto al trabajo de campo, arrojan como resultado la presencia de 144 taxones de la familia de Asteráceas en la Región de Arica y Parinacota, incluyendo 119 taxones nativos, 13 especies endémicas y 12 alóctonas. Un 73,5\% de los géneros pertenece al elemento Neotropical, lo cual da cuenta de su pertenencia a la provincia biogeográfica de la Puna (Cabrera \& Willink 1973). Ello involucra por cierto a las tribus eminentemente americanas: Barnadesieae (Chuquiraga), Nassauvieae y Onoserideae (Plazia y Aphyllocladus); esta última endémica de los Andes. Si bien las otras tribus son de distribución más amplia, muchos de los géneros presentes en el Altiplano son esencialmente de distribución andina, como Oriastrum o Mniodes, pertenecientes a Mutisieae y Gnaphalieae respectivamente. Géneros de Asteráceas estrictamente endémicos del Altiplano son Chersodoma, Parastrephia y Lophopappus. Para el caso de Chersodoma, Dillon \& Sagástegui-Alva (1996) han propuesto un origen en el NW de Argentina, con una subsecuente diversificación hacia el Norte y el Oeste en los Andes. Desde la pre-puna argentina, el género se habría expandido hacia mayores altitudes por la zona del lago Titicaca hacia el norte de Perú. Eventos de especiación condujeron a algunas especies a ocupar sitios más secos en la vertiente occidental de la Cordillera desde el centro de Perú hacia el extremo norte de Chile. También las especies de Lophopappus tienen una ocurrencia en las partes secas de las provincias Altoandina y de la Puna en Perú (Montecinos-Tubée et al. 2015) aunque algunas especies ocurren también en bosques pluviosos (Katinas et al. 2013). Por otro lado, hay especies que provienen de grupos de distribución andina austral, como es el caso de Leucheria daucifolia, única especie de este género eminentemente chileno que alcanza el sur de Perú. Es también el caso de especies de los géneros hermanos Oriastrum y Chaetanthera, con preeminencia en los Andes de Chile Central, que parecen haberse diversificado durante el Cenozoico, en posible relación con los cambios climáticos asociados al alzamiento andino (Hershkovitz et al. 2006, Luebert \& Weigend 2014).

El encuentro reciente de polen fósil de la familia en depósitos de Antártica confirma la presencia temprana de la familia en el sur de América, en el Cretácico tardío (Barreda et al. 2015), con una rica historia posterior de especiación y ocupación paulatina de ambientes por distintos grupos en distintas épocas. La tolerancia a condiciones cada vez más secas de algunas de las tribus más basales de Asteraceae, podría haber jugado un papel preponderante en la evolución de las Compuestas en el sur de Sudamérica (Barreda et al. 2015). Si bien la información paleobotánica más reciente confirma la presencia de la familia a partir del periodo Cretácico en el sur de Sudamérica, con una posterior radiación al resto del mundo, los elementos florísticos y las comunidades vegetacionales actuales deben haber adquirido su forma en función a las variaciones climáticas del Pleistoceno-Holoceno (Luebert \& Gajardo 2005).

En géneros que no pertenecen al elemento Neotropical, como es el caso de Senecio (género cosmopolita) también es destacable la presencia de grupos netamente andinos adaptados a condiciones extremas como es el caso de la serie Culcitium, bien representada en Parinacota (Senecio zoellneri, S. candollei, S. haenkeanus, S. serratifolius).

Los ecosistemas de puna del Altiplano andino son considerados como únicos y de alto interés para la conservación a escala global (Rundel \& Palma 2000). En este sentido, las áreas protegidas de la Región de Arica y Parinacota cumplen un rol crucial tanto en la protección de la flora y fauna, así como en la mantención de servicios ecosistémicos, especialmente la dotación de agua para la población regional, la agricultura y la industria minera, así como paisajes únicos para el turismo. Destaca en este sentido el Parque Nacional Lauca, que existe a partir de 1970. En conjunto con la Reserva Nacional Las Vicuñas y el Monumento Natural Salar de Surire, las tres unidades de SNASPE forman el núcleo de la Reserva de la Biosfera Lauca. El potencial de esta Reserva para el desarrollo sustentable de las comunidades altiplánicas ya ha sido reconocido, pero falta aún dar pasos concretos en aspectos de gobernanza que logren aunar los intereses de las comunidades con los intereses regionales y nacionales de 
conservación cautelados por el personal de CONAF.

Las especies registradas como endémicas tienen en general una presencia muy localizada, de forma que deberían ser incorporadas en un próximo proceso de clasificación de especies de acuerdo al "Reglamento para la Clasificación de Especies Silvestres según Estado de Conservación (RCE)"; varias de ellas han sido clasificadas como "En Peligro" o "Vulnerables" (Gatica-Castro et al. 2015). Si bien una parte de las especies endémicas se encuentra en el Parque Nacional Lauca, el estado de conservación de sus poblaciones permanece incierto. Otras especies endémicas y de distribución restringida se encuentran en precordillera, y no están representadas en las áreas protegidas de la región. De hecho la ampliación del Parque Nacional Lauca y la Reserva Nacional Las Vicuñas hacia sectores precordilleranos ha sido propuesta en varias ocasiones (Hernández 1980, CEE 2000). Ello beneficiaría no sólo la conservación de especies de Asteráceas endémicas y de distribución restringida, como Aphyllocladus denticulatus var. calvus que no tiene protección actualmente, sino a un gran número de especies nativas de otras familias, y especies de fauna carismática asociada, como el caso de la taruca (Hippocamelus antisensis) (Zúñiga 2011). Ello es hoy imperioso debido a los posibles efectos del cambio climático (global o regional) que según los modelos actuales, podría reducir el rango de distribución de varias especies (P. Pliscoff com. pers.). Los cambios más rápidos proyectados dicen relación con modificaciones en los patrones fenológicos; sin embargo, existen muy pocos estudios al respecto (e.g. Belmonte \& Moscoso 1985), los cuales ciertamente resultan hoy de una alta prioridad.

Existen para el Altiplano chileno algunos detallados estudios etnobotánicos (e.g. Castro et al. 1982, Villagrán \& Castro 2004). Ellos pueden, en conjunto con estudios fenológicos y taxonómicos, propiciar avances hacia una conservación más efectiva, incorporando las necesidades de las comunidades rurales aymara y los desafíos que plantea el aún incipiente desarrollo turístico (Román 2014), así como la evaluación del estado del ecosistema en su conjunto. Para ello se requiere ir mejorando el conocimiento de la biodiversidad y sus usos actuales e históricos; y es importante que dicho conocimiento se sustente en una adecuada y actualizada taxonomía.

Apéndice 1: Catálogo de las especies de Asteraceae (Compuestas) de la Región de Arica y Parinacota

Abreviaciones de regiones: A-P = Arica y Parinacota; Tarap. $=$ Tarapacá; Antof. $=$ Antofagasta; Atac. $=$ Atacama; Cqbo.

$=$ Coquimbo; Metrop. $=$ Metropolitana; Mag. $=$ Magallanes.

Tribu Barnadesieae

Chuquiraga kuschelii Acevedo, Bol. Mus. Nac. Hist. Nat. 24: 86, fig. 3, 1949. Tipo: Chile, Tarapacá, Arica, Puquios,
3.700 m s.n.m., 10-XI-1946, G. Kuschel s/n (SGO, LP).

Arbusto endémico de la región de Arica y Parinacota: transición del desierto a precordillera, en taludes pedregosos, 2.900-3.900 m s.n.m.

Exs.: A. Moreira 1970, 10-VI-2012. Quebrada Allane, 3.630 m s.n.m. (SGO).

Chuquiraga spinosa Less. subsp. rotundifolia (Wedd.) C. Ezcurra, Darwiniana 26: 242, fig. 6 B, 1985. Chuquiraga rotundifolia Wedd., Chloris Andina 1: 4 (1855) Tipo: Perú, Cordillera de Tacora, entre Arica y La Paz, 4000 m, d'Orbigny s/n (P).

Arbusto nativo, Andes S de Perú, Bolivia, N de Chile: A-P, Tarap.; precordillera, rara en piso puneño, $3.300-4.500 \mathrm{~m}$ s.n.m.

Exs.: A. Moreira 1928, 08-VI-2012. Termas de Jurasi, 4.260 m s.n.m. (SGO).

\section{TRIBU ONOSERIDAE}

Aphyllocladus denticulatus (J. Rémy) Cabrera var. calvus (Phil.) Cabrera, Darwiniana 9(3-4): 369, 1951. Jobaphes virgatus Phil. var. calvus [calva] Phil., Anal. Mus. Nac. Santiago de Chile, Secc. 2, Bot. 8: 32, 1891. Verz. Antofagasta Pfl. 32, 1891. Tipo: Chile, Antofagasta, Chacarillas, prope Pica, III-1885, C. Rahmer s/n (SGO).

Arbusto. Especie y variedad endémicas de Chile. La var. denticulatus de la reg. de Atac.; la var. calvus regs. A-P y Tarap., desierto, 2.000-2.900 m s.n.m.

Exs.: A. Moreira 1984, 11/06/2012. Bajos de Timar, 2.330 m s.n.m. (SGO).

Plazia daphnoides Wedd., Chloris Andina 1: 13, 1855. Tipo: Pérou: Cordillère de Tacora!, entre Tacna et La Paz, h. 4000 mètres, Weddell s/n (P).

Arbusto nativo, S de Perú, Bolivia, NW de Argentina y N de Chile: A-P; precordillera, 3.000-4.200 m s.n.m.

Exs.: A. Moreira, M. Muñoz \& V. Morales 1657, 26-V-2011. Termas de Jurasi, 4.070 m s.n.m. (SGO).

\section{Tribu NASSAUVIEAE}

Leucheria daucifolia (D. Don) Crisci, Darwiniana 20(12): 52, fig. 10 D, 1976. Ptilurus daucifolius D. Don, Trans. Linn. Soc. London 16(2): 219 (1830). Tipo: In Peruviae summis alpibus Cordilleras de los Andes Hispanicè dictis. Ruiz \& Pavon (BM).

Hierba perenne nativa del Altiplano de Bolivia, S y centro de Perú y Chile: A-P, piso altoandino, 4.500-4.800 m s.n.m. 
Exs.: M. Arroyo 84-845A, 15-IV-1984, camino de Pacollo a Nevados de Putre, Ruinas de Taapaca, 4.000 m s.n.m. (CONC).

Lophopappus foliosus Rusby, Bol. Torrey Bot. Club 21:487, t. 225, 1894. Sintipos: [Bolivia:] Collected by Mr Bang (No. 66) in the vicinity of La Paz, altitude about 10,000 feet, 1889, and at Talca Chuguiaguillo, April, 1890 (No. 791) (NY, K, US, GH).

Arbusto nativo del Altiplano del S de Perú, Bolivia, NW de Argentina y Chile: A-P; precordillera, 3.700-3.900 m s.n.m. En Chile solo registrado en Quebrada Allane.

Exs.: A. Moreira 1962, 10-VI-2012. Quebrada Allane, 3.830 m s.n.m. (SGO).

Lophopappus tarapacanus (Phil.) Cabrera, Revista Mus. La Plata, Secc. Bot. 12: 157, 1971. Gochnatia tarapacana Phil., Anal. Mus. Nac. Santiago de Chile, Secc. 2, Bot. 8: 34, 1891. Tipo: Chile: Provincia Tarapacá: Sotoca, 16-III1885, F. Philippi s/n (SGO, LP).

Sin.: Lophopappus cuneatus R.E. Fr.

Arbusto nativo de los andes de Perú, Bolivia y Chile: A-P, Tarap., precordillera, inicio del altiplano, 3.100-4.200 m s.n.m.

Exs.: A. Moreira, M. Bonifacino, D. Gutiérrez \& M. Monge 2005, 19-X-2012. Ruta A-201, camino a Portezuelo Chapiquiña, 3.729 m s.n.m. (SGO).

Nota: L. cuneatus es considerado sinónimo de $L$. tarapacanus (Phil.) Cabrera, por Faúndez \& Macaya (1998); sinonimia no aceptada por Katinas et al. (2013), indicando que L. cuneatus posee sólo corolas bilabiadas, mientras que L. tarapacanus posee, además de corolas bilabiadas, corolas tubulosas infundibuliformes o tubulosas-bilabiadas, observados en un isotipo en LP (los ejemplares en SGO tienen capítulos inmaduros). Los ejemplares Tipo fueron los únicos citados por Katinas et al. (2013) para Chile. Los autores también mencionan un ejemplar de Bolivia de $L$. cuneatus (Murguia 96) en SI, que posee flores bilabiadas y tubulosas-bilabiadas en un mismo capítulo. Los ejemplares observados en Parinacota poseen corolas bilabiadas.

Perezia ciliosa (Phil.) Reiche, Anales Univ. Chile 116: 426, 1905. Clarionea ciliosa Phil., Anal. Mus. Nac. Santiago de Chile, Secc. 2, Bot. 8: 35, 1891. Tipo: Chile, Antofagasta: Copacoya (hoy Toconce), 3500 m, 18-II-1885, F. Philippi $\mathrm{s} / \mathrm{n}(\mathrm{SGO})$.

Hierba acaule nativa del Altiplano del S de Perú, Bolivia y N de Chile: A-P, Tarap.; altiplano, en pajonales, 3.800-4.600 m s.n.m.

Exs.: M. Ricardi, C. Marticorena \& O. Matthei 332, 29-
III-1961, Ruta a Portezuelo de Chapiquiña, 4.000 m s.n.m. (CONC).

Perezia multiflora (Humb. \& Bonpl.) Less., Linnaea 5: 19, 1830. Chaetanthera multiflora Humb. \& Bonpl., Pl. aequinoct. 2: 168, tab. 135. 1809. Tipo: Ecuador. Dpto. Napo. Habitat in regionibus montis Antisanae frigidis $(\mathrm{P})$.

Hierba perenne nativa de Colombia hasta el centro de Argentina y N de Chile: A-P, altiplano; 3.800- $4.400 \mathrm{~m}$ s.n.m.

Exs.: A. Moreira 1932, 09-VI-2012. Subida a Portezuelo de Chapiquiña, 4.400 m s.n.m. (SGO).

Perezia pinnatifida (Humb. \& Bonpl.) Wedd., Chloris Andina 1: 40, 1855. Chaetanthera pinnatifida Humb. \& Bonpl., Pl. aequinoc. 2: 170, tab. 136. 1809. Tipo: [Ecuador:] Habitat in regionibus montis Cotopaxi frigidis $(\mathrm{P})$.

Hierba acaule, nativa de los Andes desde Perú y posiblemente Ecuador (de donde sólo se conoce la colección del tipo), Bolivia, NW de Argentina y N de Chile: A-P, Tarap.; altiplano; en pastizales, entre las rocas de laderas secas o al abrigo de las matas de gramíneas, 3.500-4.800 m s.n.m. Exs.: O. Zöllner 4663, 22-I-1969. Cerca del Portezuelo de Chapiquiña, 4.400 m s.n.m. (SGO).

Nota: Según Katinas (2012), Perezia pinnatifida podría considerarse una forma no escaposa de Perezia pungens, pero dado que coinciden en las mismas áreas con idénticas condiciones ecológicas individuos con escapos largos, y otros con escapos muy cortos, dicha autora considera a $P$. pinnatifida y a $P$. pungens como especies independientes.

Perezia pungens (Humb. \& Bonpl.) Less., Linnaea 5: 20, 1830. Chaetanthera pungens Humb. \& Bonpl., Pl. aequinoc. 2: 146, tab. 127. 1809. Tipo: Ecuador. Prov. Pichincha, in desexis Pichincha et Antisanae (Quito), ex herb. Humboldt (P).

Hierba perenne, nativa de los Andes del sur de Colombia, Ecuador, Perú, Bolivia, centro de Argentina y N de Chile (AP., Tarap., Antof., Atac., Cqbo.), precordillera y altiplano, 3.800-4.800 m s.n.m.

Exs.: A. Moreira 1900, 07-VI-2012. Camino a Tacora, Mirador Quebrada Allane, 3.849 m s.n.m. (SGO).

Nota: La especie presenta variaciones en el tamaño, forma y margen de las hojas, número, disposición y tamaño de sus capítulos, lo que llevó a la creación de diversos nombres, hoy sinónimos. Con los ejemplares presentes en SGO a la vista, no se puede diferenciar de $P$. atacamensis Phil., que habita las regiones de Antofagasta y Atacama, entre 3.5005.000 m s.n.m. Vuilleumier (1969) las considera sinónimos, 
pero Katinas (2012) las separa, entre otros caracteres, basada en la mayor o menor pubescencia en sus aquenios. En $P$. pungens los aquenios son glabros o escasamente estrigosos vs. seríceo-velludos en $P$. atacamensis. Esta especie se indica por primera vez para la Región de Arica y Parinacota.

Polyachyrus sphaerocephalus D.Don, Trans. Linn. Soc. London 16 (2): 230, 1830. Tipo: Perú, Née (MA, G).

Subarbusto nativo de Perú y norte de Chile: A-P, Tarap., Antof.; desierto y precordillera, 3.300-3.900 m s.n.m.

Exs.: A. Moreira, M. Muñoz, V. Morales 1603, 25-V-2011. Camino interior Putre-Chungará, 3.682 m s.n.m. (SGO).

Trixis cacalioides (Kunth) D. Don, Trans. Linn. Soc. London 16: 187, 1833. Perdicium cacalioides Kunth in Humb., Bonpl. \& Kunth, Nov. Gen. Sp. Pl. 4 (ed. folio): 121 (1818). Tipo: Crescit in declivitate orientali Andium Peruvianorum ad ripam fluvii Matara, alt. 430 hex. Floret Augusto (P).

Arbusto nativo de Argentina, Bolivia, Perú, Paraguay, Chile: regs. A-P y Tarap., 0-2.800 m s.n.m.; desierto; en los grandes valles especialmente Azapa, y en quebradas menores como la Quebrada Cardones.

Exs.: A. Moreira, M. Muñoz \& V. Morales 1576, 24-V-2011. Cuesta Cardones, 2.185 m s.n.m. (SGO).

\section{Tribu Mutisieae}

Chaetanthera perpusilla (Wedd.) Anderb. \& S. E. Freire, Taxon 39(3): 431, fig.1-2, 1990. Luciliopsis perpusilla Wedd., Chloris Andina 1: 160 (1856). Tipo: Bolivie: pelouses rases et un peu arides de la Lancha!, dans la partie supérieure du ravine de Chuquiaguillo, aux environs de La Paz, Weddell 1851 (P).

Hierba anual, nativa de Bolivia y N de Chile: A-P, Tarap.; precordillera, 2.200-3.300 m s.n.m.

Exs.: A. Moreira, M. Muñoz \& V. Morales 1582, 24-IV2011. Camino Arica-Putre, salida mano derecha hacia Livilcar, 3210 m s.n.m. (SGO).

Mutisia acuminata Ruiz \& Pav. var. hirsuta (Meyen) Cabrera, Opera Lilloana 13: 59, 1965. Mutisia hirsuta Meyen, Reise um die Erde 1: 451 (1834). Tipo: [Walper in Observat. Bot. : 284-285 (1843) cita Peruvia: Cordillera de Tacna] (B, destruido y F).

Arbusto nativo del centro y Sur de Perú, W y centro de Bolivia, 2.000-3.500 m s.n.m. Variedad del centro y Sur de Perú, W de Bolivia y extremo N de Chile: A-P, Tarap., precordillera; 2.900-3.500 $\mathrm{m}$ s.n.m.

Exs.: J.C. Torres-Mura, 22-VI-1995. Murmuntani, $3.300 \mathrm{~m}$ s.n.m. (SGO).
Mutisia hamata Reiche, Anales Univ. Chile 115: 103, 1904. nom. nov. para M. microphylla Phil., 1891 non Willd. ex DC., 1838. Tipo: Chile, Antofagasta, Amincha, 3800 msm, 25-II-1885, F. Philippi s/n (SGO).

Arbusto voluble, nativo, del S de Bolivia, NW de Argentina, y N de Chile: A-P, Tarap., Antof.; precordillera, 3.200-4.200 m s.n.m.

Exs.: A. Moreira, M. Muñoz \& V. Morales 1651, 26-V-2011. Termas de Jurasi, 4.070 m s.n.m. (SGO).

Mutisia lanigera Wedd., Chloris Andina 1: 16, 1855. Tipo: Bolivie: province de Carangas, d'Orbigny, $\mathrm{n}^{\circ} 1341$ (P).

Subarbusto voluble, nativo del S de Perú, W de Bolivia y extremo $\mathrm{N}$ de Chile: A-P, Antof.; precordillera y altiplano, al abrigo de grandes rocas de origen volcánico; como enredadera en Polylepis rugulosa; 3.500-4.500 m s.n.m.

Exs.: A. Moreira, M. Muñoz \& V. Morales 1685, 27-V-2011. Cruce a Pachama, en bosque de queñoas, 3.648 m s.n.m. (SGO).

Oriastrum stuebelii (Hieron.) A.M.R. Davies var. stuebelii, Chaetanthera \& Oriastrum: 272, 2010. Chaetanthera stuebelii Hieron., Bot. Jahrb. Syst. 21: 368, 1895. Tipo: Bolivia, Depto. La Paz, Prov. Aroma, Sicasica inter Tomarapé et La Paz, 3800 msm., Oct.-Nov., Stuebel 15 a (B, destruido); Bolivia, Depto. Oruro, Prov. Avaroa, de Challapata $80 \mathrm{~km}$ hacia Potosí, $4050 \mathrm{~m}$, IV-1992, Beck 21142 (Neotipo LPB).

Hierba perenne, nativa del Altiplano de Bolivia, Perú, NW Argentina y Chile: A-P, Tarap., Antof., piso altoandino, 4.500-5.000 m s.n.m.

Exs.: A. Moreira, M. Bonifacino, D. Gutiérrez \& M. Monge 2021, 20-X-2012. Portezuelo Taapaca, 4.819 m s.n.m. (SGO).

Oriastrum tarapacensis A.M.R. Davies, Chaetanthera \& Oriastrum: 278, 2010. Tipo: Chile, Prov. Iquique, camino Huara a Cancosa, km 129, 4400 m, II-1964, Marticorena, Matthei \& Quezada 348 (CONC).

Planta enana formando cojines laxos, endémica del Altiplano de Chile: A-P, Tarap.; altiplano y piso altoandino, laderas expuestas, bajo gramíneas cespitosas, 4.100- 4.600 m s.n.m. Exs.: A. Moreira, M. Bonifacino, D. Gutiérrez, M. Monge 2026, 20-X-2012. Ruta A 127, Km 11, pasado Estancia Yaypinta, en ladera sobre vega, $4.269 \mathrm{~m}$ s.n.m. (SGO).

Trichocline caulescens Phil., Anales Mus. Nac. Santiago de Chile, Secc. 2, Bot. 8: 31, 1891; Verz. Antofagasta Pfl. 31, 1891. Tipo: Chile, Tarapacá, Médanos de Pica, II-1885, F. Philippi s/n (SGO). 
Hierba perenne, acaule o caulescente, nativa de Perú y Chile: A-P, Tarap., Antof.; desierto y precordillera, 1.8503.500 m s.n.m.

Exs.: A. Moreira 1978, 11-VI-2012. $200 \mathrm{~m}$ al sur de la Virgen de Tojotojone, 3.130 m s.n.m. (SGO).

\section{Tribu Cardueae}

Centaurea melitensis L., Sp. Pl. 2: 917, 1753. Descrita de Upsala Suecia. Tipo: [Malta] "habitat in Melita" (LINN).

Hierba anual de origen europeo; maleza presente en todo Chile, incluso Juan Fernández e Isla de Pascua. En A-P en quebradas cultivadas.

Exs.: Pfister s. n., I-1950. Arica: Valle de Azapa, 50 m s.n.m. (CONC).

\section{Tribu Cichorieae}

Helminthotheca echioides (L.) Holub, Folia Geobot. Phytotax. 8(2): 176, 1973. Picris echioides L. Sp. Pl. 2: 792, 1753. Tipo: Habitat in Angliea, Galliea sylvis caeduis, aggeribus (LINN).

Hierba anual, de origen europeo, introducida en Sudamérica. En Chile crece entre A-P y Los Lagos, también reportada para Isla de Pascua. Se encuentra a orillas de camino y en terrenos cultivados, pero no ocupa grandes extensiones.

Exs.: Escobar \& Manríquez 359, IV-1980, km 12 Valle de Azapa, 220 m s.n.m. (CONC).

Hypochaeris chondrilloides (A. Gray) Cabrera, Notas Mus. La Plata, Bot. 9(46): 259, 1944. Achyrophorus chondrilloides A. Gray, Proc. Amer. Acad. Arts 5: 145 (-146). 1861 Tipo: Argentina, Río Negro, Patagonia Norte, 1838-1842, Expedición Wilkes (GH, NY).

Hierba perenne, caulescente, nativa de Chile, Bolivia y Argentina. Crece en suelos salitrosos y arenosos, desde el nivel del mar hasta 3.500 m s.n.m. En Chile en A-P, Antof. y Atac., transición de desierto a precordillera.

Exs.: M. Ricardi et al. 196, V-1972. km 25 camino Zapahuira a Putre, 3.450 m s.n.m. (CONC).

Hypochaeris eremophila Cabrera, Notas Mus. La Plata, Bot. 13(56): 22, 1948. nom nov. . para Distoecha taraxacoides Phil., Anales Mus. Nac. Santiago, Chile, secc. 2, Bot. 8: 37, tab. 2, fig. 2, 1891, Verz. Antofagasta Pfl. 37, tab. 2, fig. 2, 1891, non Distoecha taraxacoides Ball, 1885. Lectotipo: Argentina, Colorados, 3.600 m, 15-I-1885, F. Philippi s/n (SGO).

Hierba perenne, acaule, nativa de Perú, Bolivia, NW Argentina, N de Chile: A-P, Antof., Atac., altiplano, laderas expuestas, 2.800 a $4.700 \mathrm{~m}$ s.n.m.

Exs.: A. Moreira, M. Muñoz \& V. Morales 1656, 26-V-2011. Termas de Jurasi, 4.070 m s.n.m. (SGO).

Hypochaeris eriolaena (Sch. Bip.) Reiche, Anales Univ. Chile 116: 589, 1905. Achyrophorus eriolaenus Sch. Bip., Bonplandia 4: 54, 1856. Tipo: Perú, Puno, cordiller. pascuis sterilibus pr. Azangaro, VI-1854, W. Lechler 1754 (P).

Hierba arrosetada, nativa de Perú, Chile y Bolivia, en zonas altoandinas secas y pedregosas; 2.200-5.100 m s.n.m. En Chile solo en A-P; altiplano a 4.200-4.300 m s.n.m. El único ejemplar recolectado hasta la fecha (Cosapilla, Limani) se encuentra en el Herbario del Museo de La Plata (LP).

Exs.: A. Moreira, M. Bonifacino, D. Gutiérrez, M. Monge 2027 A, 20-X-2012. Ruta A127 km 11, pasado Estancia Yaypinta, en ladera sobre vega, 4.269 m s.n.m. (SGO).

Hypochaeris meyeniana (Walp.) Griseb., Abh. Königl. Ges. Wiss. Göttingen 19([1]): 199 (1974). Oreophila meyeniana Walp., Nov. Actorum Caes. Leop.-Carol. Nat. Cur. 19, Suppl. 1: 292 (1843). Tipo: Peruvia: in planitie circa Tacoram, altitudine 14-17,000 pedum. (B, destruido).

Hierba perenne, nativa de Perú, Bolivia, NW Argentina y Chile: A-P a Atac.; altiplano, laderas rocosas entre 3.4005.000 m s.n.m.

Exs.: A. Moreira \& F. Luebert 2387, 16-III-2015. Ruta 127, Colpitas-Caquena, km 5,5, pasado Estancia Yaypinta, 4.200 m s.n.m. (SGO).

Nota: Urtubey et al. (2009: 704) anotan el Tipo como Meyen 22, probablemente colectado en abril 1831 (fotos LP, MO), e indican que la localidad Tacora podría corresponder ahora a Chile.

Hypochaeris taraxacoides Ball, J. Linn. Soc. Bot. 22:48, 1885. Oreophila taraxacifolia Meyen \& Walp., Nov. Actorum Acad. Caes. Leop.-Carol. Nat. Cur. 19, Suppl. 1: 291, 1843, non Oreophila taraxacifolia Loisel., 1827. Tipo: Peruvia: in planitie circa Tacoram, altitudine $14-17,000$ pedum. (v.s.) (B, destruido).

Hierba perenne, nativa de vegas y bofedales desde Colombia al S de Perú, Bolivia, NW Argentina y N de Chile: A-P; altiplano, 3.900-5.000 m s.n.m.

Exs.: A. Moreira \& F. Luebert 2417, 18-III-2015. Bofedal de Parinacota, 4.280 m s.n.m. (SGO).

Picrosia longifolia D. Don, Trans. Linn. Soc. London 16: 184, 1830. Tipo: Perú. Habitat in Limae, Lurini, Arnedo et Surco cultis locis, H. Ruiz \& J.A. Pavón s/n (MA). 
Hierba perenne, nativa. Especie de amplia distribución en las regiones cálidas y templadas de América del Sur, Perú, Bolivia, Paraguay y S de Brasil hasta la Patagonia. Muy variable en su desarrollo de acuerdo al hábitat. En A-P en quebradas con uso agropecuario intensivo.

Exs.: O. Zoellner 4100, 5-VII-1970. Quebrada de Tiliviche (CONC).

Sonchus asper (L.) Hill., Herb. Brit. 1: 47, 1769. Sonchus oleraceus L. var. asper L., Sp. Pl.: 794. 1753. Tipo: Habitat in Europae cultis, Herb. Burser VI: 14 (UPS).

Hierba perenne, originaria de Europa e introducida como planta ruderal en casi todas las regiones templadocálidas del mundo. En Chile en A-P y desde Valparaíso a Magallanes, también Isla de Pascua. En A-P en quebradas con uso agropecuario intensivo.

Exs.: Escobar \& Manríquez 360, IV-1980. Arica: Valle de Azapa, km 12, 220 m s.n.m. (CONC).

Sonchus oleraceus L., Sp. Pl.: 794 (1753). Tipo: Habitat in Europae cultis, Herb. Linn. N 949.6 (LINN).

Hierba perenne, originaria de Europa, hoy introducida en casi todo el mundo. En Chile abundante a orillas de caminos y sitios eriazos, desde A-P, Tarap. hasta Magallanes. También en Isla de Pascua, Juan Fernández e Islas Desventuradas. En A-P en lugares de uso agropecuario.

Exs.: O. Matthei \& R. Rodriguez 262, III-1987. Putre 3.500 m s.n.m. (CONC).

Sonchus tenerrimus L., Sp. Pl. 2: 794, 1753. Tipo: Upsala, Suecia (LINN).

Hierba perenne originaria de Europa. En Chile en casi todo el país, también en Juan Fernández, tanto en cultivos como en sitios eriazos. En A-P en sectores cultivados de los valles y precordillera.

Exs.: M. Ricardi et al. 287, V-1972. Parinacota: camino Chapiquiña, frente a Central Hidroeléctrica, 3.400 m s.n.m. (CONC).

Taraxacum officinale Weber ex F.H. Wigg., Prim. Fl. Holsat.: 56. 1780. Tipo: "Dens leonis latiore folio Bauh. In Lusitania, Bohemia, Dania”, J. Burser Hortus siccus VI.37 (UPS).

Hierba perenne, originaria de Europa e introducidas en casi todo el mundo. En Chile adventicia desde A-P hasta Magallanes, también en Isla de Pascua.

Exs.: $\sin$ exs. Observada en sitios cultivados alrededor de Belén. Citada en Faúndez et al. (2014) y González \& Molina (2015).

\section{Tribu Senecioneae}

Chersodoma arequipensis (Cuatrec.) Cuatrec., Brittonia 12 (3): 185, 1960. Senecio arequipensis Cuatrec., Fieldiana Bot. 27(2): 62, 1951. Tipo: Perú, southern slopes of Chachani Mountains, north of Arequipa, ca. 3000 msm, III-1920, Mr. \& Mrs. F.E. Hinkley 55 (S).

Subarbusto dioico, intrincado-ramoso, nativo de la puna árida S de Perú y N de Chile: Regs. A-P, Tarap., Antof.; desierto y precordillera, entre rocas, $2.500-3.700 \mathrm{~m}$ s.n.m. Exs.: A. Moreira 2484, 17-VI-2015. Quebrada bajo Alto Copaquilla, 3.260 m s.n.m. (SGO).

Chersodoma candida Phil., Anales Mus. Nac. Santiago de Chile, Secc. 2, Bot. 8: 33, 1891; Antofagasta Pfl. 33, 1891. Tipo: Chile, Antofagasta, entre Amincha y Paroma, 25-II1885, F. Philippi s/n (SGO).

Arbustito nativo, dioico, densamente hojoso, de Bolivia, NW Argentina, y N de Chile: A-P, Tarap., Antof.; altiplano, 3.900-4.600 m s.n.m. En Parinacota frecuente en queñoales de Polylepis tarapacana.

Exs.: A. Moreira, M. Muñoz \& V. Morales 1615, 25-V-2011. Orillas Lago Chungará, 4.574 m s.n.m. (SGO).

Chersodoma jodopappa (Sch. Bip. ex Wedd.) Cabrera, Revista Mus La Plata, Secc. Bot. 6: 350, 1946. Senecio jodopappus Sch. Bip. ex Wedd., Bonplandia 4(4): 51, 1856. Tipo: Perú, vecindades de Lago Titicaca, 3900 m, Lechler 1706 (K, P).

Arbusto nativo, densamente ramoso de Perú, Bolivia, NW de Argentina y N de Chile: A-P, Tarap., Antof.; precordillera y altiplano, 3.200-4.200 m s.n.m.

Exs.: A. Moreira, M. Muñoz, V. Morales 1681, 27-V-2011. Subida a Portezuelo de Chapiquiña, 4.147 m s.n.m. (SGO).

Nota: Existen ejemplares con características intermedias entre las especies, por lo que podría tratarse de híbridos. El Tipo e Isotipo de Senecio jodopappus depositados en $\mathrm{P}$ (Perú, Lago Titicaca) vistos en plants.jstor.org, presentan hojas lanoso-blanquecinas, lanceoladas y con 2-3 dientes a cada lado.

Pseudogynoxys cordifolia (Cass.) Cabrera, Brittonia 7(2): 53-74, 1950. Gynoxys cordifolia Cass. Dict. Sci. Nat. 48: 456. 1827. Tipo: Perú, 1779, J. Dombey (MPU).

Hierba perenne nativa de Perú, ahora indicada para Chile, Región de A-P, provincia de Arica, valle de Azapa. Introducida en sector de cultivos.

Exs.: J. Castillo s/n, 26-VI-1974. Valle de Azapa sector Las Maitas, 250 m s.n.m. (SGO). 
Senecio adenophyllus Meyen \& Walp., Nova Actorum Acad. Caes. Leop.-Carol. Nat. Cur. 19 Suppl. 1: 282, 1843. Tipo: Peruvia: in planitie circa Tacorum, alt. 14-17,000 ped. , Meyen s/n (B destruido, Neotipo P).

Subarbusto nativo, con olor a resina y color verde intenso, del S de Perú, Bolivia, NW de Argentina y N de Chile, altiplano a piso altoandino, 4.000-4.900 m s.n.m.

Exs.: A. Moreira 1911, 07-VI-2012. Camino a Azufrera Chupiquiña, detrás volcán Tacora, 4.820 m s.n.m. (SGO).

Senecio algens Wedd., Chloris Andina 1: 104, 1856. Tipo: Bolivie: fentes des rochers, au niveau des neiges, dans la quebrada de las lagunas, près de Potosi!, d'Orbigny $\mathrm{n}^{\circ}$ 1405. (P).

Hierba perenne, pigmea, cespitosa, nativa del Altiplano de Perú, Bolivia, NW Argentina y N de Chile: A-P, Tarap., Antof., altiplano a piso altoandino, 3.700-5.000 m s.n.m. Exs.: A. Moreira 1942, 09-VI-2012. Portezuelo Chapiquiña, Ojo de Agua, 4.450 m s.n.m. (SGO).

Senecio behnii Ricardi \& Martic., Gayana, Bot. 11: 12, f. 4, 1964. Tipo: Chile, Prov. Tarapacá, Depto. de Arica, Camino Arica-Portezuelo de Chapiquiña, 3.300 msm, 25-III-1961, Ricardi, Marticorena \& Matthei 142 (CONC).

Subarbusto erecto, endémico de Chile: A-P, Tarap., precordillera, 3.200-3.800 m s.n.m.

Exs.: A. Moreira, M. Muñoz, V. Morales 1663, 26-V-2011. $6,5 \mathrm{~km}$ al W del cruce a Putre con ruta internacional, 3.744 m s.n.m. (SGO).

Senecio breviscapus DC., Prodr. 6: 418, 1838. Tipo: Chilensibus Cordilleris legit cl. Haenke. (v.s. in h. Haenk. ab. ill. de Sternberg miss.) (PR, G-DC, P).

Hierba perenne, acaule, nativa de bofedales y vegas altoandinas de Argentina, Bolivia, Perú y Chile: A-P a Reg. Metrop., 2.250-4.900 m s.n.m. En A-P en vegas del altiplano.

Exs.: C. Villagrán, M. Arroyo, L. Armesto \& P. Uslar, 21-V1979. Cerro Guaneguane, 4.900 m s.n.m. (CONC).

Senecio candollei Wedd., Chloris Andina 1: 106, 1856, nov. nom. para Culcitium humile DC., Prodr. 6: 325 (1838) non Senecio humilis Desf. 1799. Tipo: Perú. Reg. Mont. America, T. Haenke s/n (P, M).

Hierba perenne, densamente tomentoso-lanosa, nativa de Argentina, Bolivia, Perú y Chile: A-P, usualmente en bosquetes de queñoa (Polylepis tarapacana) del altiplano y piso altoandino, $4.500-4.800 \mathrm{~m}$ s.n.m.

Exs.: A. Moreira 1913, 07-VI-2012. Camino a Azufrera
Chupiquiña, detrás volcán Tacora, bajo queñoas, $4.670 \mathrm{~m}$ s.n.m. (SGO).

Senecio coscayanus Ricardi \& Martic., Gayana, Bot. 11: 15-17, fig. 5, 1964. Tipo: Chile, prov. Tarapacá, Camino Huara-Cancosa, cerca de Coscaya, 3.200 m s.n.m., 2-IV1961, Ricardi, Marticorena \& Matthei 392 (CONC).

Subarbusto endémico de Chile, originalmente descrito para Tarapacá, se confirma ahora su presencia en Parinacota; precordillera, 3.200-3.600 m s.n.m.

Exs.: A. Moreira 2490, 18-VI-2015. Qapac Ñam, PutreSocoroma, km 3, 3.580 m s.n.m. (SGO).

Senecio ctenophyllus Phil., Anales Mus. Nac. Santiago de Chile, Secc.2, Bot. 8: 45, 1891; Verz. Antofagasta Pfl. 45, 1891. Tipo: Chile, Prov. Tarapacá, entre Mocha y Guaviña, III-1885, C. Rahmer s/n (SGO).

Arbusto glauco, glabérrimo, endémico de Chile: Regs. A-P a Antof., precordillera, 3.000-3.600 m s.n.m.

Exs.: A. Moreira 1972, 11-VI-2012. Ruta Putre-Socoroma, 3.480 m s.n.m. (SGO).

Senecio dryophyllus Meyen et Walp., Nova Actorum Acad. Caes. Leop.-Carol. Nat. Cur. 19, Suppl. 1: 283, 1843. Tipo: Peruvia: in planitie circa Tacorum, alt. 14-17,000 ped. Meyen s/n (B destruido). Cabrera (1985: 161) indica un clastotipo en MO.

Subarbusto con tallos erectos, glabros, verdes y rojizos, nativo de Argentina, Bolivia, Perú y Chile: Regs. A-P, Antof.; precordillera y altiplano, 3.900-4.500 m s.n.m.

Exs.: A. Moreira 1894, 07-VI-2012. Camino a Tacora, suelo pedregoso, volcánico, rojizo, 4.330 m s.n.m. (SGO).

Senecio evacoides Sch. Bip., Bonplandia (Hannover) 4(4): 52, 55.1856. Tipo: [Peru] Lechler 1942 (P, BR, G, GOET, K, LP, P, S).

Subarbusto pigmeo, subacaule, nativo del Altiplano de Perú, Bolivia y NW Argentina; 3.500-4.300 m s.n.m. Por primera vez citado para Chile, prov. de Parinacota, precordillera. Exs.: A. Moreira 1924, 08-VI-2012. Termas de Jurasi, en mitad de la ladera, 4.290 m s.n.m. (SGO).

Senecio haenkeanus Cuatrec., Fieldiana Bot. 27(1): 44, 1950. nov. nom. para Culcitium haenkei Wedd., Chloris Andina 1: 139, 1855, non Senecio haenkei DC. 1838. Tipo: Perou, Cordillere de Guanoco, 1790, Haenke 1776 (NY).

Hierba perenne, erecta, amarillento-lanoso-tomentosa, nativa de Perú y Chile: A-P, piso altoandino, 4.500-4.800 m s.n.m. 
Exs.: A. Moreira \& F. Luebert 2406, 17-III-2015. Camino a Azufrera Chupiquiña, detrás volcán Tacora, bajo queñoas, 4.700 m s.n.m. (SGO).

Senecio humillimus Sch.Bip. ex Wedd., Chloris Andina 1: 104, t. 19 B, 1856. Tipo: Pérou: au sommet de la Cordillère de Tabina! (Lechler $n^{\circ}$ 1924); Bolivie: pelouses arides des montagnes, autour de la ville de Potosi! (d'Orbigny, $\mathrm{n}^{\mathrm{o}}$ 1398; Wedd.) (P; isolectotipos, G, P).

Hierba perenne, pigmea, nativa de Argentina, Bolivia, Perú y Chile: A-P, altiplano, 4.000-4.600 m s.n.m.

Exs.: A. Moreira, M. Bonifacino, D. Gutiérrez \& M. Monge 2025, 20-X-2012. Quebrada profunda antes de Colpitas, después de cruce del río, 4.086 m s.n.m. (SGO).

Senecio jarae Phil., Anal. Mus. Nac. Santiago de Chile, Secc. 2, Bot. 8: 44, 1891. Tipo: Argentina, Antofagasta alta, traído de Calalaste, I-1885, F. Philippi s/n (LP, SGO).

Hierba perenne, nativa de Argentina, Bolivia, Perú y Chile: A-P a Antof., piso altoandino, 4.500-4.800 m s.n.m.

Exs.: Werdermann 1166, IV-1926. Cordillera volcán Tacora, Cerro Quiñuta, 4.800 m s.n.m. (CONC).

Senecio laucanus Ricardi \& Martic., Gayana Bot. 11: 17, f. 6, 1964. Tipo: Chile, Prov. Tarapacá, Depto. Arica, Camino de Putre a Chucuyo, Km 17, 4250 msm, 12-II-1964, Marticorena, Matthei \& Quezada 208 (CONC).

Hierba perenne en cojines flojos, endémica de Chile: A-P, altiplano, 4.250-4.400 m s.n.m.

Exs.: A. Moreira \& F. Luebert 2470, 20-III-2015, Las Cuevas, 4.400 m s.n.m. (SGO).

Senecio nutans Sch.Bip., Bonplandia 4 (4): 51, 1856. Tipo: [Peru:] [Lechler 1747]. (P, G, K, NY, P). Senecio graveolens Wedd., Chloris Andina 1: 111, 1856.

Arbustito resinoso, densamente ramoso, nativo de Argentina, Bolivia, Perú y Chile: A-P a Antof., precordillera y altiplano, 3.600-4.800 m s.n.m.

Exs.: A. Moreira, M. Muñoz \& V. Morales 1680, 27-V-2011. Subida a Portezuelo de Chapiquiña, 4.147 m s.n.m. (SGO).

Senecio pfisteri Ricardi \& Martic., Gayana Bot. 11: 25, f. 9, 1964. Tipo: Chile: Prov. Tarapacá, Depto. Arica, Portezuelo de Chapiquiña, faldeos al lado norte del campamento, 4.400 msm, 10-II-1964, Marticorena, Matthei \& Quezada 207 (CONC).

Hierba perenne, endémica de Chile: A-P a Antof., altiplano y piso altoandino, 4.000-4.850 m s.n.m.

Exs.: A. Moreira \& F. Luebert 2407, 17-III-2015. Camino a
Azufrera Chupiquiña, detrás volcán Tacora, bajo queñoas, 4.700 m s.n.m. (SGO).

Senecio phylloleptus Cuatrec., Collect. Bot. (Barcelona) 3(3): 272-274, 1953. Tipo: Peru, Dept. Arequipa, gravelly soil along stream-course, alt. 3,000-3,200 m. F. W. Pennell $13239(\mathrm{~F})$.

Subarbusto nativo de los Andes de Bolivia, S de Perú y Chile: A-P, muy común en precordillera, 2.900-3.900 m s.n.m.

Exs.: A. Moreira, M. Muñoz \& V. Morales 1587 A, 24-V2011. Camino Arica-Putre a Livilcar, 3.210 m s.n.m. (SGO).

Nota: Esta especie fue indicada por Ricardi \& Torres (1958) como nueva para Chile, pero luego corregida a Senecio reicheanus Cabrera, en Marticorena \& Quezada 1985: 151. Consideramos que es buena especie y difiere de $S$. reicheanus por tener las hojas más largas, angostas y de distinto largo en cada axila. El ápice oscuro de las brácteas es constante.

Senecio puchii Phil., Anales Mus. Nac. Santiago de Chile, Secc. 2, Bot. 8: 45, 1891; Verz. Antofagasta Pfl. 45, 1891. Tipo: Chile: Mezclado con ramas de Senecio atacamensis en el viaje al desierto de Atacama (Tipo no encontrado).

Subarbusto bajo, muy ramificado, nativo de Argentina, Bolivia y Chile: A-P a Antof., altiplano a piso altoandino, 4.000-4.800 m s.n.m.

Exs.: A. Moreira, M. Muñoz \& V. Morales 1611, 25-V-2011. Camino Putre-Chungará, 4.595 m s.n.m. (SGO).

Senecio reicheanus Cabrera, Lilloa 15: 403, f. 147, 1949. Tipo: Chile, Tarapacá, cordillera del cerro Japu, 3600 msm, III-1926, E. Werdermann 1104 (LP).

Subarbusto de tallos erectos, nativo de Bolivia y Chile: A-P, Tarap., precordillera, 2.800-4.200 m s.n.m.

Exs.: A. Moreira 1945, 09-VI-2012. Bajada desde Portezuelo de Chapiquiña, 4.200 m s.n.m. (SGO).

Nota: Incluida para Bolivia por Foster (1958: 218) pero no por Cabrera (1985); ver Hind (2011).

Senecio saxicolus Wedd., Chloris Andina 1: 131, 1856. Tipo: [Perou]: dans les fentes de rochers sur la Cordillere de Tacora, au-dessous de Palca, h. 3500-4000 m, 1851, Weddell (P).

Subarbusto ramoso en la base, nativo de Chile y Perú, altiplano a costa.

Exs.: W. Biese 2825, 21-X-1949. Depto. Arica, Desembocadura Río Lluta (SGO). 
Nota: Especie muy semejante a $S$. reicheanus, pero con flores radiadas. Cabrera (1949), además del Tipo, cita un segundo ejemplar para Huasco, en la costa de la Región de Atacama (Worth \& Morrison 16255, duplicado en SI), del cual Cabrera dice es algo más robusto que el Tipo. Hemos estudiado la foto y efectivamente es más robusta y de hojas muy auriculadas, por lo cual no concuerda con la especie $S$. saxicolus.

Senecio scorzonerifolius Mey. \& Walp., Nova Actorum Acad. Caes. Leop.-Carol. Nat. Cur. 19, Suppl. 1: 282, 1843. Tipo: Peruvia: in planitie circa Tacorum, alt. 14-17,000 ped. (B destruido).

Hierba perenne, nativa del Altiplano del S de Perú, Bolivia, NW de Argentina y N de Chile: A-P, Tarap., Antof.; altiplano y piso altoandino, bajo gramíneas cespitosas; 4.000-4.900 m s.n.m.

Exs.: A. Moreira \& F. Luebert 2423, 18-III-2015. Ladera W del Cerro Guaneguane, pajonal de Festuca orthophylla, 4.370 m s.n.m. (SGO).

Senecio serratifolius (Meyen \& Walp.) Cuatrec., Fieldiana, Bot. 27(1): 45. 1950. Culcitium serratifolium Meyen et Walp., Nov. Actorum Acad. Caes. Leop.-Carol. Nat. Cur. 19, Suppl.1: 278 (1843). Tipo: Perú [Cuzco] Urubamba, Pumahuanca, 4100 m, Zamalloa 1005, 3.03.1957 (Neotipo LP).

Hierba perenne, ligeramente lanuginosa o glabra, nativa de Argentina, Bolivia, Perú y Chile: A-P., Tarap., en vegas y suelos pantanosos del altiplano; 4.000-4.700 m s.n.m.

Exs.: A. Moreira \& F. Luebert 2383, 16-III-2015. Vega chica camino a Portezuelo Taapaca, 4.190 m s.n.m. (SGO).

Senecio spinosus DC., Prod. 6:420, 1838. Tipo: in Peruviâ legit cl. Née, et posteà in Peruvianis Cordilleris cl., Haenke (G-DC, P).

Subarbusto de tronco leñoso delgado, tortuoso, nativo de Bolivia, Perú y Chile: A-P, altiplano, 3.900-4.600 m s.n.m.

Exs.: A. Moreira, M. Bonifacino, D. Gutiérrez \& M. Monge 2034, 20-X-2012. Ruta A 127, km 11, pasado Estancia Yaypinta, en la ladera con Polylepis tarapacana, $4.308 \mathrm{~m}$ s.n.m. (SGO).

Senecio subulatus D.Don ex Hook. \& Arn. var. salsus (Griseb.) Cabrera, Lilloa 15: 90, f. 19. 1949. Senecio salsus Griseb. Abh. Königl. Ges. Wiss. Göttingen 19([1]): 190 (1874); Pl. Lorentz.: 142 (1874). Tipos: Argentina, Catamarca, frequens in campo de Arenal in salsis pr. Amaicha, fruticeta quoque formans in planitie alta pr. Laguna blanca.: Lorentz 425 (Lectotipo GOET; isolectotipos GOET, LP).
Arbusto de tallos surcados, color blanco-amarillento, nativo. Especie y variedad nativa de Bolivia, Argentina y Chile: A-P a Antof.: precordillera, 3.200-4.000 m s.n.m.

Exs.: A. Moreira, M. Bonifacino, D. Gutiérrez \& M. Monge 2000, 19-X-2012. Ruta Arica-Putre, saliendo de cuesta Cardones, km 94, 3.200 m s.n.m. (SGO).

Senecio tacorensis Cabrera, Bol. Soc. Arg. Bot. 10(1): 38, t. 1, f. B. 1962. Tipo: Perú. Tacora, 14-15.000 pies, IX1865, R. Pearce, (K). Senecio olivaceobracteatus Ricardi \& Martic., Gayana Bot. 11: 20, fig. 7, 1964 (sinonimizado aquí).

Subarbusto densamente albo-tomentoso, nativo de Bolivia y Chile: A-P a Antof.; precordillera, altiplano y piso altoandino, 3.300- $4.700 \mathrm{~m}$ s.n.m.

Exs.: A. Moreira, M. Muñoz \& V. Morales 1646, 26-V-2011. Camino Putre - Portezuelo Taapaca, 4.560 m s.n.m. (SGO).

Nota: Se ha estudiado la descripción y el tipo de $S$. tacorensis (plants.jstor.org) y también el ejemplar Tipo de S. olivaceobracteatus de CONC, concluyendo que corresponden a la misma especie.

Senecio trifurcifolius Hieron., Bot. Jahrb. Syst. 21(3): 358, 1895. Tipo: Peruvia: crescit in altiplanitie inter Tacora et Sajama alt. s. m. 4200-4300 m, ubi floret mense Decembri ([Stübel] coll. peruv. n. 105) (B, destruido). Cabrera (1985: 210) anota un clastotipo en MO.

Subarbusto pigmeo, nativo de los Andes del S de Perú, Bolivia? y N de Chile: A-P.; piso altoandino, 4.500-4.800 m s.n.m.

Exs.: E. Werdermann 1153, IV-1926. Cordillera Volcán Tacora, Cerro Quiñuta, 5.100 m s.n.m. (CONC).

Nota: Afín a $S$. puchii, pero los aquenios son pubescentes y las hojas solo trifurcadas.

Especie dudosa para Chile. Hasta ahora sólo se han observado dos ejemplares de esta especie en el herbario (CONC). Uno de ellos corresponde al ejemplar aquí citado, el que fue recolectado en territorio peruano del Volcán Tacora. La identificación del otro espécimen se mantiene como dudosa, ya que se encuentra en malas condiciones.

Senecio zapahuirensis Martic. \& Quezada, Bol. Soc. Biol. Concepción 51(1): 149, f. 1-10, 1978. Tipo: Chile, Prov. Arica, camino Poconchile a Zapahuira, quebrada Chilcane, 2900 msm (18 $22^{\circ}$ S; 69 37’ W), 8-V-1972, Ricardi, Weldt \& Quezada 306 (CONC).

Hierba perenne, erecta, glauca, endémica de Chile: A-P., Tarap., desierto y precordillera, 2.100-3.200 m s.n.m.

Exs.: A. Moreira, M. Muñoz \& V. Morales 1580, 24-V-2011. 
Cuesta Cardones, 2.185 m s.n.m. (SGO).

Senecio zoellneri Martic. \& Quezada, Bol. Soc. Biol. Concepción 48: 102, f. 8-16, 1974, nom. nov. para Culcitium albifolium Zoellner, Anales Mus. Hist. Nat. Valparaíso 3: 65, 1 fig., 1970, non Senecio albifolius DC. 1837. Tipo: Chile, Tarapacá, Depto. Arica, en portezuelo de Chapiquiña, 4500 msm., 21-I-1969, O. Zoellner s/n (probable en CONC).

Hierba perenne, nativa de Bolivia y Chile: A-P, altiplano y piso altoandino, 4.300-4.800 m s.n.m.

Exs.: A. Moreira, M. Muñoz \& V. Morales 1639, 26-V-2011. Antes de Portezuelo Taapaca, 4.505 m s.n.m. (SGO).

Werneria aretioides Wedd., Chloris Andina 1: 86, 1856. Tipo: Bolivie: sur les montagnes des lagunas de Potosi! (d'Orbigny, ${ }^{\circ}$ 1400) (P).

Subarbusto pigmeo, cespitoso o formando cojines apretados, nativo del Altiplano del S de Perú, Bolivia, NW de Argentina y N de Chile: A-P, Tarap., Antof.; altiplano, 4.000-4.800 m s.n.m.

Exs.: A. Moreira, M. Muñoz \& V. Morales 1610, 25-V-2011. Camino Putre-Chungará, 4.595 m s.n.m. (SGO).

Werneria denticulata S.F. Blake, Contr. U.S. Natl. Herb. 22(8): 651. 1924, nom. nov. para Werneria brachypappus Phil., Anales Univ. Chile 43: 501. 1873, non W. brachypappa Sch.Bip. 1856. Tipo: Chile, Antofagasta, Salitreras de Antofagasta, 1872, W. Doell s/n (SGO, LP).

Hierba perenne, pigmea, nativa de Argentina, Perú? y Chile: A-P a Antof., altiplano, 3.800-4.600 m s.n.m.

Exs.: A. Moreira 2496, 18-VI-2015. Termas de Churiguaya, 4.454 m s.n.m. (SGO).

Nota: Ariza Espinar (2007: 331), hace un comentario sobre esta especie e indica que el Tipo de Philippi no posee hojas denticuladas. Se ha vuelto a estudiar el tipo e isotipo de $W$. brachypappus en SGO y LP respectivamente (D. Gutiérrez com. pers.) y ambos poseen hojas con pequeños dientes en sus bordes, por lo tanto la de Blake es buena especie.

Werneria glaberrima Phil., Anales Museo Nacional; Secc.2, Bot. 8: 40, 1891; Verz. Antofagasta Pfl. 40. 1891. Tipo: Tarapacá: Linzor, Copacoya, Colana, II-1885, F. Philippi $\mathrm{s} / \mathrm{n}(\mathrm{SGO})$.

Hierba perenne, nativa de Bolivia y Chile: A-P a Antof., altiplano, 3.500-4.850 m s.n.m.

Exs.: E. Belmonte 86143, 06-VIII-1986. Salar de Surire, 4.300 m s.n.m. (CONC).

Werneria heteroloba Wedd., Chloris Andina 1:88, Plate
16 A, 1856. Tipos: Pérou: Cordillères du département de Cuzco! (Gay). - Bolivie: sur les pelouses marécageuses de la Lancha!, Cordillère de La Paz, avec le W. pygmaea (Wedd.); bord des eaux, dans les montagnes des lagunas de Potosi! (d'Orbigny, $\mathrm{n}^{\circ}$ 1415) (Lectotipo P; isolectotipos G, P).

Hierba perenne, pigmea, acaule, nativa del Altiplano de Perú, Bolivia, NW de la Argentina y N de Chile: A-P a Cqbo., en vegas y bofedales del altiplano, 3.900-4.800 m s.n.m.

Exs.: C. Marticorena et al. 250, 13-II-1964. Lago Chungará, 4.550 m s.n.m. (CONC).

Nota: muy similar a $W$. pinnatifida, ambas consideradas como válidas y presentes en Chile (Freire \& Ariza-Espinar 2014). Se diferencian por el número de brácteas involucrales que llega a 20-25 en $W$. pinnatifida (presente desde Antof. a Atac.). Los ejemplares encontrados hasta la fecha en A-P corresponden a $W$. heteroloba.

Werneria pygmaea Gillies ex Hook. \& Arn. var. pygmaea, J. Bot. (Hooker) 3: 348, 1841. Tipo: Argentina: Valle de los Ciegos, Andes of Mendoza; Dr. Gillies. (E). W. brachypappa Sch.Bip. Bonplandia (Hannover) 4:53, 1856 [Ariza Espinar 2007: 331, hace un comentario de este binomio].

Hierba perenne, pigmea, nativa de las vegas y bofedales altoandinos desde Venezuela hasta Argentina y Chile: A-P a reg. Metrop., 4.000-4.800 m s.n.m.

Exs.: A. Moreira, M. Muñoz \& V. Morales 1612, 25-V-2011. Orillas Lago Chungará, 4.574 m s.n.m. (SGO).

Werneria solivifolia Sch.Bip., Bonplandia 4(4): 53, 1856. Tipo: Peru, Cordillera de Puno, V-1854, Lechler W. 1710 (K).

Hierba acaule, perenne, nativa de la puna de Perú, Bolivia y Chile: A-P, altiplano, 4.000-4.500 m s.n.m.

Exs.: M. Ricardi, C. Marticorena \& O. Matthei 298, 29-III1961. Bofedal de Parinacota, 4.450 m s.n.m. (CONC).

Werneria spathulata Wedd., Chloris Andina 1: 85, f. 17A, 1856. Tipo: Bolivie: partie supérieure du ravin de Chuquiaguillo, dans les pelouses un peu tourbeuses de la Lancha!, Cordillère de La Paz, 1851 (Weddell s.n.) (P).

Hierba perenne, pigmea, nativa del Altiplano de Perú, Bolivia, NW de Argentina y N de Chile: A-P, Tarap., Antof.; altiplano, 4.000-4.600 m s.n.m.

Exs.: C. Marticorena et al. 223, 13-II-1964. Camino de Chucuyo a las Lagunas de Cotacotani, km 5, 4.400 m s.n.m. (CONC). 
Xenophyllum incisum (Phil.) V.A. Funk var. incisum, Novon 7: 239, 1997. Werneria incisa Phil., Anales Museo Nacional Chile, Secc. 2, Bot. 8: 41, 1891, Verz. Antofagasta Pfl. 41, 1891. Tipo: Chile. Antofagasta: entre Copacoya e Inacaliri, 19-II-1885, F. Philippi s.n., (SGO, GOET, K, US).

Subarbusto nativo del NW de Argentina, Bolivia y Chile: A-P, Tarap. y Antof.; altiplano; poco común en A-P.

Exs.: A. Moreira \& M. Diazgranados 2625, 26-V-2016, km 28 camino Umirpa a Tignamar, 3.895 m s.n.m. (SGO).

Xenophyllum lycopodioides (S.F. Blake) V.A. Funk, Novon 7: 240, 1997. Werneria lycopodioides S.F. Blake, J. Wash. Acad. Sci. 18: 493, 1928. Tipo: Chile. Prov. Tacna, Cordillera volcán Tacora, Cerro Quiñuta, 5000 m, IV-1926, E. Werdermann 1164 (GH).

Subarbusto nativo de Perú, Bolivia y Chile: A-P a Antof.; altiplano y piso altoandino, 4.100-5.200 m s.n.m. En Perú sólo registrado en Cerro Quiñuta, al norte del Volcán Tacora. Exs.: A. Moreira, M. Muñoz \& V. Morales 1640, 26-V-2011. Subida a portezuelo Taapaca, $4.505 \mathrm{~m}$ s.n.m. (SGO).

Nota: Xenophyllum ciliolatum (A. Gray) V.A. Funk, basada en Werneria ciliolata A. Gray, ha sido indicado como presente en Chile (Funk 1997), sin citar material. Luego Hind (2011) incluye a X. lycopodioides en la sinonimia de esa especie. Se han estudiado ambos Tipos y ambas especies parecen válidas, pero Werneria ciliolata A. Gray, Proc. Amer. Acad. Arts 5: 140 (1861), recolectada en Casa Cancha, Andes de Perú, no ha sido registrada para Chile. Ulloa et al. (2004) la indican para Perú, pero sólo mencionan el mismo ejemplar del tipo, Werdermann 1164, de Tacora.

Xenophyllum poposum (Phil.) V.A. Funk, Novon 7: 240, 1997. Werneria poposa Phil., Anales Mus. Nac. Chile, Secc. 2, Bot. 8: 40, 1891, Verz. Antofagasta Pfl. 40, 1891. Tipo: Chile. Antofagasta: Copacoya, 3500 m, 18-II-1885, F. Philippi s/n (LP, SGO).

Subarbusto que forma céspedes o cojines, nativo del Altiplano del S de Perú, Bolivia, NW de Argentina y N de Chile: A-P a Antof.; altiplano y piso altoandino, 4.000-5.000 m s.n.m.

Exs.: A. Moreira 2500, 19-VI-2015. Las Cuevas, cerro Milagro, 4750 m s.n.m. (SGO).

Xenophyllum pseudodigitatum (Rockh.) V.A. Funk, Novon 7: 240, 1997. Werneria pseudodigitata Rockh., Bot. Jahrb. 70: 288, 1939. Tipo: Argentina: Salta, La Caldera, alrededores del Nevado del Castillo, $24^{\circ} 35^{\prime} 25^{\prime \prime} \mathrm{S}$; 6526’16” W, III-1873, Lorentz 96 (CORD, K).

Subarbusto que forma cojines flojos, nativo de la puna argentina (Salta-Jujuy) y chilena (A-P, Tarap., Antof.); vegas del altiplano, 4.000-5.000 m s.n.m.

Exs.: A. Moreira 2495, 18-VI-2015. Quebrada Ancochallane, 4.505 m s.n.m. (SGO).

Xenophyllum weddellii (Phil.) V.A. Funk, Novon 7 (3): 240, 1997. Werneria weddellii Phil., Anales Mus. Nac. Chile, Secc.2, Bot. 8: 40, 1891, Verz. Antofagasta Pfl. 40, 1891. Tipo: Chile. Antofagasta: [Machuca, Huasco, Copacoya, Inacaliri] Laguna Huasco, III-1885, F. Philippi s/n (SGO).

Subarbusto, nativo de Bolivia (La Paz), Perú y Chile: A-P, Tarap: común en vegas, márgenes de bofedales y sitios húmedos del altiplano, 4.000-4.800 m s.n.m.

Exs.: A. Moreira, M. Muñoz \& V. Morales 1658, 26-V-2011, Termas de Jurasi, 4.070 m s.n.m. (SGO).

\section{Tribu Gnaphalieae}

Achyrocline ramosissima Britton, Bull. Torrey Bot. Club 19:148, 1892. Tipo: Perú [depto. Puno] cordillera prope Azangaro, VI- 1854, W. Lechler 1780 (K).

Subarbusto nativo de Perú, Bolivia, NW de Argentina y ahora encontrado en el $\mathrm{N}$ de Chile: A-P: precordillera, 2.200-4.000 m s.n.m.

Exs.: A. Moreira 2503, 20-VI-2015. Entrada a $10 \mathrm{~km}$ al W de Putre, ladera NW, 3.860 m s.n.m. (SGO).

Nota: Achyrocline tomentosa Rusby ha sido indicado para la Región de A-P por Marticorena \& Quezada (1977); se separa de $A$. ramosissima por tener tallos erectos, de hojas ovado-lanceoladas de 3-8(-11) cm de largo por 0,7-1,2 (-1,8) $\mathrm{cm}$ de ancho, también discolores y con el nervio medio bien marcado en la cara inferior (Freire en Zuloaga et al. 2014).

Achyrocline rupestris Cabrera, Darwiniana 9(1): 43, fig. 2, 1949. Tipo: Argentina. Salta: Dep. San Antonio de los Cobres, Quebrada de Polvorilla, entre rocas a $4.300 \mathrm{~m}$ s.m., 2-II-1944, A. L. Cabrera 8395 (BAB, K-fragmento, LP).

Subarbusto nativo del NW de Argentina y N de Chile: A-P: precordillera, 3.500-3.900 m s.n.m.

Exs.: A. Moreira 1968, 10-VI-2012. Quebrada Allane, 3.830 m s.n.m. (SGO).

Cuatrecasasiella argentina (Cabrera) H. Rob., Fl. Neotrop. Suppl. 2: 15, 1985.

Luciliopsis argentina Cabrera, Darwiniana 9(1): 41-42, fig. 1, 1949. Tipo: Argentina, Depto. Humahuaca, El Aguilar, vegas a 4300 m, 14-I-1948, A.L.Cabrera 9239 (planta masculina, Isotipo BAA). Tucumán: Dep. Tafí, Peñas Azules, Casa de Piedra, San José, 3150 m s. m., leg. XII-1931, R. Schreiter 6990 (planta femenina) (Lectotipo 
Schreiter 6990 LIL; isolectotipo LP).

Hierba perenne, pigmea, formando céspedes, nativa de las vegas altoandinas de Argentina (Jujuy a La Rioja), Bolivia y Chile: A-P; piso altoandino, 4.200-4.600 m s.n.m.

Exs.: M. Ricardi 3583, 17-IX-1955. Aguas Calientes, Tacora, 4.600 m s.n.m. (CONC).

Facelis plumosa (Wedd.) Sch. Bip., Linnaea 34: 532, 1866. Lucilia plumosa Wedd., Chloris Andina 1: 155 (1856). Tipo: Pérou: Cordillèrs, entre Puno et Arequipa!, h. 4000 mètres [Weddell s.n.] (P).

Hierba anual, nativa de Perú, Bolivia, NW Argentina y Chile: A-P; precordillera, 3.000-4.000 m s.n.m.

Exs.: A. Moreira 1973, 11-VI-2012. Sobre quebrada antes de llegar al pueblo de Chapiquiña, 3.360 m s.n.m. (SGO).

Gamochaeta americana (Mill.) Wedd., Chlor. Andina 1(46): 151, 1856.

Gnaphalium americanum Mill., Gard. Dict. (ed.8) n ${ }^{\circ}$ 17, 1768; Gnaphalium purpureum L. var. americanum (Mill.) Klatt, Linnaea 42 (1): 140, 1878. Tipo: Jamaica, 1731, W. Houston s/n (BM).

Hierba anual o perenne, de amplia distribución, desde América Central a Sudamérica; adventicia en Norteamérica y Europa. En Chile en A-P y desde Coqbo. a Mag.; desde nivel del mar hasta $3.500 \mathrm{~m}$ s.n.m.

Exs.: C. Marticorena et al. 52, 09-II-1964. Camino de Arica al Portezuelo de Chapiquiña, km 96, 3.450 m s.n.m. (CONC).

Gamochaeta chamissonis (DC.) Cabrera, Bol. Soc. Argent. Bot. 9: 368, 1961. Gnaphalium chamissonis DC., Prodr. 6: 233, 1838; Gnaphalium purpureum L. var. chamissonis (DC.) Klatt, Linnaea 42(2): 140, 1878. Tipo: Chile, IIIII-1816, L.C.A. von Chamisso (G-DC, HAL).

Hierba perenne, nativa de Argentina (Chubut a Tierra del Fuego) y Chile: A-P, Coqbo. a Aysén; quebradas y precordillera, 700-3.800 m s.n.m.

Exs.: A. Moreira 1957, 10-VI-2012. Quebrada Allane, 3.830 m s.n.m. (SGO).

Gamochaeta deserticola Cabrera, Revista Invest. Agríc. 11(4): 405, 1957. Tipo: Argentina, prov. Salta, Incahuasi, I-1940, Schulz 2656 (LP, CTES).

Hierba perenne, nativa de Argentina (Salta y Jujuy), Bolivia y Chile: A-P a la Araucanía, excepto Atac.; nivel del mar a $3.500 \mathrm{~m}$ s.n.m., precordillera.

Exs.: U. Levi 240, XII-1955. Putre, 3.500 m s.n.m. (LP).
Gamochaeta humilis Wedd., Chlor. And. 1:153, 1856. Tipo: Bolivia, Depto. La Paz, Chuquiaguillo, La Lancha, 4500 m, 1854, Weddell s/n (P).

Hierba perenne, formando céspedes plateados, nativa de Bolivia, Perú y norte de Chile (A-P y Antof.), altiplano; 3.500-4.600 m s.n.m. Por primera vez recolectada en Chile y la Región de A-P. La reciente revisión indica además su precencia en Antof. (Freire et al. 2016).

Exs. Moreira, Muñoz \& Morales 1621, 25-V-2012, camino de Caquena a Parinacota, 4.470 m s.n.m. (SGO).

Mniodes coarctata Cuatrec., Folia Biol. Andina 1: 4, 1954. Tipo: Perú, depto. Arequipa, 52 miles E-NE of Arequipa, 15.000 feet, 18-IV-1952, C.B.Koford 25 (UC).

Hierba cespitosa, de ramas apretadas, nativa de los Andes del S de Perú y N de Chile: A-P; piso altoandino, 4.500$5.000 \mathrm{~m}$ s.n.m.

Exs.: M. Ricardi 3375, 17-IX-1955. Aguas Calientes, Tacora, 4.600 m s.n.m. (SGO, como Mniodes andina).

Nota: Dillon \& Sagástegui (1991), indican esta especie para Chile. Ricardi \& Torres (1958) opinan que es M. andina A. Gray, pero luego en el Catálogo de Marticorena \& Quezada (1985) sólo indican M. coarctata.

Mniodes kunthiana (DC.) S.E. Freire, Chemisquy, Anderb. \& Urtubey, Pl. Syst. Evol. 301(4): 1246. 2015. Conyza kunthiana DC., Prodr. 5: 379. 1836, nov. nom. para Conyza pusilla Kunth 1820 non Houtt. 1782. Tipo: [Ecuador] Amerique Equatoriale, Humboldt \& Bonpland s/n (P).

Hierba perenne, acaule, formando cojines plateados, nativa de Bolivia, NW de Argentina y Chile: A-P, altiplano sobre $4.000 \mathrm{~m}$ s.n.m. Por primera vez recolectada e indicada para Chile.

Exs.: A. Moreira, M. Bonifacino, D. Gutiérrez, M. Monge 2031, 20-X-2012. Ruta A-127, km 11, pasado Estancia Yaypinta, sobre pequeña vega, 4.269 m s.n.m. (SGO).

Nota: Lucilia violacea Wedd., Chloris Andina 1: 155, 1856, anteriormente válida para Chile y reconocible por los pelos largos del aquenio, corresponde según Freire et al. (2014b), a Mniodes kunthiana.

Mniodes piptolepis (Wedd.) S.E. Freire, Chemisquy, Anderb. \& Urtubey, Pl. Syst. Evol. 301(4): 1246. 2015. Luciliocline piptolepis (Wedd.) M.O. Dillon \& Sagást., Arnaldoa 10(1): 53, 2003. Merope piptolepis Wedd., Chloris Andina 1: 162, 1856. Tipo: Perou austral prope Maravillas inter Puno et Arequipa, Weddell 4514 (Lectotipo P; isolectotipo LPfragmento). 
Hierba perenne, pigmea, nativa del Altiplano de Perú, Bolivia, NW Argentina y Chile: A-P; altiplano, 3.5004.500 m s.n.m.

Exs.: A.Moreira, M. Muñoz, V. Morales 1649, 26-V-2011, camino Portezuelo Taapaca a Putre, 4.250 m s.n.m. (SGO).

Mniodes schultzii (Wedd.) S.E. Freire, Chemisquy, Anderb. y Urtubey Pl. Syst. Evol. 301(4): 1246. 2015. Luciliocline schultzii (Wedd.) M.O. Dillon \& Sagást., Arnaldoa 10(1): 53, 2003. Merope schultzii Wedd., Chloris Andina 1: 163, 1856. Belloa schultzii (Wedd.) Cabrera, Revista Invest. Agric. 11(4): 404, 1958. Tipo: Perú, provincia de Carabaya, cordillera de Ayapata, Lechler 1984 (Lectotipo P; isolectotipos, G, GOET, LP, P).

Hierba perenne, pigmea, caespitosa, nativa de Perú, Bolivia, Argentina y Chile: A-P; altiplano, 3.900-4.600 m s.n.m.

Exs.: A. Moreira 1930, 9-VI-2012. Subida a Portezuelo Chapiquiña, 4.400 m s.n.m. (SGO).

Nota: El ejemplar de A. Moreira, M. Bonifacino, D. Gutiérrez, M. Monge n 2029 (SGO) se asemeja a Belloa argentea (Wedd.) Cabrera $=$ Merope argentea Wedd., taxón considerado por Freire et al. (2014b) como sinónimo de Mniodes schultzii.

Mniodes subspicata (Cabrera) S.E. Freire, Chemisquy, Anderb. \& Urtubey, Pl. Syst. Evol. 301(4): 1246. 2015. Luciliocline subspicata (Wedd.) Anderb. \& S.E. Freire, Bot. J. Linn. Soc. 106: 188, 1991. Belloa subspicata Wedd., Chloris Andina 1: 159, 1856. Tipo: Bolivia, Potosí, d'Orbigny 1373 (P).

Hierba perenne, pigmea, cespitosa, nativa del Altiplano de Perú, Bolivia, NW Argentina y Chile; precordillera, 3.0004.900 m s.n.m.

Exs.: A. Moreira 1904, 07-VI-2012. Camino a Tacora, Mirador Quebrada Allane, 3.849 m s.n.m. (SGO).

Pseudognaphalium cheiranthifolium (Lam.) Hilliard \& B.L. Burtt, Bot. J. Linn. Soc. 82(3): 205. 1981. Gnaphalium cheiranthifolium Lam., Encycl. [J. Lamarck \& al.] 2(2): 752. 1788. Tipo: [Uruguay]. 'Commerson à trouvé cette plante à Monte-Video' (P-Lam.?).

Hierba perenne de amplia distribución, nativa del Sur de Brasil, Bolivia, Uruguay, Argentina y Chile: A-P a Los Ríos, incl. Juan Fernández. En suelos rocosos y arenosos desde el nivel del mar hasta $3.600 \mathrm{~m}$ s.n.m.

Exs.: O. Matthei \& R. Rodríguez 299, 21-III-1987. Camino entre Putre y Socoroma, km 8, 3.600 m s.n.m. (CONC).

Pseudognaphalium cymatoides (Kunze ex DC.) Anderb.,
Opera Bot. 104: 147. 1991. Gnaphalium cymatoides Kunze ex DC., Prodr. 6: 225. 1838. Tipo: Chile. Andes, 4200 m, Dec., et ad Concon, E. F. Poeppig s.n., Diar. 379 (P).

Hierba anual o bienal, nativa de Bolivia, Argentina y Chile: A-P a Los Lagos; desde el nivel del mar hasta $4.300 \mathrm{~m}$ s.n.m.; precordillera y altiplano.

Exs.: O Matthei \& R. Rodríguez 269, 21-III-1987, Quebrada de Ipilla, 3.000 m s.n.m. (CONC).

Pseudognaphalium gayanum (J. Rémy) Anderb., Opera Bot. 104: 147. 1991. Gnaphalium gayanum J. Rémy, Hist. Chile, Bot. 4: 225. 1849. Tipo: Chile. Colchagua, Cordillera de San Fernando, Talcaregue, II-1831, C. Gay s/n (P).

Hierba perenne, endémica de Chile: A-P a Magallanes; desde el nivel del mar hasta 4.500 m s.n.m.; quebradas, precordillera y altiplano.

Exs.: M. Ricardi et al. 155, 05-V-1972. Camino Zapahuira a Putre, km 13, 3.300 m s.n.m. (CONC).

Pseudognaphalium lacteum (Meyen \& Walpers) Anderb., Opera Botanica 104: 147, 1991. Gnaphalium lacteum Meyen et Walpers, Nov. Actorum Acad. Caes. Leop.-Carol. Nat. Cur. 10, Suppl. 1: 276, 1843. Tipo: Perú, en planicie cerca de Tacora, 14-17000 pies [Meyen] (GH).

Hierba perenne, pigmea, nativa de la puna de Perú, Bolivia, NW de Argentina, N al C-S de Chile: A-P a Biobío; en A-P: precordillera y altiplano; 3.500-4.300 m s.n.m.

Exs.: A. Moreira 1889, 06-VI-2012. Subida a portezuelo de Chapiquiña, quebrada con queñoas, 3.730 m s.n.m. (SGO).

Nota: Especie característica por las brácteas de color blanco brillante. Descrita originalmente para Tacora (Perú-Chile). Los ejemplares de Coquimbo (Sur de Socos) y Concepción (San Pedro) citados en Freire et al. (2014a) son costeros y no pasan de los $300 \mathrm{~m}$ s.n.m. Se ha descrito para Bolivia, Gnaphalium badium Wedd., prov. de Carangas, muy parecido a Pseudognaphalium lacteum, pero de brácteas del involucro de color café y profusamente florido, del cual se encontró un ejemplar en Bofedal de Caquena, ladera al W, Moreira y Luebert 2439, 24/03/2015, pero Freire et al. (2014a) opinan que la variabilidad de la especie P. lacteum es tan grande que esta especie caería dentro de ella.

Pseudognaphalium munoziae N. Bayón, C. Monti \& S.E. Freire, Phytotaxa 105: 1-10, 2013. Tipo: Chile, Región Arica y Parinacota: Subida a Portezuelo de Chapiquiña, $18^{\circ} 20^{\prime} 1,7^{\prime \prime} \mathrm{S}, 69^{\circ} 31^{\prime} 1^{\prime \prime} \mathrm{W}, 4147 \mathrm{~m}, 5-\mathrm{V}-2011$, Moreira, Muñoz \& Morales 1676 (SGO).

Hierba perenne, endémica de Chile. La especie recientemente descrita (Freire et al. 2013), ha sido hallada en pocas 
localidades en las regiones de A-P y Tarap., precordillera, 3.500-4.200 m s.n.m.

Exs.: A. Moreira 1953, 10-VI-2012. Inicio de bajada a Quebrada Allane, 3.550 m s.n.m. (SGO).

Pseudognaphalium psilophyllum (Meyen \& Walp.) Anderb., Opera Bot. 104: 147. 1991. Gnaphalium psilophyllum Meyen \& Walp., Nov. Actorum Acad. Caes. Leop. Carol. Nat. Cur. 19 (Suppl. 1): 275. 1843. Tipo: Chile, 1834, Besser, s/n (Foto en F de B [destruido]). Neotipo: Chile. Región de Valparaíso. Prov. Marga Marga, Limache, 9-XI-1927, 900 m s.m., Garaventa 1151 (CONC).

Hierba perenne, nativa del sur de Perú, Bolivia, norte a sur de Argentina y Chile: A-P a Los Lagos; 900-4.000 m s.n.m., precordillera y altiplano.

Exs.: A. Moreira 1967, 10-VI-2012. Quebrada Allane en mitad de la ladera, 3.830 m s.n.m. (SGO).

Pseudognaphalium tarapacanum (Phil.) Anderb., Opera Bot. 10: 148 1991. Gnaphalium tarapacanum Phil. Anales Mus. Nac. Chile, Secc. 2, Bot. 8: 46, 1891, Verz. Antofagasta Pfl. 46, 1891. Tipo: Chile, Tarapacá, Paroma, 25-II-1885, F. Philippi s/n y Bolivia, Calcalhuay, I-1886, C. Rahmer (SGO).

Hierba perenne, nativa de la puna del NW de Argentina, Bolivia y N a C-S de Chile: A-P a Biobío; entre 300-800 m s.n.m. (centro-sur) y 2.600-4.200 m s.n.m. (norte); precordillera y altiplano.

Exs.: A. Moreira, M. Muñoz \&V. Morales 1659, 26-V-2011. $2 \mathrm{~km}$ al poniente cruce Termas Jurasi hacia Putre, $3.875 \mathrm{~m}$ s.n.m. (SGO).

\section{TRibu Astereae}

Baccharis acaulis (Wedd. ex R.E. Fr.) Cabrera, Bol. Soc. Argent. Bot. 16(3): 255, 1975. Heterothalamus acaulis Wedd. ex R.E. Fr., Nova Acta Regiae Soc. Sci. Upsal., ser. 4, 1: 79 (1905). Tipos: Bolivia, Prov. Larecaja, Viciniis Sorata prope Apacheta de Logena in graminosis. Reg. alpina 4000 m. Mandon 209, Aug. 1859 [Argentina:] Innerhalb des Gebietes sehr gemein.- Moreno in locis salsis subhumidis, 3500 m. s. m. (23 Oct. 1901; Fr[ies] 701) (Lectotipo S).

Hierba perenne, pigmea, acaule, nativa de la puna, en Bolivia, Argentina y Chile: A-P, Tarap., Antof.; en suelos húmedos y salinos; constituye un tapiz casi puro en el margen de arroyos y lagunas salobres. Altiplano, 4.0004.300 m s.n.m.

Exs.: A. Moreira, M. Bonifacino, D. Gutiérrez \& M. Monge 2023, 20-X-2012. Quebrada profunda antes de Colpitas, 4.086 m s.n.m. (SGO).
Baccharis alnifolia Meyen \& Walp., Nov. Actorum Acad. Caes. Leop.-Carol. Nat. Cur. 19, Suppl. 1: 264, 1843. Tipo: Peruvia: Arequipa. (No localizado).

Arbusto siempreverde, nativo de Perú y Chile: A-P, Tarap., Antof.; precordillera, 2.800-3.800 m s.n.m.

Exs.: A. Moreira 1980, 11-VI-2012. $200 \mathrm{~m}$ al sur de la Virgen de Tojotojone, 3.130 m s.n.m. (SGO).

Baccharis alpina Kunth, in Humb. Bonpl. \& Kunth, Nov. Gen. Sp. (ed. fol.). 4: 38. 1818. Tipo: [Ecuador:] Crescit in radicibus montis Pichinchæ et Antisanæ, alt. 1500 hex. (Regno Quitensi.) Floret Januario. [Bonpland 2281] (P-Bonpl.)

Arbusto enano, cespitoso, nativo de los Andes de Colombia y Ecuador, hasta punas de Perú, Bolivia, Argentina y Chile: A-P, Tarap.; precordillera y altiplano; 3.300-5.000 m s.n.m. Exs.: A. Moreira 1914, 07-VI-2012. Sobre Campamento abandonado de Azufrera Tacora, 4.550 m s.n.m. (SGO).

Nota: Según Müller (2006) B. alpina ha sido confundida con Baccharis caespitosa (Ruiz \& Pav.) Pers., también enano, cespitoso, pero se diferencian en que $B$. alpina tiene los bordes de las filarias de color purpúreo, con ápice cortamente dentado o fimbriado (versus verde-amarillento o café claro, ápice largamente dentado o fimbriado en $B$. caespitosa) las hojas son enteras (versus frecuentemente obtrulladas y dentadas en $B$. caespitosa), papus no más largo que el estilo en su madurez (versus más largo que el estilo en B. caespitosa).

Baccharis boliviensis (Wedd.) Cabrera, Bol. Soc. Argent. Bot. 16(3): 256. 1975. Heterothalamus boliviensis Wedd., Chloris Andina 1: 179, 1856. Tipos: Bolivie: punas du département de Oruro!, et environs de La Paz! (d'Orbigny, n. 1389 et 1545; Pentland). (Lectotipo- d'Orbigny 1389 P, isolectotipos $\mathrm{BR}, \mathrm{F}, \mathrm{G}, \mathrm{K}, \mathrm{P}$ ).

Arbusto erecto, ramoso, nativo del S de Perú y Bolivia hasta el NW de Argentina y N de Chile: A-P. Tarap., Antof., Coqbo., muy frecuente en precordillera, $3.100-4.000 \mathrm{~m}$ s.n.m.

Exs.: A. Moreira, M. Muñoz \& V. Morales 1638, 26-V-2011. Putre hacia el E, lado del camino, 3.750 m s.n.m. (SGO).

Baccharis genistelloides (Lam.) Pers., Syn. Pl. 2: 425, 1807. Conyza genistelloides Lam. Encycl. 2: 93 (1786). Tipo: Cette plant croît au Pérou; elle est commune dans la Province de Tacunga, où M. Joseph de Jussieu l'a observée. (P-LA).

Subarbusto nativo de Colombia, Ecuador, Perú, Bolivia y Chile: A-P; altiplano, al abrigo de rocas, 3.300-4.800 m s.n.m. 
Exs.: A. Moreira 1933, 09-VI-2012. Cerro Chapiquiña, cerro de las antenas, sobre el portezuelo, 4.770 m s.n.m. (SGO).

Baccharis juncea (Lehm.) Desf., Tabl. École Bot. (ed. 3): 163. 1829. Stephananthus junceus Lehm., Flora 10(6): 96. 1827. TIPO: Hort. Hamb. 26. 1826. (S).

Hierba perenne, nativa, frecuente en suelos húmedos algo salobres de América austral, en Perú, Bolivia, Uruguay, Argentina hasta la Patagonia y Chile (A-P hasta Aisén), quebradas, desde el nivel del mar hasta $3.500 \mathrm{~m}$ s.n.m.

Exs.: F. Sudzuki 626, 16-III-1948. Valle de Codpa, $2.000 \mathrm{~m}$ s.n.m. (SGO).

Baccharis salicifolia (Ruiz \& Pav.) Pers., Syn. Pl. 2: 425, 1807. Molina salicifolia Ruiz \& Pav., Syst. Veg. Fl. Peruv. Chil. : 210. 1798. Tipo: Habitat in Peruviae altis montibus, copiosè ad Pillao et Acomayo tractus. Floret à Majo ad Septembrem (MA).

Arbusto nativo, frecuente en lugares arenosos y húmedos desde el SW de EE.UU., México, Brasil, Paraguay, Bolivia, Perú, hasta Argentina y Chile: A-P a Los Lagos, 0-3.600 m s.n.m.; quebradas y precordillera.

Exs.: A. Moreira, M. Muñoz \& V. Morales 1669, 27-V-2011. Mirador de Socoroma, 3.450 m s.n.m. (SGO).

Nota: Especie muy variable en la forma de las hojas que van desde anchamente lanceoladas a casi lineales, desde aserradas a enteras. También varía la consistencia y el grado de viscosidad de las hojas y el tamaño de los capítulos, sin que sea posible separar variedades o formas bien delimitadas. Cuando crece en los arenales de los ríos de las quebradas secas, presenta hojas estrechas, casi enteras, muy viscosas. En cambio, en los bordes de los ríos de las zonas más bajas y húmedas, tiene hojas más anchas, más dentadas y menos viscosas.

Baccharis santelicis Phil. subsp. santelicis, Anales Mus. Nac. Santiago de Chile, Secc.2, Bot. 8: 39, 1891; Verz. Antofagasta Pfl. 39, 1891. Baccharis tola Phil. subsp. santelicis (Phil.) Joch. Müller, Syst. Bot. Monogr. 76: 96. 2006. Tipo: Chile, Antofagasta, Huasco, 2-III-1885, F. Philippi s/n (SGO).

Arbusto nativo del Altiplano de Bolivia, Perú, Argentina y Chile: A-P, Tarap., Antof., Atac.; común en precordillera y altiplano; $2.800-4.800 \mathrm{~m}$ s.n.m.

Exs.: A. Moreira, M. Muñoz \& V. Morales 1585, 24-V-2011. Camino Arica-Putre, cruce Copaquilla hacia Livilcar, 3.210 m s.n.m. (SGO).

Baccharis santelicis Phil. subsp. chrysophylla F.H. Hellwig, Mitt. Bot. Staatssamml. München 29: 318, 1990.
Baccharis tola Phil. var. chrysophylla (F.H.Hellwig) Joch. Müller. Baccharis tola Phil. subsp. santelicis (Phil.) Joch. Müller var. chrysophylla (F. H. Hellwig) Joch. Müller. Tipo: Tarapacá, Weg von Zapahuira zum Portezuelo de Chapiquiña, 4300 m, 15-IV-1986, F. Hellwig 7957 (SGO).

Arbusto bajo nativo del Altiplano del W de Bolivia (Oruro), y del N de Chile: A-P; altiplano, en pastizales o en bosques abiertos de queñoa, 4.100-4.800 m s.m.n. (Müller 2006); Hellwig (1990) sólo lo trata para Chile.

Exs.: A. Moreira, M. Muñoz \& V. Morales 1616, 25-V2011. Orillas Lago Chungará, sendero interpretativo, bajo queñoas y rocas, 4.574 m s.n.m. (SGO).

Nota: A pesar de las revisiones tanto de Hellwig (1990) como de Müller (2006), estas entidades son muy variables y no es fácil distinguir las subespecies; Müller agrega además B. tola var. incarum (Wedd.) Joch. Müller con características semejantes a ambas entidades y con una única localidad en Chile en Putre, provincia de Parinacota (Herb. BR). B. incarum (Wedd.) Heering corresponde a un sinónimo de B. santelicis (según Hellwig 1990); en cambio Müller (2006) lo trata como comb. illeg. bajo Baccharis tola Phil. var. incarum (Wedd.) Joch. Müller. Mientras no se trate este grupo de Baccharis en el conjunto de los países, nos quedaremos con los nombres propuestos por Hellwig, quien revisó el material de los herbarios chilenos.

Baccharis scandens (Ruiz \& Pav.) Pers., Syn. P1. 2: 424, 1807. Molina scandens Ruiz \& Pav., Syst. Veg. Fl. Peruv. Chil. 205, 1798. Tipo: Perú, Herb. Pavón (G).

Arbusto nativo de Perú y N de Chile: A-P, Tarap., Antof.; en quebradas del desierto, desde el nivel del mar hasta 3.500 m s.n.m.

Exs.: A. Moreira 1874, 05-VI-2012. Cruce Ruta Internacional a Tacna con la ruta a Putre, suelo salobre, 70 m s.n.m. (SGO).

Conyza bonariensis (L.) Cronquist, Bull. Torrey Bot. Club 70:632, 1943. Erigeron bonariensis L., Sp. Pl.: 863, 1753. Tipo: America austral (LINN).

Hierba anual, de distribución amplia en América del Sur; considerada como introducida en Chile y presente en todo el país incluso Juan Fernández e Isla de Pascua. Común en cultivos y a orillas de caminos. En A-P en quebradas cultivadas.

Exs.: M. Ricardi 3429, IX-1955. Quebrada Vítor, Chaca, 500 m s.n.m. (CONC).

Conyza deserticola Phil., Anales Mus. Nac. Santiago de Chile, Secc.2, Bot. 8: 38, 1891; Verz. Antofagasta Pfl. 38. 1891. Tipo: Chile, Antofagasta, Cerca de Socaire y Paroma, 
3.800 m, 2-I-1885, F. Philippi s/n (SGO, LP).

Hierba perenne, nativa del S de Perú y Bolivia, NW Argentina (Jujuy a Tucumán) y N de Chile: A-P, Tarap., Antof.; precordillera y altiplano, 3.500-4.700 m s.n.m.

Exs.: A. Moreira, M. Muñoz \& V. Morales 1608, 25-V-2011. Camino interior Putre-Chungará, salida al este, $4.050 \mathrm{~m}$ s.n.m. (SGO).

Diplostephium cinereum Cuatrec., Caldasia 2(8): 228, 1943. Tipo: Perú; entre Coracora y Andahuaylas, en el lago de Tenococha, 3.900-4.000 m. alt. Colect. 1909-1914, Weberbauer 5833 (F).

Arbusto nativo de los Andes occidentales desde el S de Perú, Bolivia hasta el $\mathrm{N}$ de Chile: A-P; en precordillera y altiplano, 3.600-4.600 m s.n.m.

Exs.: A. Moreira \& F. Luebert 2442, 19-III-2015. Quebrada entre Chapiquiña y cruce Pachama, en bosque de Polylepis rugulosa, 3.650 m s.n.m. (SGO).

Diplostephium meyenii Wedd., Chloris Andina 1: 201, 1857. Tipos: Pérou: département de Tacna, dans la Cordillère de Tacora! h. 4000-4500 mètr. (Meyen, Weddell). (Sintipos P).

Arbusto nativo de Perú (2.500-4.500 m s.n.m.) y Chile: A-P, Tarap., Antof., especie característica de precordillera, 3.200-4.000 m s.n.m.

Exs.: F. Luebert \& R. Gajardo s/n, 07-XII-1998. Quebrada Aroma, 3.650 m s.n.m. (EIF).

Erigeron rosulatus [como rosulatum] Wedd., Chloris Andina 1: 193, 1857. Tipo: Bolivie: au sommet de la Cordillère de La Paz! (d’Orbigny) [326](P).

Cojín compacto, nativo del Altiplano del Sur de Perú, Bolivia y N de Chile: A-P, altiplano, 4.000-5.000 m s.n.m. Exs.: C. Marticorena, O. Matthei \& M. Quezada 214, 26-III1961. Portezuelo de Chapiquiña, campamento del Lauca, 4.400 m s.n.m. (CONC).

Grindelia glutinosa (Cav.) Mart., Pl. Hort. Erlang. 182, 1814. Aster glutinosus Cav., Ic. 2: 53, t. 168, 1793. Tipo: Plantas cultivadas en el Jardín Botánico de Madrid, de semillas procedentes de México. Bentham \& Hooker, Gen. Pl. 2: 250, 1873, estiman que el lugar de procedencia es: sur del Perú (no localizado).

Subarbusto nativo del Sur de Perú (0-3.500 m s.n.m.) y extremo $\mathrm{N}$ de Chile: Región A-P; muy común en quebradas de Lluta y Azapa, nivel del mar a 500 m s.n.m.

Exs.: A. Moreira, M. Muñoz \& V. Morales 1563, 24-V-2011.
Camino Arica-Putre, primeros kms, orillas camino, $110 \mathrm{~m}$ s.n.m. (SGO).

Grindelia tarapacana Phil., Anales Mus. Nac. Santiago de Chile, Secc.2, Bot. 8: 38, 1891; Verz. Antofagasta Pfl. 38, 1891. Tipo: Chile, Tarapacá, cerca de Usmagama, 15-III1885, C. Rahmer s/n (SGO).

Arbusto nativo del Sur de Perú (2.500-4.000 m s.n.m.) y N de Chile: A-P, Tarap.; precordillera, 2.900-3.500 m s.n.m. Exs.: A. Moreira 1981, 11-VI-2012. Salida sur de Tignamar, 3.200 m s.n.m. (SGO).

Laennecia artemisioides (Meyen \& Walp.) G.L.Nesom, Phytologia 68(3): 215, 1990 (sub artemisiifolia). Conyza artemisioides Meyen \& Walp., Nov. Actorum Acad. Caes.Leop. Nat. Cur. 19, Suppl.1: 262. 1843. Tipo: Peruvia: in planitie circa Tacoram, alt. 14-17,000 ped. (v.s.). (B destruido).

Hierba anual, nativa de la puna de Perú, Bolivia, NW de Argentina y N de Chile: A-P; precordillera, 3.500-4.200 m s.n.m.

Exs.: A. Moreira \& F. Luebert 2444, 19-III-2015. Quebrada entre Chapiquiña y cruce Pachama, en bosque de Polylepis rugulosa, 3.650 m s.n.m. (SGO).

Nota: Especie polimorfa, variable en tamaño, largo y división de las hojas y densidad de la inflorescencia, dependiendo del hábitat. En lugares áridos son bajos, de hojas menores, pocos capítulos y muy vellosas, en cambio en suelos fértiles como chacras, son más altas, de hojas mayores y más divididas, de muchos capítulos y menos vellosas (Cabrera 1978).

Parastrephia lepidophylla (Wedd.) Cabrera, Notas Mus. La Plata, Bot. 17(83): 57, 1954. Dolichogyne lepidophylla Wedd., Chloris Andina 1: 182, tab. 30 A, 1856. Tipos: Pérou: département de Tacna, sur le plateau de la Cordillère de Tacora!, h. 4000 à 5000 mètres, ou il constitue, avec $l^{\prime}$ 'espèce suivante $[P$. teretiuscula $]$ et une ou deux autres Composées, le fond de la végétation (Pentland, Weddell); département Arequipa (Meyen). - Bolivie: Cordillères du département de La Paz! (Pentland, Weddell); punas entre Oruro et Potosi! (d'Orbigny) (Sintipos P).

Arbusto resinoso, nativo y característico de la Puna de Perú, Bolivia, NW de Argentina (Jujuy a San Juan) y N de Chile: A-P, Tarap., Antof.; precordillera y altiplano, 3.400-4.800 m s.n.m.

Exs.: A. Moreira, M. Muñoz \& V. Morales 1607, 25-V-2011. Camino interior Putre-Chungará, 4.050 m s.n.m. (SGO).

Nota: Especie considerada por Nesom (1993) como sinónimo de $P$. quadrangularis, sin embargo, presenta 
ramitas notoriamente más delgadas (Cabrera 1945), y el hábitat es generalmente más húmedo, como bordes de vegas $\mathrm{y}$ cursos de agua.

Parastrephia lucida (Meyen) Cabrera, Notas Mus. La Plata, Bot. 17(83): 57, 1954. Baccharis lucida Meyen, Reise um die Erde 1: 460, 1834. Tipo: Peruvia: in planitie circa Tacoram, alt. 14-17,000 ped., (B destruido; Foto F, GH, US).

Arbusto nativo y característico de la provincia fitogeográfica de la puna del S de Perú y Bolivia, NW de Argentina y N de Chile: A-P, Tarap., Antof.; precordillera, altiplano y piso altoandino; especie característica del "tolar", 3.600-4.900 m s.n.m.

Exs.: A. Moreira, M. Muñoz \& V. Morales 1643, 26-V-2011. Portezuelo volcán Taapaca, 4.810 m s.n.m. (SGO).

Parastrephia quadrangularis (Meyen) Cabrera, Notas Mus. La Plata, Bot. 17(83): 57, 1954. Baccharis quadrangularis Meyen, Reise um die Erde 1: 460. 1834. Tipo: [Perú] Tacora (B destruido; Fotos F, US).

Arbusto nativo del altiplano del S de Perú, Bolivia, NW de Argentina y N de Chile: A-P, Tarap., Antof.; precordillera, altiplano ("tolar") y piso altoandino; 3.600-4.900 m s.n.m. Exs.: A. Moreira, M. Muñoz \&V. Morales 1644, 26-V-2011. Portezuelo volcán Taapaca, 4.810 m s.n.m. (SGO).

Parastrephia teretiuscula (Kuntze) Cabrera, Notas Mus. La Plata, Bot. 17(83): 57, 1954. Lepidophyllum teretiusculum Kuntze, Revis. Gen. Pl. 3(3): 162, 1898. Tipo: Chile: Conchi, Ascotán 3.000-3.900 m, 7-III-1892, Kuntze s/n [según Wetter \& Zanoni 1985: 334] (NY).

Arbusto del altiplano de Bolivia y Chile: A-P, Antof., precordillera, 3.300-4.000 m s.n.m. Indicado antes por Nesom (1993) para Tarap. y Antof.

Exs.: A. Huanca Mamani s/n, 30-VII-2015. Cruce de Ticnamar a Timalchaca, límite provincia de Parinacota, 3.530 m s.n.m. (SGO).

Symphyotrichum squamatum (Spreng.) G.L. Nesom, Phytologia 77(3): 292, 1994 (1995). Conyza squamata Spreng., Syst. Veg., ed. 16, 3: 515, 1826. Tipo: Uruguay, Monte Video. Sellow s.n., Herb. Sprengel 1064 (P).

Hierba perenne nativa, ampliamente distribuida en América del Sur, muy variable en altura, ramificación y densidad de la inflorescencia, dependiendo de las condiciones del medio. En Chile: A-P a Chiloé, nivel del mar a $1.500 \mathrm{~m}$ s.n.m. Adventicia en varios países de Europa y en otras regiones del mundo.

Exs.: O. Matthei \& R. Rodríguez 384, 22-III-1987. Valle de Azapa, 690 m s.n.m. (CONC).

\section{TRIBU ANTHEMIDEAE}

Cotula mexicana (DC.) Cabrera, Bol. Soc. Argent. Bot. 8: 207, 1960. Soliva mexicana DC., Prodr. 6: 143. 1837. Tipo: México, Sessé \& Mociño exped. (Torner collection n ${ }^{\circ} 1473$, DC. lám. 589) (Iconotipo).

Hierba anual, pigmea, nativa de vegas y arroyos de las altas montañas desde México hasta el centro de Argentina y $\mathrm{N}$ de Chile: A-P, Tarap., Antof., Cqbo.; altiplano, 4.000-4.400 m s.n.m.

Exs.: C. Marticorena, O. Matthei \& M. Quezada 219, 03II-1964. Camino Chucuyo - Lagunas de Cotacotani, km 5, 4.400 m s.n.m. (CONC).

\section{TRIBU InUleae}

Pluchea chingoyo (Kunth) DC., Prodr. 5: 452, 1836. Conyza chingoyo Kunth, Nov. Gen. Sp. 4: 76,1820. Tipo: Perú, Santa, Bonpland 3758 (P).

Arbusto nativo de Perú y Chile: A-P, muy común en el desierto, en la desembocadura y el interior de quebradas de Lluta, Azapa, Vítor y Camarones; nivel de mar hasta los 1.000 m s.n.m.

Exs.: F. Sudzuki 265, 12-II-1948. Quebrada de Vítor, $100 \mathrm{~m}$ s.n.m. (SGO).

Tessaria absinthioides (Hook. \& Arn.) DC., Prodr. 5: 457, 1836. Baccharis absinthioides Hook. \& Arn., Bot. Beechey Voy. : 57,1832. Tipo: Chile, Conception, Valparaíso, Bridges $55(\mathrm{GL})$.

Arbusto nativo, frecuente en suelos arenosos húmedos de Brasil, Paraguay, Bolivia, Uruguay, Argentina y Chile: A-P al Maule; en A-P muy común en la desembocadura y el interior de quebradas de Lluta, Azapa, Vítor y Camarones; nivel del mar hasta $3.000 \mathrm{~m}$ s.n.m.

Exs.: A. Moreira, M. Muñoz \& V. Morales 1562, 24-V2011, ruta Arica-Putre, primeros kms, orillas camino, 112 m s.n.m. (SGO).

\section{Tribu Coreopsideae}

Bidens pilosa L. var. minor (Blume) Sherff, Bot. Gaz. 80(4): 387, Pl.CII, figs. c,d y k-r, 1925. Tipo: Prope Buitenzorg, Java, Blume. Probablemente en Royal Herbarium Leyden.

Hierba anual introducida. Habita a orillas de caminos y en terrenos antropizados. En Chile en Cqbo., Metrop., desde el nivel del mar hasta 1.000 m s.n.m. En A-P en quebradas cultivadas.

Exs.: A. Moreira 2511, 21-VI-2015. Las Maitas, Azapa, 215 m s.n.m. (SGO). 
Bidens triplinervia Kunth var. macrantha (Wedd.) Sherff, Bot. Gaz. 80(4): 383, 1925. Bidens humilis Kunth [var.] macrantha Wedd., Chloris Andina 1: 69,1856. Bidens andicola Kunth var. decomposita Kuntze, Revis. Gen. Pl. 3(2): 136, 1898 (Pl. CXXIII, figs. f y g). Tipo: Ecuador. Andium Quitensium, crescit in rupestris montes Pichincha, 13000', W. Jameson 55 (P, E, F).

Hierba perenne, nativa de los Andes de Colombia, Ecuador, Perú, Bolivia, Argentina y N de Chile: A-P, Tarap., Antof.; precordillera y zonas cultivadas, $3.000-4.000 \mathrm{~m}$ s.n.m. Exs.: M. Ricardi \& C. Marticorena 4764, 25-IX-1958. Km 94 camino de Azapa a Chapiquiña, Episcacha, $3.500 \mathrm{~m}$ s.n.m. (CONC).

Nota: Especie muy variable en tamaño y divisiones de las hojas, por lo que tiene un gran número de sinónimos. Seguimos el criterio de Kiesling (2013), que considera $B$. andicola var. decomposita Kuntze, Revis. Gen. Pl. 3(2): 136, 1898 (Pl. CXXIII, figs. f y g), como sinónimo de $B$. triplinervia var. macrantha. Ambos nombres han sido utilizados para las plantas de Arica y Parinacota.

Coreopsis fasciculata Wedd., Chloris Andina 1: 71,1856. Tipo: Pérou! Cordillères du département de Cuzco? (Gay), (P). Coreopsis suaveolens Sherff, Bot. Gaz. 89: 369, 1930 (sinonimia según Hind 2011).

Subarbusto nativo de Ecuador, Bolivia, Perú y Chile: A-P, Tarap.; precordillera, 2.800-4.200 m s.n.m.

Exs.: A. Moreira, M. Muñoz \& V. Morales 1597, 24-V-2011. Cuesta antes de Putre, 3.400 m s.n.m. (SGO).

Heterosperma nanum (Nutt.) Sherff, Bot. Gaz. 91: 312, 1931. Microdonta nana Nutt., Trans. Amer. Phil. Soc., ser. 2, 7: 370,1841. Tipo: Peru: near Arequipa (Mr. Curson). (Posiblemente en BM o PH).

Hierba anual, pigmea, nativa de la puna desde el S de Perú y Bolivia, hasta el NW de Argentina y N de Chile: A-P, Tarap. Antof.; quebradas, 2.500-3.500 m s.n.m.

Exs.: M. Ricardi, C. Marticorena \& O. Matthei 118, III1961. Camino de Arica al Portezuelo de Chapiquiña, 3.150 m s.n.m. (CONC).

Heterosperma ovatifolium [ovatifolia] Cav., Descr. Pl.: 204,1802. Tipo: Perú, se cría junto a la Madalena, L. Née. (MA).

Hierba anual, multicaule, nativa de Ecuador, Perú, Bolivia, Argentina y N de Chile: A-P, Tarap.; quebradas; 500-4.000 m s.n.m.

Exs.: R. Pöhlmann s.n, 03-XII-1897. Pintatane, Vítor, 1.180 m s.n.m. (SGO).

\section{Tribu Tageteae}

Tagetes minuta L., Sp. Pl. 2: 887, 1753.

Tipo: Habitat in Chili. Tagetes multiflora, minuto flore albicante' in Dillenius, Hort. Eltham. 2: 374, t. 280, f. 362, 1732. (Iconotipo).

Hierba anual nativa americana, de Bolivia, Perú, Paraguay, Uruguay, Argentina y Chile: A-P a Biobío; 0-2.500 m s.n.m., sitios de cultivos. Maleza en África y Australia.

Exs.: O. Matthei \& R. Rodríguez 364, 22-III-1987. Valle de Azapa, Pampa Algodonal, 840 m s.n.m. (CONC).

Tagetes multiflora Kunth, in Humb. Bonpl. \& Kunth, Nov. Gen. Sp. (ed. fol.) 4: 154, 1818. Tipo: Ecuador, Crescit prope Quito in radicibus montis Pichinchæ, alt. 1500 hex., Bonpland \& Humboldt (P).

Hierba anual, nativa de los Andes de Colombia, Ecuador, Brasil, Perú, Bolivia, NW Argentina y N de Chile: A-P, Tarap., Antof.; precordillera, 3.100-3.900 m s.n.m.

Exs.: M. Muñoz 4043, 28-XII-1999. Entrada a Socoroma, 3.160 m s.n.m. (SGO).

\section{Tribu BahieAe}

Schkuhria multiflora Hook. \& Arn., J. Bot. (Hooker) 3: 332, 1841. Tipo: Argentina. Mendoza. Chilicilo, J. Gillies 147 (K, E).

Hierba anual nativa, desde el S de EE.UU. y México a Perú, Bolivia, NW Argentina y Chile: A-P a Coqbo., precordillera, 3.000-4.000 m s.n.m.

Exs.: A. Moreira \& F. Luebert 2455, 19-III-2015. 1 km antes de virgen de Tojotojone, $3130 \mathrm{~m}$ s.n.m. (SGO).

Schkuhria pinnata (Lam.) Kuntze ex Thell., Repert. Spec. Nov. Regni Veg. 11: 308.1912. Pectis pinnata Lam., J. Hist. Nat. 2: 150, pl. 31 (1792). Tipo: Chile: (no localizado).

Hierba anual, nativa de América, el sur de EE.UU. y México hasta Argentina, Paraguay, Uruguay, Bolivia y Chile: A-P a Coqbo., quebradas del desierto, 200-3.000 m s.n.m. Introducida en Europa y otras regiones del planeta. Exs.: O. Matthei \& R. Rodríguez 352, 22-III-1987. Valle de Azapa, Pampa Algodonal, 840 m s.n.m. (CONC).

\section{Tribu HelenieAe}

Flaveria bidentis (L.) Kuntze, Revis. Gen. Pl. 3(3): 148. 1898. Ethulia bidentis L., Syst. Nat. (ed. 12) 2: 536, 1767. Tipo: Probablemente América (LINN).

Hierba anual nativa americana, desde el sur de Estados 
Unidos hasta el centro de Argentina y Chile (Gutiérrez \& Moreira-Muñoz 2015). Frecuente en campos de cultivo, entre 0 y 3.000 m s.n.m. En A-P en quebradas al borde de cultivos. Exs.: H. Niemeyer s/n, XI-1982. Taltape, valle de Camarones, 990 m s.n.m. (SGO).

\section{Tribu Heliantheae}

Ambrosia arborescens Mill., Gard. Dict., ed. 8, Ambrosia n5, 1768. Tipo: "Native to Peru, from whence the younger Jussieu sent the seeds to the royal garden at Paris ... I was favored with this plant ... succeeded in the Chelsea garden" (Tipo BM?).

Arbusto nativo del sur de Perú. Considerado introducido en Arica y Parinacota, posiblemente debido a sus propiedades medicinales; alrededores de Socoroma (González et al. 2016).

Exs.: J. González, J. Molina \& L. Lazaro s/n, 16-V-2015, Socoroma, 3.058 m s.n.m. (CONC).

Ambrosia artemisioides Meyen \& Walp. ex Meyen, Nov. Actorum Acad. Caes. Leop.-Carol. Nat. Cur. 19, Suppl. 1: 268, 1843. Tipo: In glareosis prope Tacna, V-1854, Lechler 1568 (Isoneotipos GH y BR).

Arbusto nativo de Perú, Bolivia y Chile: A-P, Tarap., Antof.; transición del desierto a precordillera, 2.000-3.800 m s.n.m. Exs.: A. Moreira, M. Muñoz \& V. Morales 1575, 24-V-2011. Camino Arica-Putre, km 66, 2.000 m s.n.m. (SGO).

Ambrosia peruviana Willd., Sp. Pl. 4: 377, 1805. Tipo: Perú (F).

Hierba perenne descrita para Perú, hoy presente en América central hasta el norte de Chile: A-P, en cultivos y a orillas de caminos en el valle de Azapa.

Exs.: O. Zoellner 4970, I-1971. Arica: Valle de Azapa, 50 m s.n.m. (CONC).

Galinsoga parviflora Cav., Icon. Plant. 3:41, tab. 281, 1794. Tipo: Ejemplar cultivado en Madrid a partir de semillas traídas de Perú por Dombey. Ex Peruvia et Regno Chilensi (MA).

Hierba anual, originaria de Perú, frecuente como planta ruderal en toda América cálida y en muchos países de Europa. En Chile en quebradas y bordes de cultivos, desde A-P, I-X y en JF e IP.

Exs.: B. Knapton s/n, VII-2004. Parinacota: Socoroma, 3.000 m s.n.m. (CONC).

Spilanthes leiocarpa DC., Prodr. 5: 626, 1836. Tipo: Perú, ad sinum Chorillo, Macrae, 1825 (K).

Hierba perenne nativa de América del Sur, en zonas costeras arenosas y cerca de los cursos de agua. Común en humedales de Perú (0-1.500 m s.n.m.) y en Chile: A-P, valle de Azapa. Reportada como nativa (Zuloaga et al. 2008) y como introducida para Chile (Ugarte et al. 2011).

Exs.: A. Ramírez s/n, 10-II-1958. Valle de Azapa (SGO).

Viguiera pazensis Rusby, Mem. Torrey Bot. Club 3(3): 59, 1893. Tipos: [Bolivia:] Vic. La Paz, 10,000 ft., 1889 [Bang] (44). = Rusby 1683, 1684 and 2714 [Isosintipos (Bang 44): BM, E, GH, K, M, MSC, NY, PH, US, Z]. Aldama helianthoides (Rich.) E.E.Schill. \& Panero (Sinonimia según Zuloaga et al. 2008).

Arbusto nativo de Ecuador, S de Perú, Bolivia, NW de Argentina y N de Chile: A-P., Tarap. Común en precordillera, 1.900-3.500 m s.n.m.; frecuente en alrededores de Belén y Tignamar.

Exs.: A. Moreira \& F. Luebert 2451, 19-III-2015. Ruta Belén - Saxamar, $1 \mathrm{~km}$ antes de virgen de Tojotojone, 3.130 m s.n.m. (SGO).

Nota: Estudios moleculares recientes sugieren que las especies sudamericanas del género Viguiera Kunth deben ser transferidas a Aldama La Llave (Schilling \& Panero 2011). Hasta que no se estudien las especies chilenas, que no se encuentran bien delimitadas, seguiremos utilizando la nomenclatura tradicional.

\section{Viguiera sp.}

Arbusto de hojas lanceoladas, generalmente dobladas en su nervio medio, con pelos recostados y flores amarillas. Desierto y precordillera; frecuente en Quebrada de Cardones, 2.000-2.800 m s.n.m.

Exs.: A. Moreira 2479, 17-VI-2015. Quebrada de Cardones, sector guardería CONAF, 2.140 m s.n.m. (SGO).

Nota: No fue posible identificar esta especie, con su indumento piloso suave en hojas (generalmente dobladas en su nervio medio) y tallos. Se parece a $V$. adenotricha S.F.Blake descrita para la Región de Coquimbo, pero presenta menor pilosidad [Ver también comentario en $V$. pazensis].

\section{Tribu Perityleae}

Perityle emoryi Torr., Not. Milit. Reconn. 142, 1848. Tipo: EE.UU., California, Mountains east of San Diego, 29-XI1846, W.H.Emory s/n (NY).

Hierba anual o bienal, nativa de América. Especie muy 
variable en la forma de las hojas por lo que tiene muchos sinónimos. En América del Norte como maleza de los desiertos del SW de EE.UU., México (Baja California), también en Ecuador (Islas Galápagos), Perú y Chile: Tarap., Antof., Atac., Coqbo; nivel del mar hasta 2.000 m s.n.m. En A-P, quebradas del desierto.

Exs.: A. Moreira, M. Muñoz \& V. Morales 1571, 24-V-2011. Camino Arica-Putre, km 66, 2.000 m s.n.m. (SGO).

Villanova robusta Phil., Anales Mus. Nac. Santiago de Chile, Secc. 2, Bot. 8: 47, 1891; Verz. Antofagasta Pfl. 47, 1891. Tipo: Chile: Tarapacá, Jaiña, 17-III-1885, C. Rahmer, (SGO).

Hierba perenne, endémica de Chile: A-P, Tarap.; precordillera, 3.200-3.800 m s.n.m.

Exs.: A. Moreira \& F. Luebert 2462, 19-III-2015. Ruta Belén - Saxamar, cuesta Tojotojone, 3.120 m s.n.m. (SGO).

\section{Tribu EupatorieAe}

Helogyne apaloidea Nutt., Trans. Amer. Philos. Soc. 7: 449, 1841. Tipo: Peru. Depto. Arequipa: towards Arequipa, [1834-1835], Curson [s.n.] (BM).

Arbusto del S de Perú y N de Chile: A-P, Tarap., Antof.; desierto, 2.000-3.000 m s.n.m.

Exs.: A. Moreira, M. Muñoz \& V. Morales 1577, 24-V-2011. Cuesta Cardones, 2.185 m s.n.m. (SGO).

Ophryosporus heptanthus (Sch.Bip. ex Wedd.) R.M. King \& H. Rob., Phytologia 58(4): 258, 1985. Eupatorium heptanthum Sch.Bip. ex Wedd., Chloris Andina 1: 217, 1857, non Sch.Bip. ex Rusby (1907). Tipo: Hab. Perou: sur les montagnes, aux environs de la ville d'Azangaro! (Lechler 1751); Cordilleres de Tacora! (Wedd.) (P, GOET).

Arbusto nativo de Bolivia, Perú y Chile: A-P, precordillera, bordes de cultivos, 3.000-3.500 m s.n.m.

Exs.: A. Moreira, M. Muñoz \& V. Morales 1695, 27-V-2011. $2 \mathrm{~km}$ al norte de Belén, 3.240 m s.n.m. (SGO).

Nota: Hasta ahora mencionada como $O$. origanoides (Meyen \& Walp.) Hieron. para Chile (Plos 2012, Plos \& Sancho 2013).

Ophryosporus pinifolius (Phil.) R.M. King \& H. Rob., Phytologia 25(2): 66, 1972. Stevia pinifolia Phil., Anales Mus. Nac. Santiago de Chile, Secc. 2, Bot. 8: 37, 1891; Verz. Antofagasta Pfl. 37, 1891. Tipo: Tarapacá, Usmagama, 15III-1885, C. Rahmer s/n (SGO). Piqueria pinifolia (Phil.) Hieron. ex B.L. Rob., Proc. Amer. Acad. Arts. 42:11, 1906.

Arbusto nativo de Perú (Tacna) y Chile: A-P., Tarap., común en precordillera, 2.700-3.700 m s.n.m.
Exs.: A. Moreira, M. Muñoz \& V. Morales 1671, 27-V-2011. Mirador de Socoroma, 3.450 m s.n.m. (SGO).

Stevia philippiana Hieron., Bot. Jahrb. Syst. 40(4): 364, 1908. Stevia menthaefolia Philippi, Flor. Atac. 29, $\mathrm{n}^{\circ}$ 185,1860; nom. illeg., non Sch. Bip. 1852. Tipo: Antofagasta, Cachinal de la Costa, R. A. Philippi s/n (SGO; isotipo, B destruido [foto en F 14775 y en GH 00012857]).

Hierba perenne, endémica de Chile: A-P; precordillera, 3.000-3.800 m s.n.m.

Exs.: A. Moreira, M. Muñoz, V. Morales 1674, 27-V-2011. Pasado puente Murmuntani, 3.574 m s.n.m. (SGO).

Nota: Esta especie hasta ahora se ha asociado a Stevia chamaedrys Griseb., descrita para Argentina, pero no corresponde a esta especie porque en ella el papus consiste en algunas escamitas cortas y $0-9$ aristas de corta y variable longitud, y nuestra planta tiene a veces un aquenio con papus formado por solo escamitas cortas o con algunas aristas y 4 aquenios con ca. de 10-15 (-16) aristas iguales y casi tan largas como la corola (Gutiérrez et al. 2016).

\section{AGRADECIMIENTOS}

A Barbara Knapton por la gran ayuda prestada en terreno, compartiendo su conocimiento de sitios y material fotográfico. Al personal de CONAF que ha realizado un permanente apoyo logístico en terreno, especialmente Andrés Huanca Mamani y Arturo Gómez. Sergio Moreira ha estado a cargo de la labor de montaje de los ejemplares. Con Michael Dillon (Field Museum) hemos mantenido una larga amistad, buenas discusiones y permanente colaboración en la determinación de especies. Diego Gutiérrez, Mariana Grossi, Marcelo Monge, Elizabeth Melgarejo, Berni Britto, Mauricio Diazgranados, Federico Luebert y Mauricio Bonifacino nos han acompañado en terreno y han compartido generosamente fotografías e información de distribución de las especies de la región andino-altiplánica. A Nicholas Hind (Kew Gardens) y Liliana Katinas (La Plata), por su apoyo permanente en las consultas de Asteráceas. También a Estrella Urtubey y Susana Freire por su apoyo en la identificación de especies de Hypochaeris y Gnaphalieae. A Fernando Zuloaga por su constante apoyo en bibliografía e imágenes de ejemplares de Darwinion (SI). Luis Faúndez, Rodrigo Flores y Aira Faúndez de la Universidad de Chile han facilitado materiales de herbario. Juan Correa, Francisco Casado, Eliana Belmonte, Jimena Saavedra y Taryn Fuentes han apoyado la labor de terreno. Juan González y Jorge Molina han aportado información de último minuto. Los editores de la revista y dos revisores anónimos han ayudado a mejorar notablemente el trabajo. Proyectos Fondecyt 11085016, 1120448 y 1150425. 


\section{REFERENCIAS}

Ardiles, V. \& M. Fariña. 2014. Flora no vascular de la región de Arica y Parinacota, Chile: nuevos registros y consideraciones biogeográficas. Boletín del Museo Nacional de Historia Natural (Chile) 63: 213-223.

Ariza Espinar, L. 2007. Notas taxonómicas en Senecioneae (Asteraceae) de Argentina. Boletín de la Sociedad Argentina de Botánica 42(3-4): 329-332.

Arroyo, M.T.K., C. Villagrán, C. Marticorena \& J.J. Armesto. 1982. Flora y relaciones biogeográficas en un transecto altitudinal en los Andes del Norte de Chile (18 $\left.-19^{\circ} \mathrm{S}\right)$. En: A. Veloso \& E. Bustos (eds.), El ambiente natural y las poblaciones humanas de los Andes del Norte Grande de Chile (Arica, lat. 18²8'S), Vol. 1, pp. 71-92. Rostlac, Montevideo, Uruguay.

Barreda, V.D., L. Palazzesi, M.C. Tellería, E.B. Olivero, J.I. RAINEE \& F. Forest. 2015. Early evolution of the angiosperm clade Asteraceae in the Cretaceous of Antarctica. PNAS: www.pnas.org/cgi/doi/10.1073/pnas.1423653112

Belmonte, E. \& D. Moscoso. 1985. Patrones fenológicos de 81 especies de Precordillera y Altiplano de la I Región, 18$19^{\circ} \mathrm{S}$. Revista Gema (Universidad de Tarapacá) 2: 46-67.

Bentham, G. \& J.D. Hooker. 1873-1876. Genera plantarum ad exemplaria imprimis in herbariis kewensibus servata definita, vol. 2. A. Black, London. 1279 pp.

Brako, L. \& J. Zarucchi. 1993. Catalogue of the Flowering Plants and Gymnosperms of Perú. Monographs in Systematic Botany from the Missouri Botanical Garden 45: 1-1286.

CABrera, A.L. 1945. Sinopsis del género Lephidophyllum (Compositae). Boletín de la Sociedad Argentina de Botánica 1: 48-58.

Cabrera, A.L. 1949. El género Senecio en Chile. Lilloa 15: 27501.

Cabrera, A.L. 1965. Revisión del género Mutisia (Compositae). Opera Lilloana 13: 5-227.

Cabrera, A.L. 1978. Flora de la provincia de Jujuy, República Argentina. Parte X, Compositae. Colección Científica del INTA, vol. 13: 1-726.

Cabrera, A.L. 1985. El género Senecio (Compositae) en Bolivia. Darwiniana 26(1-4): 79-217.

Cabrera, A. L., S.E. Freire \& L. Ariza Espinar. 1999. Asteraceae, tribu VIII, Senecioneae. En: A. T. Hunziker (ed.), Flora Fanerogámica Argentina 62: 3-164. PROFLORA, CONICET, Argentina.

Cabrera, A.L. \& A. Willink. 1973. Biogeografía de América Latina. Monografías Científicas de la OEA. Serie de Biología, Monografía Nro. 13, Washington DC. 120 pp.

Castro, M., C. Villagrán \& M.T.K. Arroyo. 1982. Estudio etnobotánico en la pre-Cordillera y Altiplano de los Andes de Arica (18-19 S). En: A. Veloso \& E. Bustos (eds.), El Ambiente Natural y las Poblaciones Humanas de los Andes del Norte Grande de Chile (Arica, Lat. $18^{\circ} 28^{\prime} \mathrm{S}$ ), vol. 2, pp. 133-205. Rostlac, Montevideo, Uruguay.

Centro de Estudios Espaciales (CEE). 2000. Diagnóstico, redefinición cobertura actual SNASPE, I Región, Provincia de Parinacota. Informe Final. Código BIP 20125132-0, Universidad de Chile, Santiago. 307 pp.

Charrier, R., N. Muñoz \& S. Palma-Heldt. 1994. Edad y contenido paleoflorístico de la Formación Chucal y condiciones paleoclimáticas para el Oligoceno TardíoMioceno Inferior en el Altiplano de Arica, Chile. Congreso Geológico Chileno, No. 7, Actas, 1: 434-437.

CONAF (Corporación Nacional Forestal). 1998. Plan de Manejo Reserva Nacional Las Vicuñas. Documento de Trabajo ${ }^{\circ}$ 296. Región de Tarapacá, Chile. 116 pp.

CONAMA (Comisión Nacional del Medio Ambiente). 2002. Estrategia y Plan de Acción para la Conservación de la Biodiversidad en la Región de Tarapacá. 26 pp. URL http:// www.sinia.cl/1292/articles-40875_pdf_tarapaca.pdf.

Dillon, M.O. 2006. Nuevos registros de Asteraceae para la flora de Perú - New records in the Asteraceae flora of Peru. Arnaldoa 13(2): 314-317.

Dillon, M.O. \& A. Sagástegui-Alva. 1991. Family Asteraceae, Part V. Fieldiana Botany 26: 1-70.

Dillon, M.O. \& A. Sagástegui-Alva. 1996. Revision of the dioecious genus Chersodoma Phil. (Senecioneae, Asteraceae), including a new species and status change. Brittonia 48(4): 582-604.

Dillon, M.O. \& A. Sagástegui-Alva. 2001. Tribal classification and diversity in the Asteraceae of Peru. Arnaldoa 8(2): 2543.

Dillon, M.O. \& F. Luebert. 2014. Synopsis of Plazia Ruiz \& Pav. (Onoserideae, Asteraceae), including a new species from northern Peru. PhytoKeys 34: 1-13.

FAúNDEZ, L. \& J.B. MacaYA. 1998. Presencia de Lophopappus foliosus Rusby (Asteraceae) en Chile y antecedentes taxonómicos sobre el género Lophopappus Rusby. Noticiario Mensual del Museo Nacional de Historia Natural 332: 3-6.

Faúndez, L., R. Flores, A. Faúndez \& M. Treumún. 2014. Reino Plantae. En: J. Hernández, C. Estades, L. Faúndez \& J. Herreros de Lartundo (eds.), Biodiversidad Terrestre de la Región de Arica y Parinacota, pp. 164-229. Ministerio del Medio Ambiente (MMA), Facultad de Ciencias Forestales y de la Conservación de la Naturaleza, Universidad de Chile, Santiago, Chile.

Foster, R.C. 1958. Catalogue of the ferns and flowering plants of Bolivia. Contributions Gray Herbarium Harvard University 184: 1-223.

Freire, S.E. \& L. Ariza-Espinar. 2014. Werneria. En: F.O. Zuloaga, M.J. Belgrano \& A.M. Anton (eds.), Flora Argentina. Dicotyledoneae, Asteraceae: Senecioneae a Vernonieae. Vol. 7, Tomo 3, pp. 220-226. Instituto de Botánica Darwinion, Buenos Aires, Argentina.

Freire, S.E., N. Bayón, C. Baeza, D. Giuliano \& C. Monti. 2014a. Revision of the genus Pseudognaphalium (Asteraceae, Gnaphalieae) in Chile. Gayana Botánica 71(1): 68-107.

Freire, S.E., M.A. Chemisquy, A.A. Anderberg, S.G. Beck, R.I. Meneses, B. Loeuille \& E. Urtubey. 2015. The Lucilia group (Asteraceae, Gnaphalieae): phylogenetic and taxonomic considerations based on molecular and morphological evidence. Plant Systematics and Evolution 301(4): 1227-1248.

Freire, S.E., C. Monti, A. Moreira-Muñoz \& N. Bayón. 2013. Pseudognaphalium munoziae (Gnaphalieae, Asteraceae): A new South American species from Chile. Phytotaxa 105(1): 1-10.

Freire, S.E., L. SAlomón, N. Bayón, C.M. Baeza, M. MuñozSchick \& M.A. Migoya. 2016. Taxonomic revision of the 
La familia Asteraceae en Arica y Parinacota: Moreira-Muñoz, A. ET AL.

genus Gamochaeta (Gnaphalieae, Asteraceae) in Chile. Gayana Botánica 73(2): 292-345.

FunK, V.A. 1997. Xenophyllum, a new Andean genus extracted from Werneria s.l. (Compositae: Senecioneae). Novon 7: 235-241.

Funk, V.A., A. Susanna, T.F. Stuessy \& R.J. Bayer (eds.). 2009. Systematics, Evolution, and Biogeography of Compositae. International Association of Plant Taxonomy. Institute of Botany, University of Vienna, Austria. 965 pp.

GAJARDO, R. 1994. La vegetación natural de Chile: clasificación y distribución geográfica. Editorial Universitaria, Santiago. $165 \mathrm{pp}$.

Gatica-Castro, A., A. Marticorena, G. Rojas, G. Arancio \& F.A. SQueo. 2015. Estado de conservación de la flora nativa de las regiones de Arica-Parinacota y de Tarapacá, Chile. Gayana Botánica 72(2): 305-339.

Geonames, 2015. The GeoNames geographical database. [en línea] $<$ http://www.geonames.org/> [consulta: 4 enero 2016].

GonZÁlez Ferrán, O. 1995. Volcanes de Chile. Instituto Geográfico Militar. Santiago, Chile. 640 pp.

González, J. \& J. Molina. 2015. Flora presente en la Región de Arica y Parinacota. Universidad de Tarapacá, Arica. 115 pp.

GonzÁlez, J., J. Molina \& A. Marticorena. 2016. Ambrosia arborescens Mill. (Asteraceae) nuevo registro para la flora advena de la Región de Arica y Parinacota, Chile. Chloris Chilensis año $19 \mathrm{~N}^{\circ} 1$. URL: http://www.chlorischile.cl

Gutiérrez, D.G. \& A. Moreira-Muñoz. 2015. Flaveria Juss. En: F.O. Zuloaga, M.J. Belgrano \& A.M. Anton (eds.), Flora Argentina: Flora Vascular de la República Argentina: Dicotyledoneae Asteraceae: Cichorieae, Helenieae a Mutisieae, vol. 7, tomo II, pp. 88-90. Instituto de Botánica Darwinion, Buenos Aires, Argentina.

Gutiérrez, D.G., M. MuÑoz-Schick, M.A. Grossi, J.F. RodríGuezCravero, V. Morales \& A. Moreira-Muñoz. 2016. The genus Stevia (Eupatorieae, Asteraceae) in Chile: a taxonomical and morphologic analysis. Phytotaxa (en prensa).

Hartley, A. J. 2003. Andean uplift and climate change. Journal of the Geological Society, London 160: 7-10.

Hellwig, F. 1990. Die Gattung Baccharis L. (Compositae-Astereae) in Chile. Mitteilungen der Botanischen Staatssammlung München 29: 1-456.

HernándeZ, L. 1980. Zonificación con fines de manejo de las formaciones vegetales presentes en el Parque Nacional Lauca (Ia Región). Tesis Ing. Forestal, Fac. de Ciencias Forestales, Universidad de Chile. 101 pp.

Hershrovitz, M.A., M.T.K. Arroyo, C. Bell \& F. Hinojosa. 2006. Phylogeny of Chaetanthera (Asteraceae: Mutisieae) reveals both ancient and recent origins of the high elevation lineages. Molecular Phylogenetics and Evolution 41: 594-605.

HIND, D.J.N. 2011. An annotated preliminary checklist of the Compositae of Bolivia, versión 2. <http://www.kew.org/ science/tropamerica/boliviacompositae/> (4 enero 2016).

Huanca Mamani, A. \& L. Castro Mollo. 2014. Plantas medicinales de la comuna de Putre. Fondo de Protección Ambiental, Ministerio de Medio Ambiente, Arica. 58 pp.

IGM (Instituto Geográfico Militar). 1984. Listado de nombres geográficos. Tomos I y II. Instituto Geográfico Militar, Santiago. 1557 pp.
Jørgensen, P.M., M.H. Nee \& S.G. Beck (eds.) 2014. Catálogo de Plantas Vasculares de Bolivia. Monographs in Systematic Botany from the Missouri Botanical Garden 127: i-viii, $1-1744$.

Katinas, L. 2012. Revisión del Género Perezia (Compositae). Boletín de la Sociedad Argentina de Botánica 47(1-2): 159-261.

Katinas, L., G. SAncho \& M. Vitali. 2013. A revision of Lophopappus (Asteraceae, Nassauvieae). Phytotaxa 103(1): 25-45.

Kessler, M. 2006. Bosques de Polylepis. En: M. Moraes, B. Øllgaard, L.P. Kvist, F. Borchsenius \& H. Balslev (eds.), Botánica Económica de los Andes Centrales, pp. 110-120. Universidad Mayor de San Andrés, La Paz, Bolivia.

KiesLing, R. (ed.). 2013. Flora de San Juan, Vol. 3b, Familia Asteráceas (=Compuestas). Fundación Argentina, Buenos Aires. 338 pp.

Kleier, C., T. Trenary, E.A. Graham, W. Stenzel \& P.W. Rundel. 2015. Size class structure, growth rates, and orientation of the central Andean cushion Azorella compacta. PeerJ 3: e843; DOI 10.7717/peerj.843

LUEBERT, F. 2004. Apuntes sobre la vegetación de bosque y matorral del desierto precordillerano de Tarapacá (Chile). Chloris Chilensis Año 7(1). URL: http://www.chlorischile.cl

Luebert, F. \& R. Gajardo. 2005. Vegetación alto-andina de Parinacota (norte de Chile) y una sinopsis de la vegetación de la Puna meridional. Phytocoenologia 35(1): 79-128.

Luebert, F. \& P. Pliscoff. 2006. Sinopsis bioclimática y vegetacional de Chile. Editorial Universitaria, Santiago. 316 pp.

Luebert, F. \& M. Weigend. 2014. Phylogenetic insights into Andean plant diversification. Frontiers in Ecology and Evolution 2: 27.

Marticorena, C. \& M. Quezada. 1977. La presencia del género Achyrocline (Less.) DC. (Compositae-Inuleae) en Chile. Boletín de la Sociedad Biología de Concepción 51(1): 137-139.

Marticorena, C. \& M. Quezada. 1985. Catálogo de la flora vascular de Chile. Gayana Botánica 42(1-2): 1-157.

Meyen, F.J.F. 1834/1835. Reise um die Erde ausgeführt auf dem Königlich preussischen Seehandlungs-schiffe Prinzess Louise, commandirt von Captain W. Wendt, in den jahren 1830, 1831 und 1832. Berlin: in der Sanderschen Buchhandlung. 519 pp.

Montecinos-Tubée, D.B., A.M. Cleeef \& K.V. SÝkora. 2015. The Puna vegetation of Moquehua, South Peru: Chasmophytes, grasslands and Puya raimonii stands. Phytocoenologia 45(4): 365-397.

Moreira-MuÑoz, A. 2011. Plant Geography of Chile. Dordrecht: Springer. $343 \mathrm{pp}$.

Moreira-Muñoz, A. \& J. Troncoso. 2014. Representatividad biogeográfica de las Reservas de la Biosfera de Chile. En: A. Moreira-Muñoz \& A. Borsdorf (eds.), Reservas de la Biosfera de Chile: Laboratorios para la Sustentabilidad, pp. 24-65. Academia de Ciencias Austriaca, Instituto de Geografía UC, Santiago, Chile.

Moreira-Muñoz, A., V. Morales \& M. Muñoz-Schick. 2012. Actualización sistemática y distribución geográfica de Mutisioideae (Asteraceae) de Chile. Gayana Botánica 69(1): 9-29. 
Müller, J. 2006. Systematics of Baccharis (Compositae-Astereae) in Bolivia, including an overview of the genus. Systematic Botany Monographs 76: 1-341.

MuÑoz, A.E. \& C. BonAcic. 2006. Variación estacional de la flora y vegetación en la precordillera andina de la Comuna de Putre (I Región de Tarapacá, Chile), durante el período 2002-2003. Gayana Botánica 63(1): 75-92.

Muñoz-Schick, M. \& A. PrinA. 1987. Nota aclaratoria sobre especies colectadas por Federico Philippi en su viaje a Tarapacá. Noticiario Mensual Museo Nacional de Historia Natural de Chile 313: 2-17.

Muñoz-Schick, M., H. NúÑez \& J. YÁÑEz (eds.). 1996. Libro Rojo de los Sitios Prioritarios para la Conservación de la Diversidad Biológica de Chile. Corporación Nacional Forestal, Ministerio de Agricultura, Santiago. 203 pp.

Muñoz-Schick, M., V. Morales \& A. Moreira-Muñoz. 2012. La colección de Tipos de Plantas Vasculares del Herbario Nacional de Chile (SGO). Análisis histórico, temporal y espacial. Gayana Botánica 69(1): 70-81.

Nesom, G.L. 1993. Synopsis of Parastrephia (Asteraceae, Astereae). Phytologia 75(5): 347-357.

PArra-O., C. 2002[2003]. New combinations in South American Myricaceae. Brittonia 54(4): 322-326.

PhiLIPPI, F. 1885. Informe sobre la expedición a la provincia de Tarapacá, hecho en virtud del Supremo Decreto de 20 de Noviembre de 1884. Diario Oficial de la República de Chile n 2, 584: 1920-1928. 4-12-1885.

PhilipPI, R.A. 1891. Catalogus praevius plantarum in itinere ad Tarapaca a Friderico Philippi lectarum. Anales del Museo Nacional, Segunda sección 8, Santiago de Chile. 96 pp.

Plos, A. 2012. Revisión sistemática, análisis cladístico y biogeográfico del género Ophryosporus Meyen (Asteraceae, Eupatorieae, Critoniinae). Tesis presentada para optar por el grado académico de Doctor en Ciencias Naturales, Facultad de Ciencias Naturales y Museo Universidad Nacional de La Plata, Argentina. 392 pp.

Plos, A. \& G. SANChO. 2013. Lectotipificaciones en Ophryosporus (Asteraceae, Eupatorieae, Critoniinae). Boletín de la Sociedad Argentina de Botánica 48 (2): 335-340.

Pöhlmann, R. \& K. Reiche. 1900. Beiträge zur Kenntnis der Flora der Flussthäler Camarones und Vitor und ihres Zwischenlanden (19 s.Br.). Verh. Deutsch. Wiss. Vereins Santiago 4: 263-305.

Quintanilla, V.G. 1988. Fitogeografía y cartografía de la vegetación de Chile árido. Contribuciones Científicas y Tecnológicas USACH, Área Geociencias 82: 1-28.

Reiche, C. 1904. Estudios críticos sobre la Flora de Chile. Anales de la Universidad de Chile 115: 91-120.

Reiche, C. 1905. Estudios críticos sobre la Flora de Chile. Anales de la Universidad de Chile 116: 415-606.

Ricardi, M. 1962. Dos Compuestas peruanas nuevas para Chile. Gayana Botánica 4: 3-18.

Ricardi, M. \& C. Marticorena. 1964. Compuestas nuevas o interesantes para Chile. Gayana Botánica 11: 3-28.

Ricardi, M. \& C. Marticorena. 1966. Plantas interesantes o nuevas para Chile. Gayana Botánica 14: 3-29.

Ricardi, M. \& F. Torres. 1958. Plantas vasculares nuevas para Chile II. Boletín de la Sociedad de Biología de Concepción 33: 95-102.

Risopatrón, L. 1924. Diccionario Jeográfico de Chile. Imprenta
Universitaria, Santiago. 958 pp.

Román, B. 2014. La Reserva de la Biosfera Lauca: turismo como herramienta de desarrollo económico y conservación del patrimonio aymara. En: A. Moreira-Muñoz \& A. Borsdorf (eds.), Reservas de la Biosfera de Chile: Laboratorios para la Sustentabilidad, pp. 66-80. Academia de Ciencias Austriaca, Instituto de Geografía UC, Santiago, Chile.

Rundel, P.W. \& B. Palma. 2000. Preserving the unique puna ecosystems of the Andean Altiplano: Lauca National Park, Chile. Mountain Research and Development 20: 262-271.

Rundel, P.W., M.O. Dillon, B. Palma, H.A. Mooney, S.L. Gulmon \& J.R. Ehleringer. 1991. The phytogeography and ecology of the coastal Atacama and Peruvian deserts. Aliso 13(1): 1-50.

Rundel, P.W., A.C. Gibson, G.S. Midgley, S.J.E. Wand, B. Palma, C.C. Kleier \& J. Lambrinos. 2003. Ecological and ecophysiological patterns in a precordillera shrubland of the Andean Cordillera in northern Chile. Plant Ecology 169: 179-193.

Ruthsatz, B. 1977. Pflanzengesellschaften und ihre Lebensbedingungen in den Andinen Halbwüsten Nordwest-Argentiniens. Dissertationes Botanicae 39. J. Cramer-Verlag, 168 pp.

SAAVEDRA, J. 2012. Caracterización de la estructura poblacional de Polylepis tarapacana en sector Cerro Chiguana, Cuenca del Salar de Surire, para establecer los lineamientos de un programa de restauración ecológica. Trabajo para optar al Grado de Magíster en Ciencias Ambientales. Universidad de Tarapacá. 76 pp.

SAn Román, F. 1892. Carta Jeográfica del Desierto y Cordilleras de Atacama. Dirección de Obras Públicas, Santiago. 1 mapa.

Schilling, E.E. \& J.L. PAnero. 2011. A revised classification of subtribe Helianthinae (Asteraceae: Heliantheae) II. Derived lineages. Botanical Journal of the Linnean Society 167 (3): 311-331.

Trivelli, M. \& V. Valdivia. 2009. Alcances sobre Flora y Vegetación de la Cordillera de los Andes: Región de Arica y Parinacota y Región de Tarapacá. $2^{\mathrm{a}}$ edición, SAG, División de Protección de los Recursos Naturales Renovables, Santiago. $180 \mathrm{pp}$.

Troll, C. 1968. Geo-ecology of the mountainous regions of the tropical Americas. Proceedings of the UNESCO Mexico Symposium, 1966, Mexico City, Mexico. Dümmler in Kommission, Bonn. 223 pp.

Udvardy, M.D.F. 1975. A Classification of the Biogeographical Provinces of the World. IUCN Ocassional Paper $n^{\circ} 18$. Morges, Suiza, 49 pp.

Ugarte, E., F. Lira, N. Fuentes \& S. Klotz. 2011. Vascular alien flora, Chile. Check List 7(3): 365-382.

UlloA, C., J.L. Zarucchi \& B. León. 2004. Diez años de adiciones a la Flora del Perú: 1993-2003. Arnaldoa, Edición Especial: $1-242$.

Urtubey, E., T.F. Stuessy \& K. Tremetsberger. 2009. Systematics of the South American Hypochaeris sessiliflora Complex (Asteraceae: Cichorieae). Annals of the Missouri Botanical Garden 96(4): 685-714.

Vanderplank, S.E., A. Moreira-Muñoz, C. Нobohm, G. Pils, J. Noroozi, V.R. Clark, N.P. Barker, W. Yang, J. Huang, K. Ma, C.Q. TAng, M.J.A. Werger, M. Ohsawa \& Y. Yang. 2014. Endemism in Mainland Regions - Case Studies: 
Central Chile Ecoregion. In: C. Hobohm (ed.), Endemism in Vascular Plants. Series Plant and Vegetation 9, pp. 205308. Springer, Dordrecht.

Villagrán, C. \& V. Castro. 2004. Ciencia indígena de los Andes del norte de Chile. Editorial Universitaria, Santiago. 362 pp.

Villagrán, C., M. Kalin \& J. Armesto. 1982. La vegetación de un transecto altitudinal en los Andes del Norte de Chile. En: A. Veloso \& E. Bustos (eds.), El Hombre y los Ecosistemas de Montaña, Tomo 1, pp. 13-70. MAB 6, Montevideo, Uruguay.

Vuilleumier, B.S. 1969. The tribe Mutisieae (Compositae) in the southeastern United States. Journal of the Arnold Arboretum 50(4): 620-625.

Weberbauer, A.1911. Die Pflanzenwelt der peruanischen Anden in ihren Grundzügen dargestellt. Verlag von Wilhelm Engelmann, Leipzig. 355 pp.

Weberbauer, A. 1945. El mundo vegetal de los Andes peruanos, estudio fitogeográfico. Estación Experimental Agrícola de la Molina, Dirección de Agricultura, Ministerio de Agricultura, Perú. 776 pp.
WedDell, H.A. 1855/1857. Chloris Andina. Essai d'une flore de la région alpine des Cordillères de L'Amérique du sud, 2 vol. Chez P. Bertrand, Paris.

Wetter, M.A. \& T.A. Zanoni. 1985. Otto Kuntze, Botanist. V. Type specimens of Asteraceae described in his Revisio Generum Plantarum. Brittonia 37(3): 325-340.

Zuloaga, F.O., O. Morrone \& M.J. Belgrano (eds.). 2008. Catálogo de las Plantas Vasculares del Cono Sur (Argentina, Sur de Brasil, Chile, Paraguay y Uruguay). Monographs of the Missouri Botanical Garden 107 (vol. 2 Dicotyledoneae: A-F). 2286 pp.

Zuloaga, F.O., M.J. Belgrano \& A.M. Anton (eds.). 2014. Flora Argentina. Flora Vascular de la República Argentina, Vol. 7 (Asteraceae: Anthemideae a Gnaphalieae). Buenos Aires: Instituto de Botánica Darwinion. 546 pp.

ZúÑIGA, E. 2011. Incidencia del estado físiológico sobre la conducta alimenticia de la taruca (Hippocamelus antisensis d'Orbigny 1834) en sector Chapiquiña, Parque Nacional Lauca. Seminario Científico para optar al Título de Profesor de Biología y Ciencias Naturales, Facultad de Ciencias, Universidad de Tarapacá. 35 pp.

Recibido: 21.01.16

Aceptado: 01.09.16 